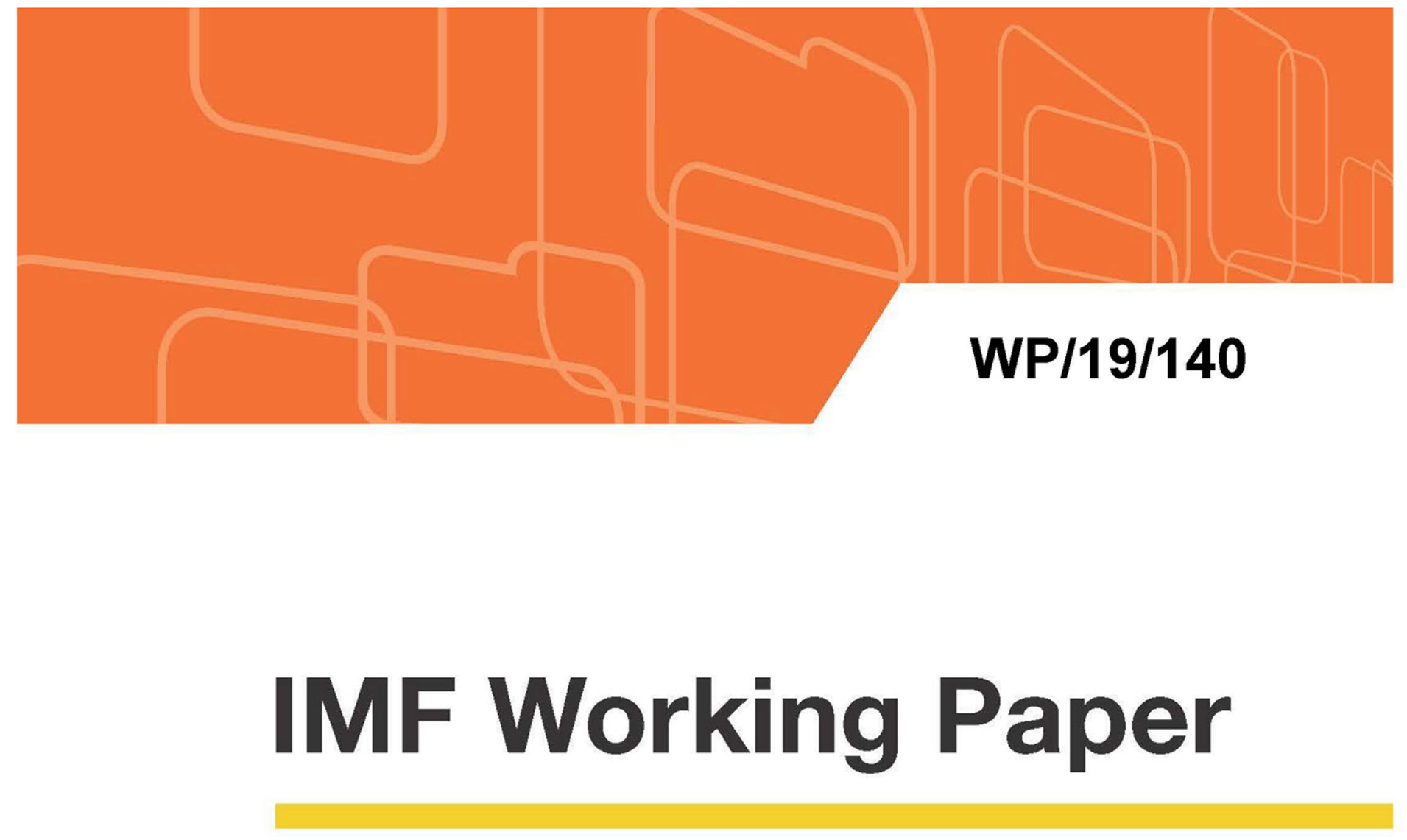

\title{
Competition and Bank Risk The Role of Securitization and Bank Capital
}

by Yener Altunbas, David Marques-Ibanez, Michiel van Leuvensteijn, and Tianshu Zhao

IMF Working Papers describe research in progress by the author(s) and are published to elicit comments and to encourage debate. The views expressed in IMF Working Papers are those of the author(s) and do not necessarily represent the views of the IMF, its Executive Board, or IMF management.

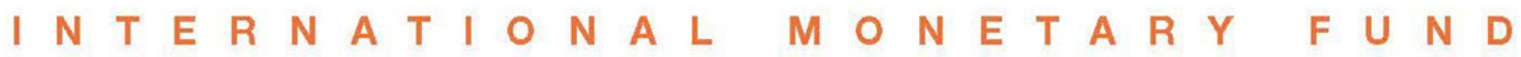




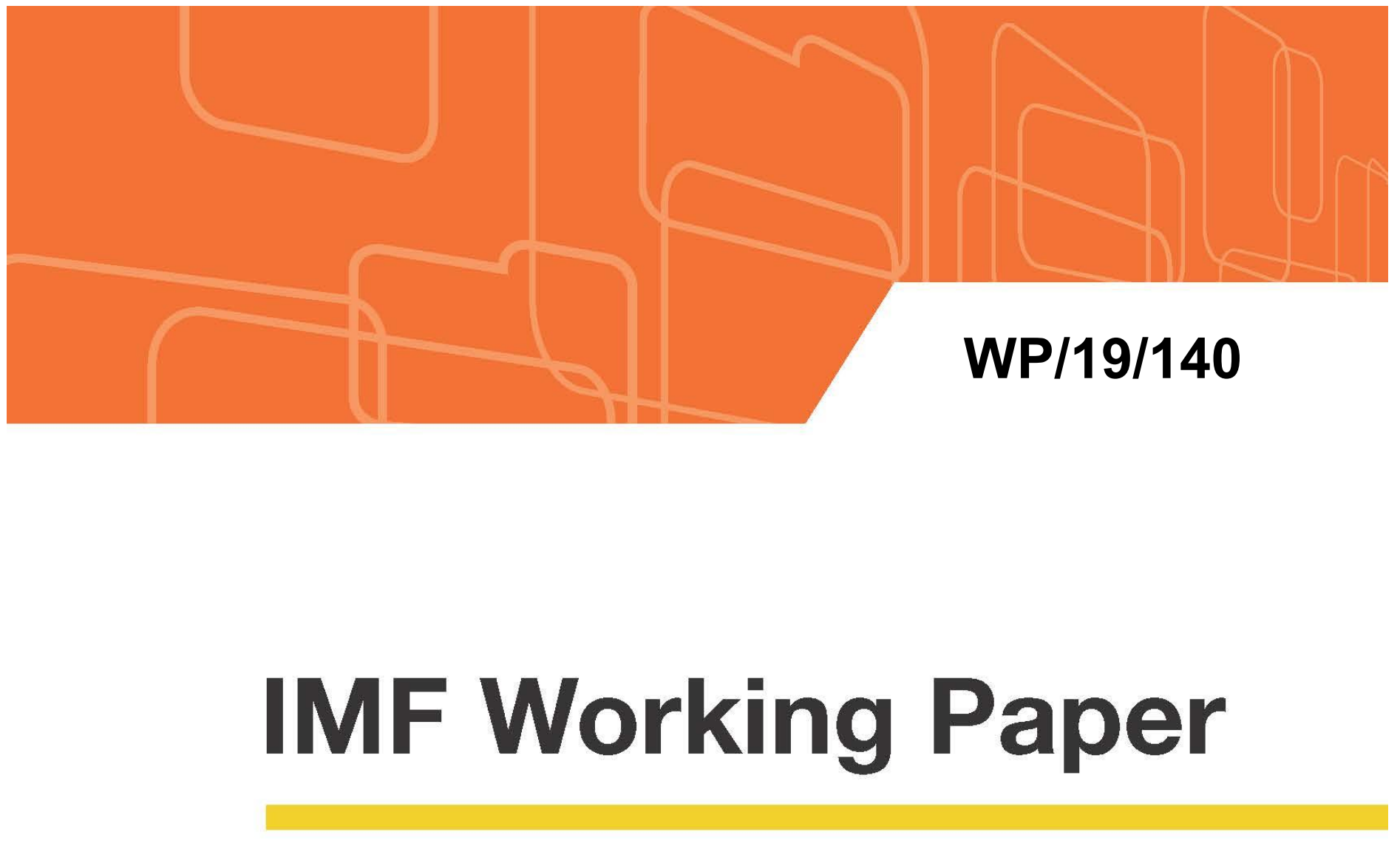

\section{Competition and Bank Risk The Role of Securitization and Bank Capital}

by Yener Altunbas, David Marques-Ibanez, Michiel van Leuvensteijn, and Tianshu Zhao

IMF Working Papers describe research in progress by the author(s) and are

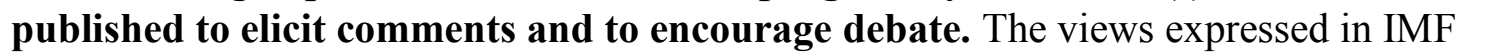

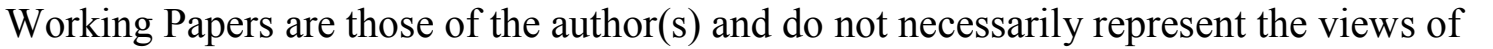

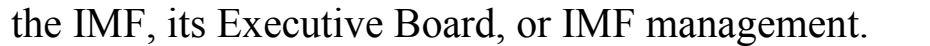

I N T E R N A T I O N A L M O N E T A R Y F U N D 


\title{
IMF Working Paper
}

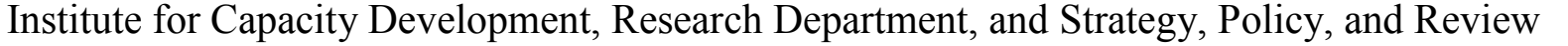 \\ $\square \square \square \square \square \square$
}

Competition and Bank Risk the Role of Securitization and Bank Capital ${ }^{1}$

\section{Prepared by Yener Altunbas, David Marques-Ibanez, Michiel van Leuvensteijn and Tianshu Zhao}

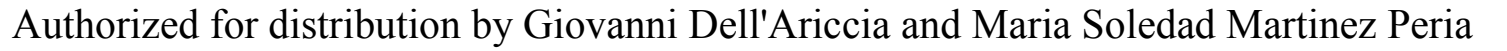

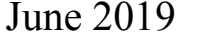

IMF Working Papers describe research in progress by the authors and are published to elicit

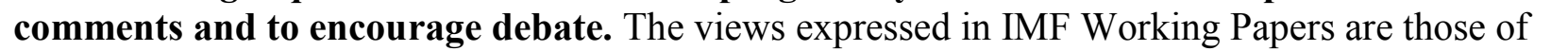

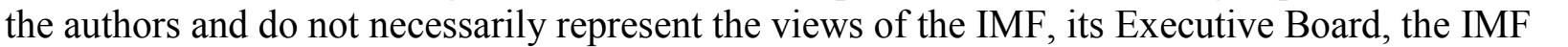

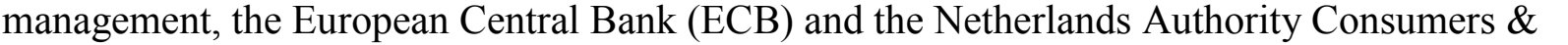

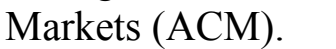

\begin{abstract}

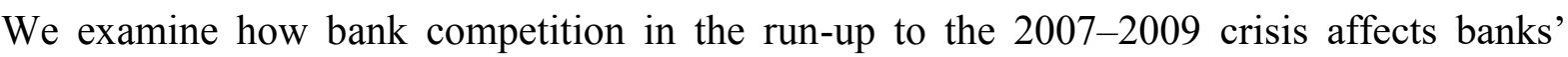

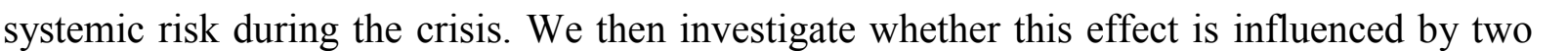

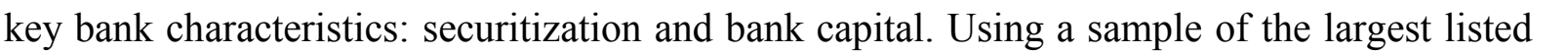

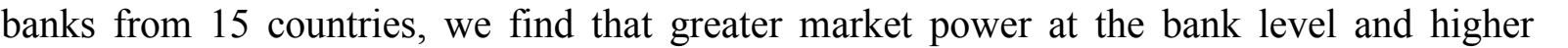

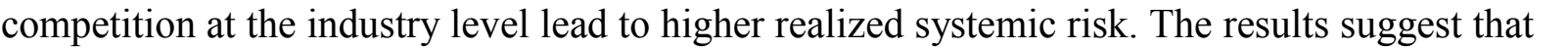

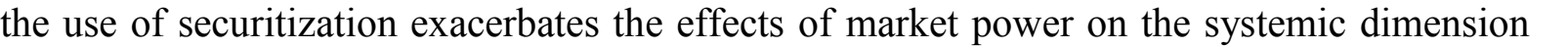

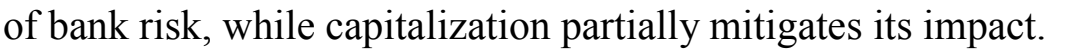

\section{JEL Classification Numbers $\square \square \square \square \square \square$}

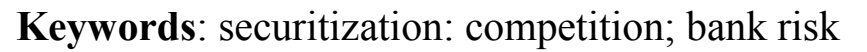

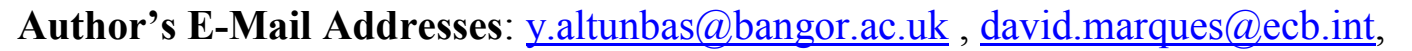

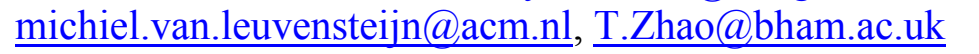

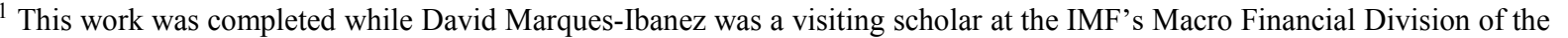

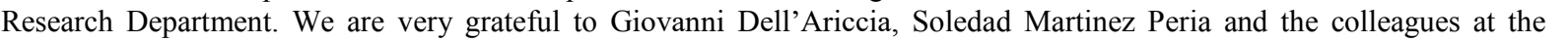

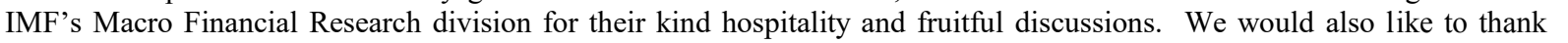

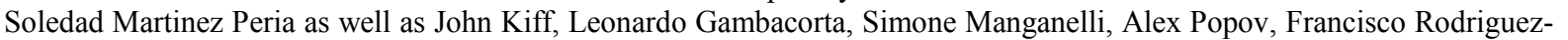

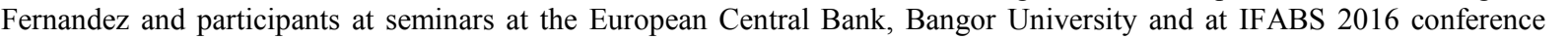

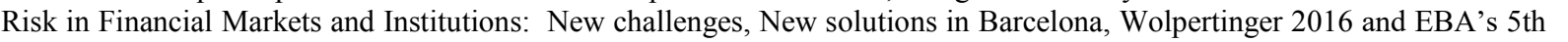

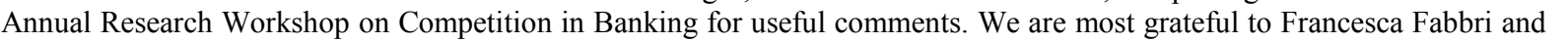

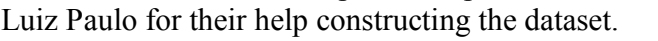


$\square \square|\Pi| ⿴ 囗 十)$

प

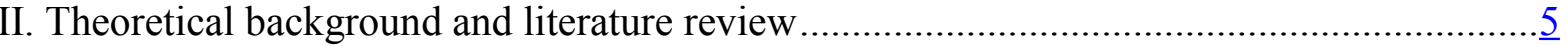

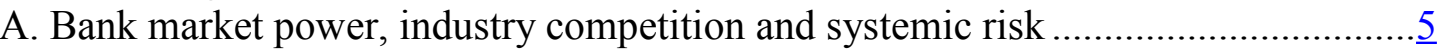

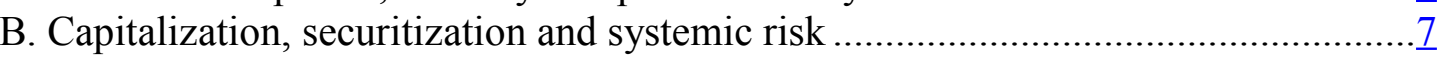

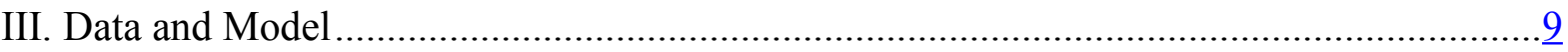

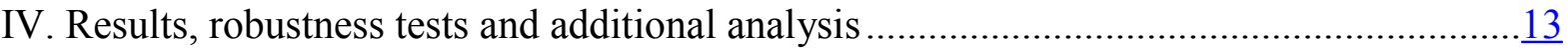

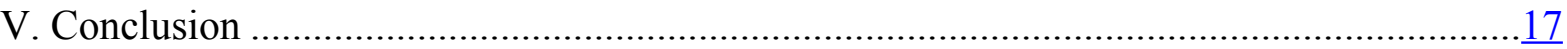

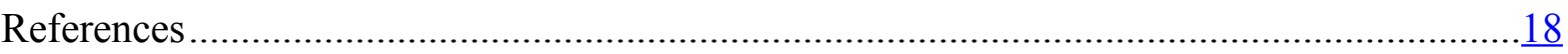
प्याणा

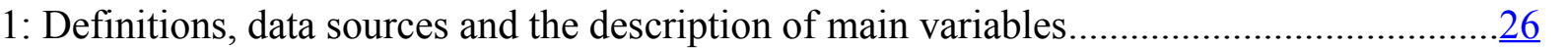

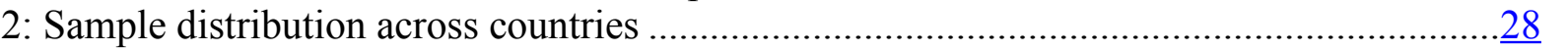

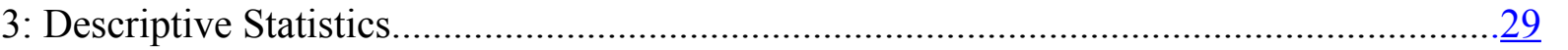

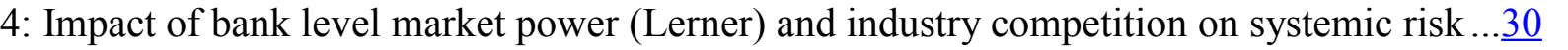

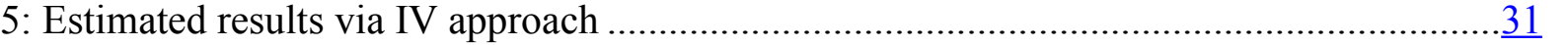

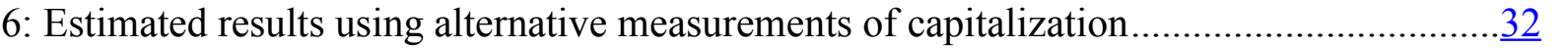

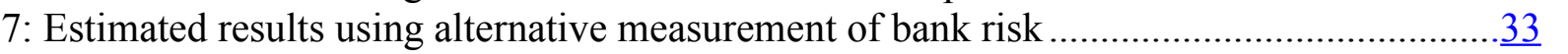

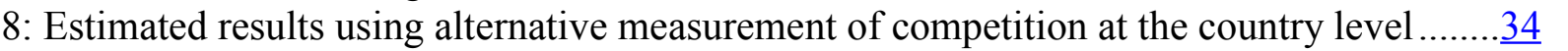

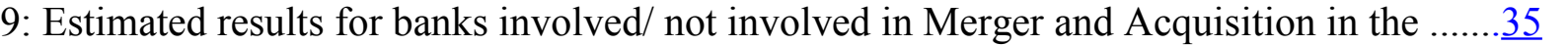

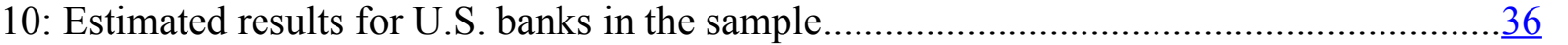

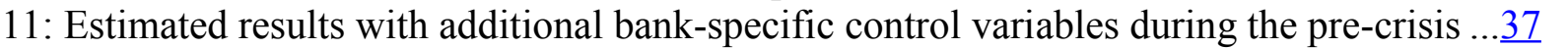

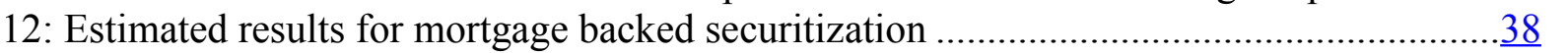

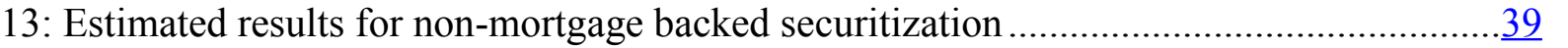

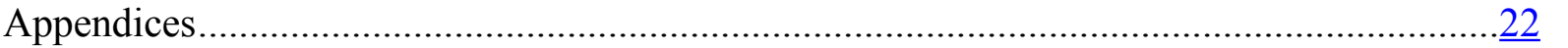




\section{INTRODUCTION}

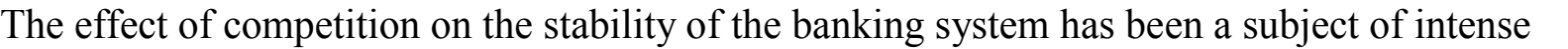

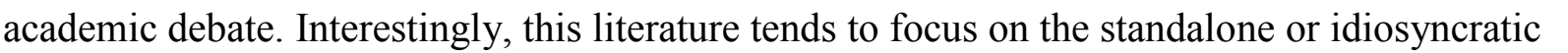

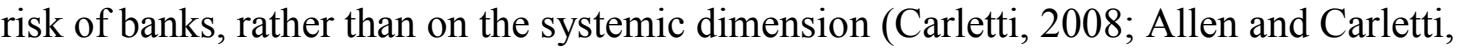

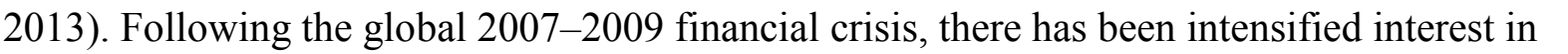

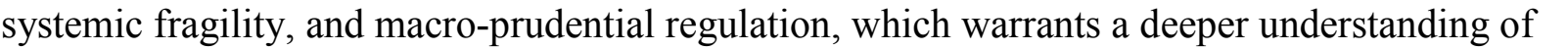
ए

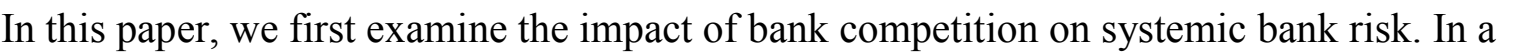

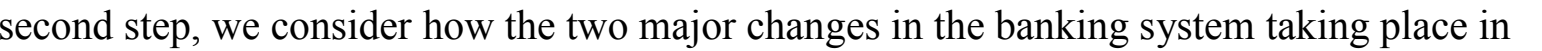

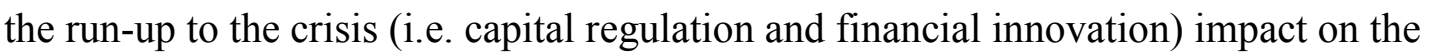

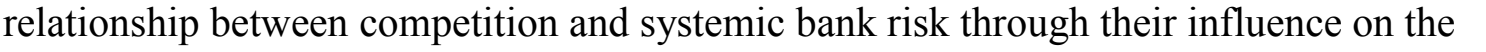

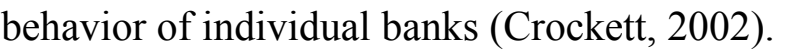

$\square$

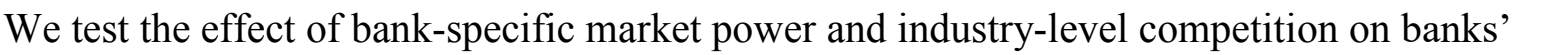

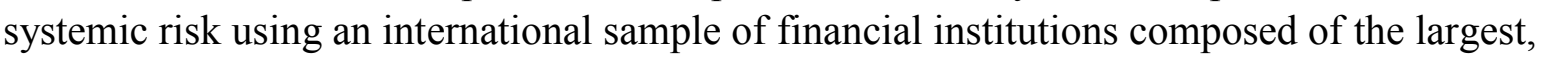

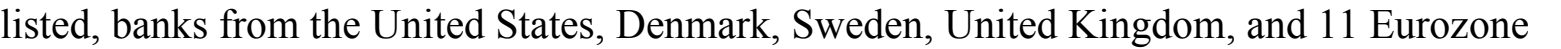

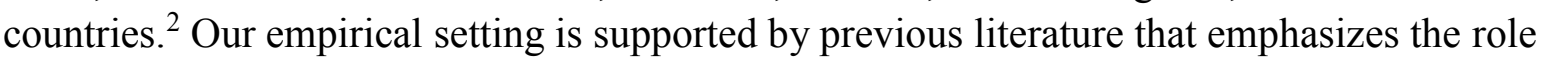

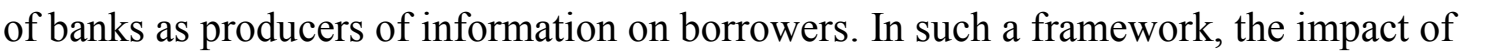

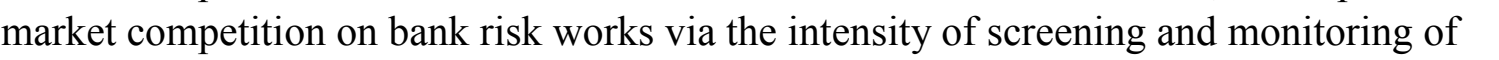

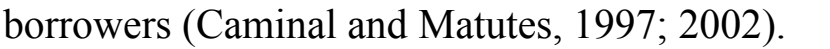

$\square$

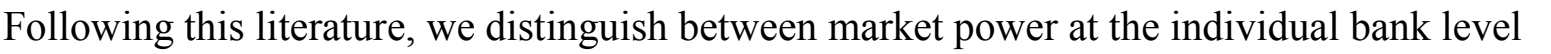

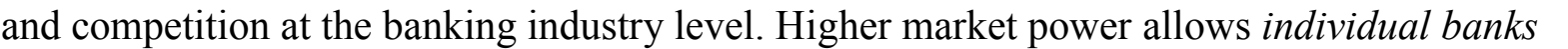

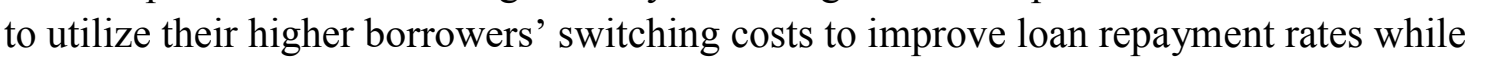

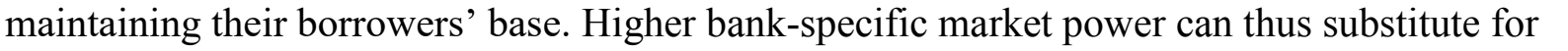

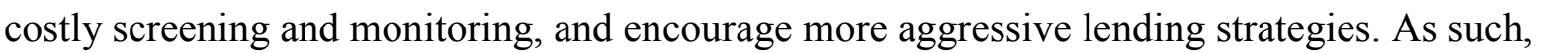
higher market power increases banks' exposure to common shocks to the economy and leads

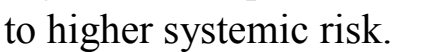

$\square$

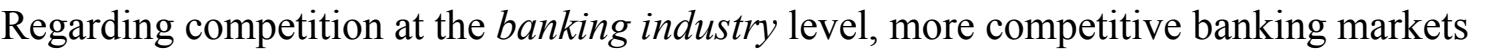
ए

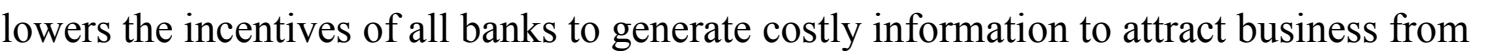

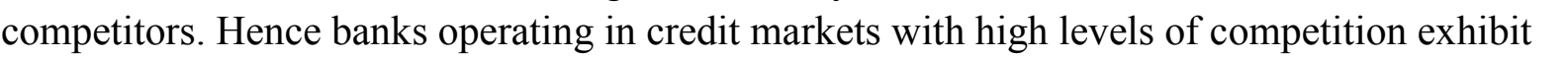

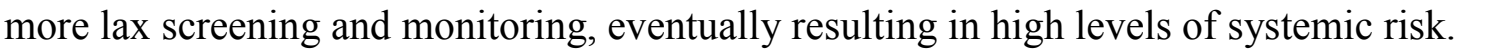
$\square$

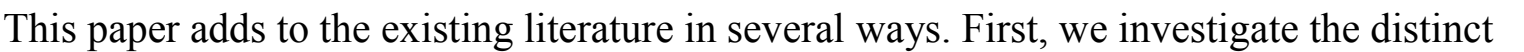

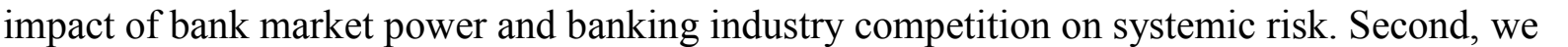

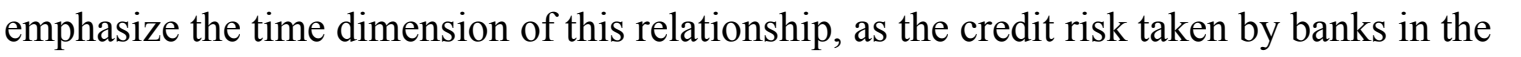

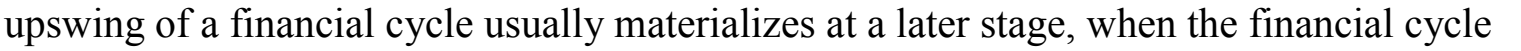

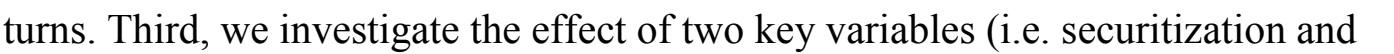

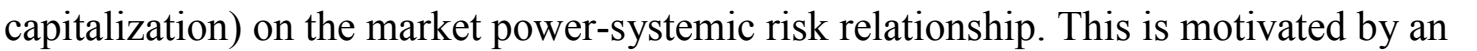

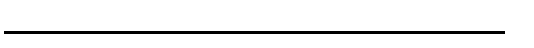

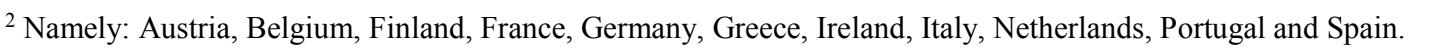




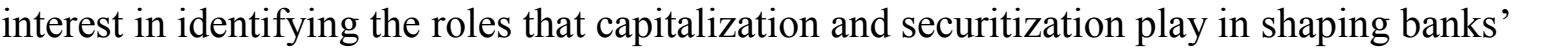

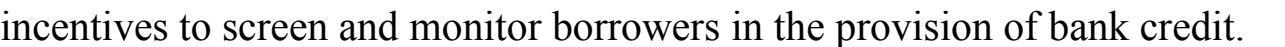

$\square$

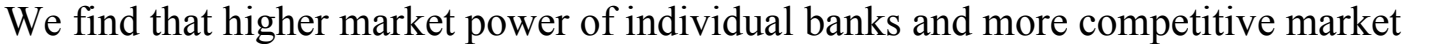

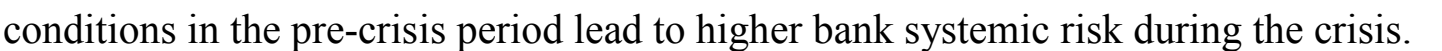

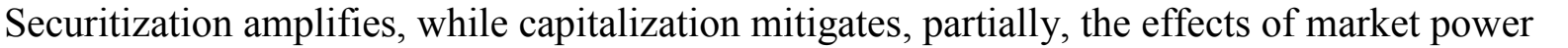

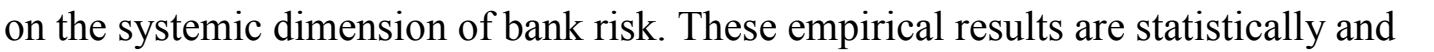

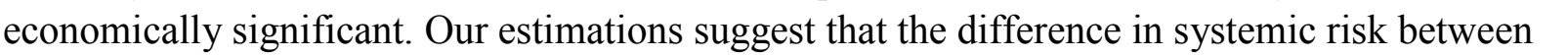

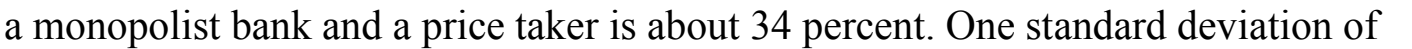

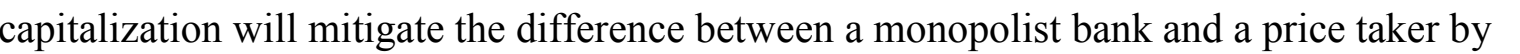

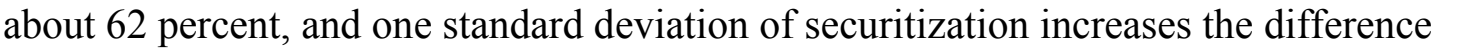

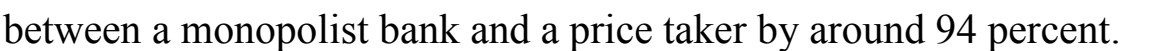

$\square$

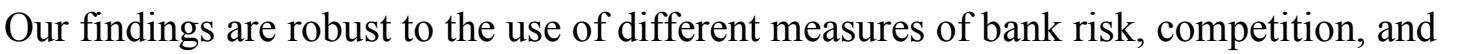

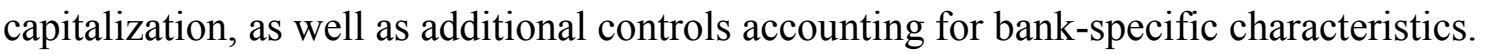

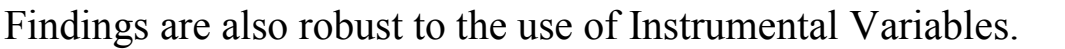

$\square$

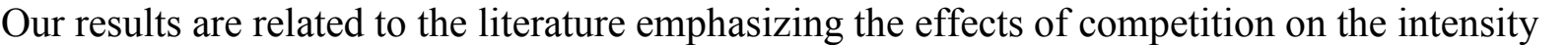

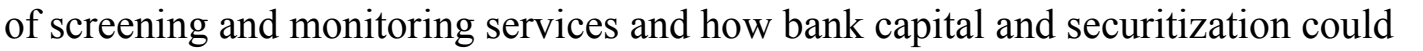

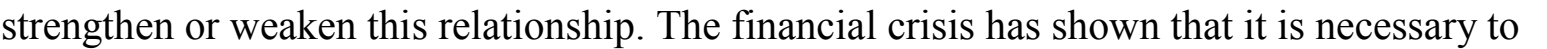

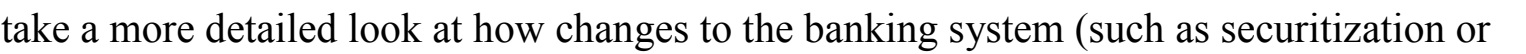

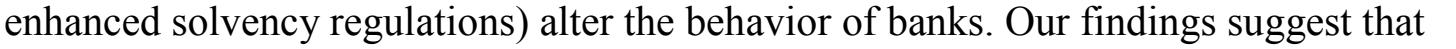
घम

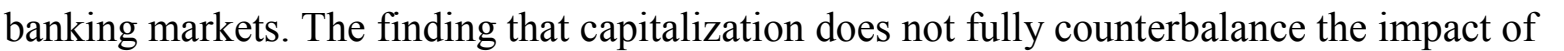

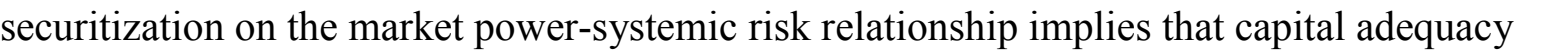

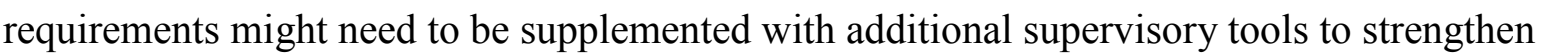
banks' incentives to screen and monitor their borrowers more intensively. $\square$ $\square$

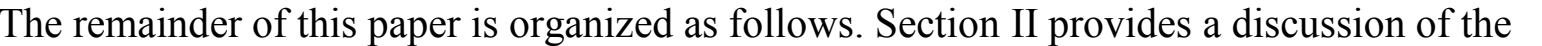
ए

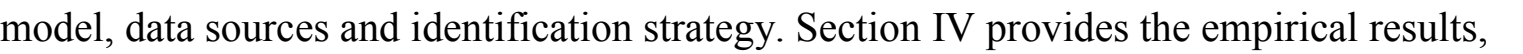

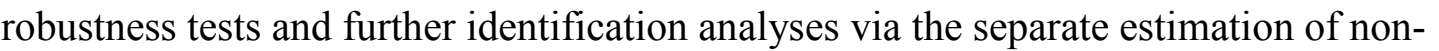

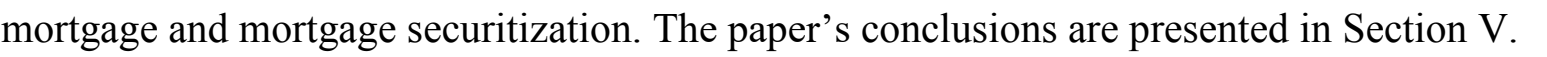
$\square$

\section{THEORETICAL BACKGROUND AND LITERATURE REVIEW}

\section{A. Bank market power, industry competition and systemic risk}

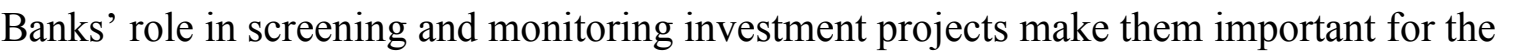

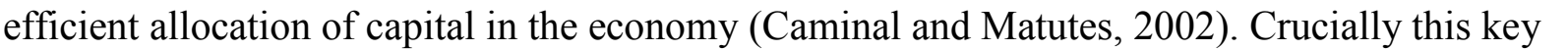
ए

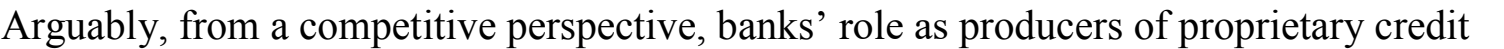

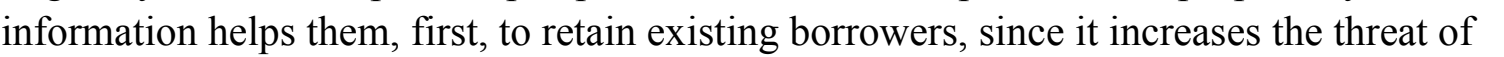

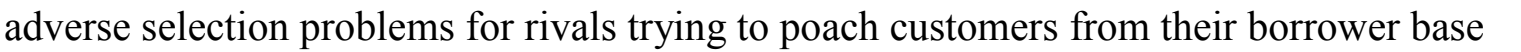

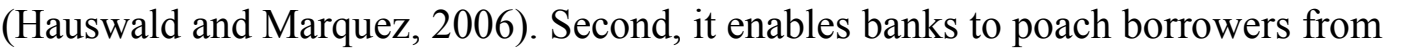

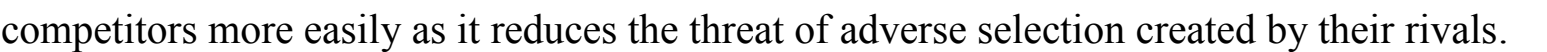




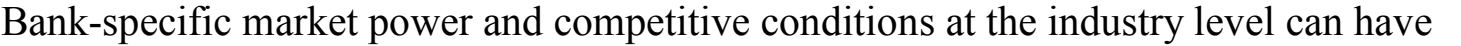

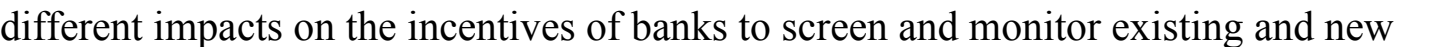

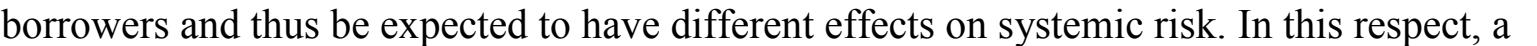

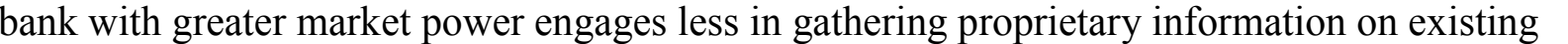

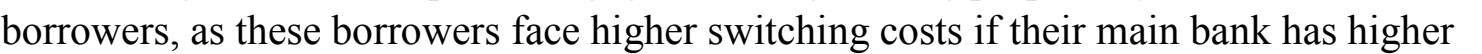

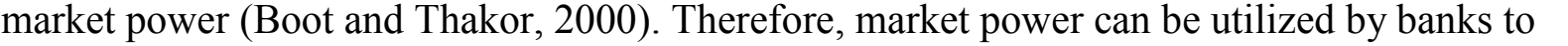

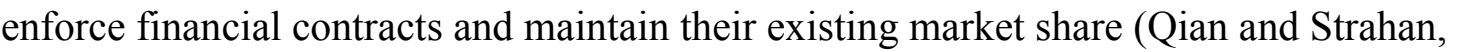

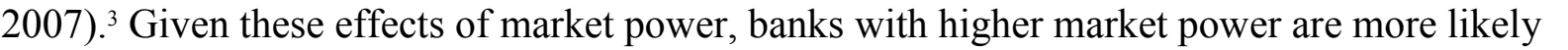
पाm

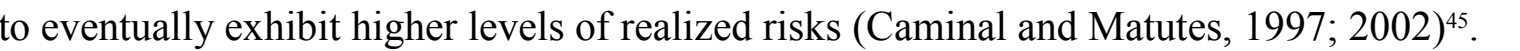

$\square$

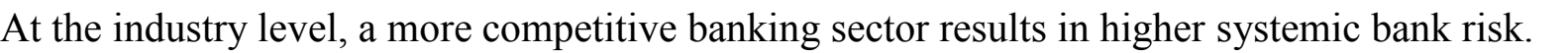

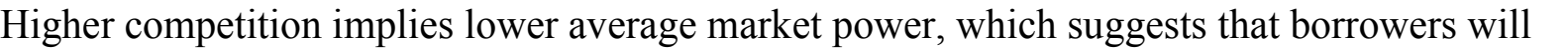

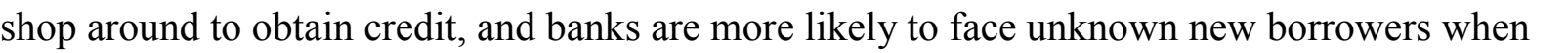

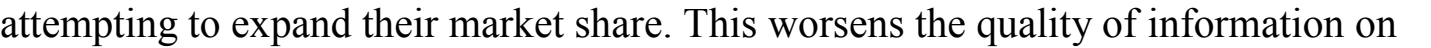

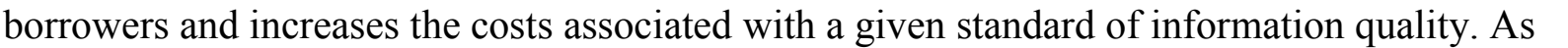

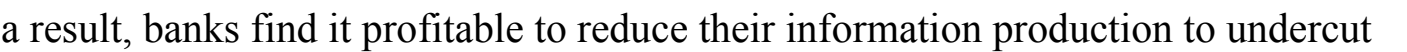

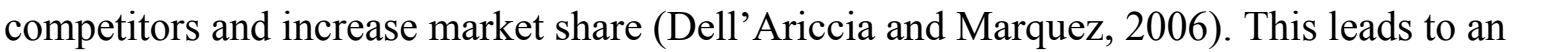
ए।

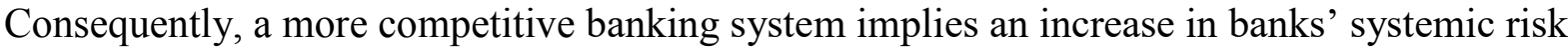

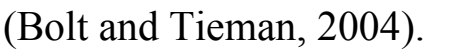

$\square$

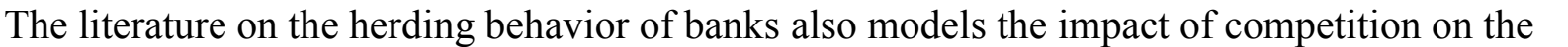

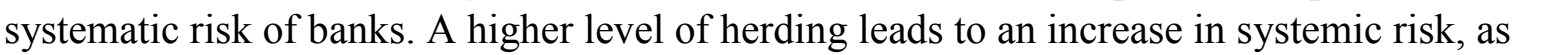

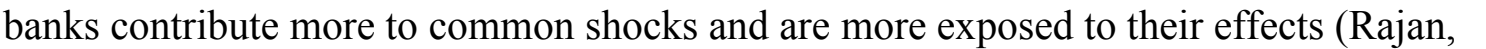

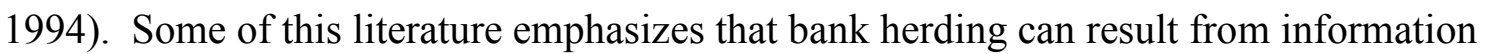

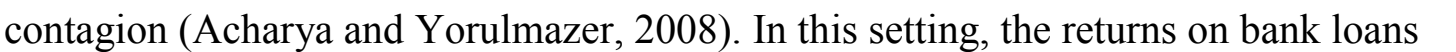

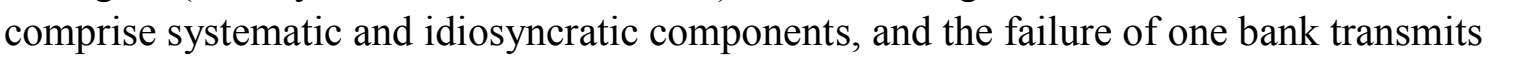

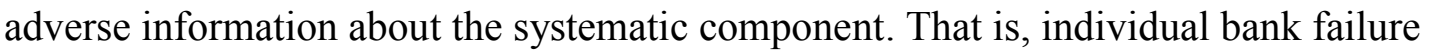

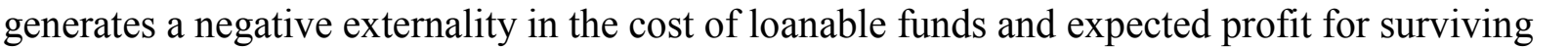

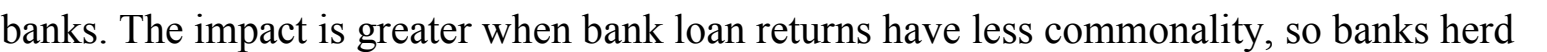

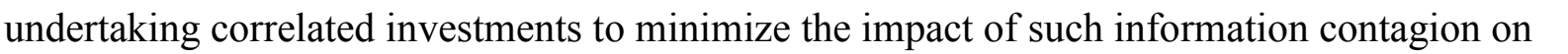

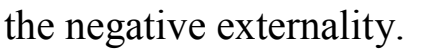

$\square$

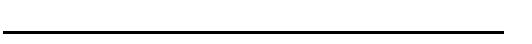

$\square$ While market power allows the bank to appropriate a higher proportion of information rents due to banks' engageme $\square \amalg \amalg$

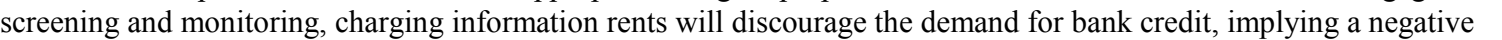

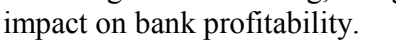

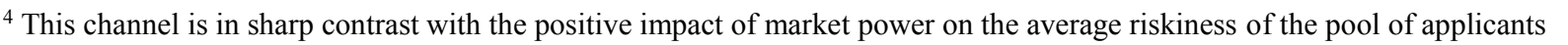

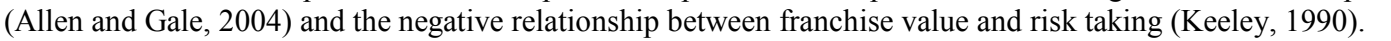

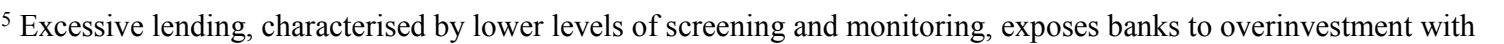

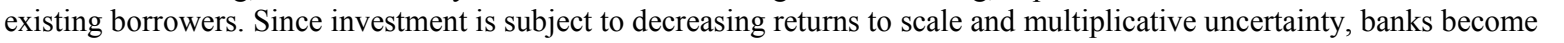

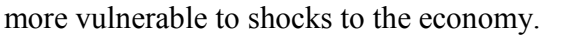

$\square$ 


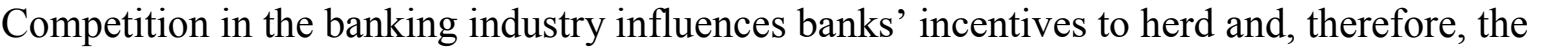

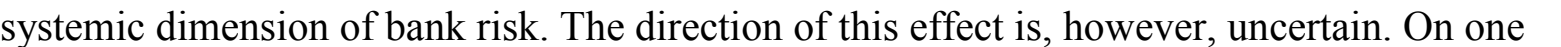

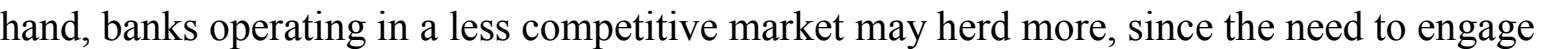

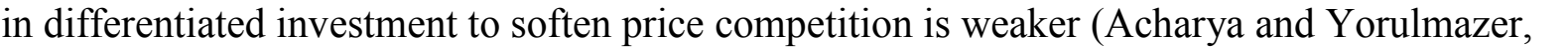

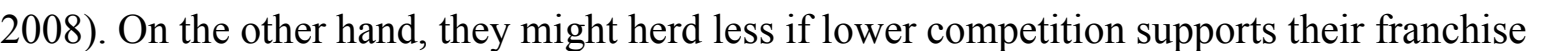

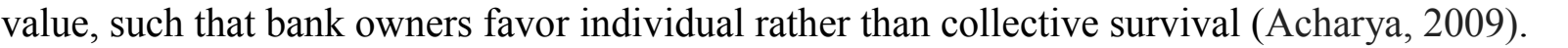
$\square$

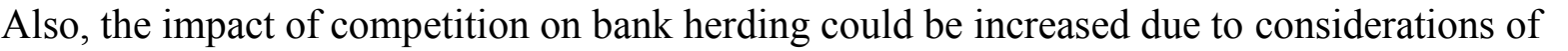

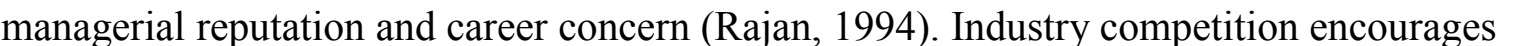

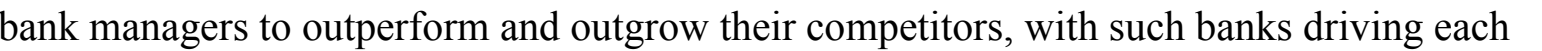

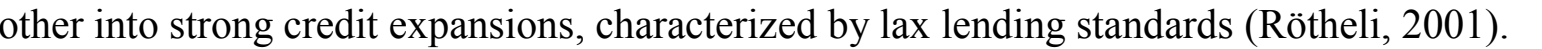

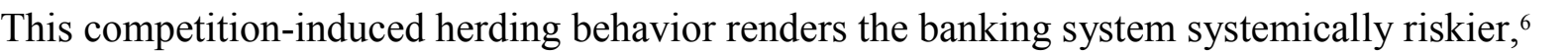

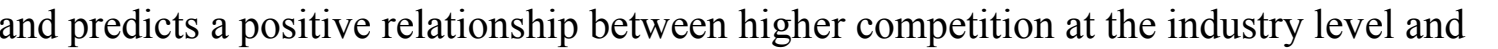

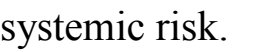

$\square$

\section{B. Capitalization, securitization and systemic risk}

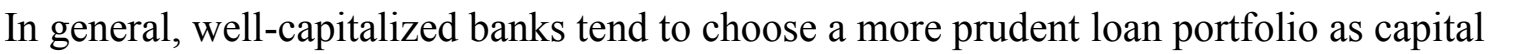

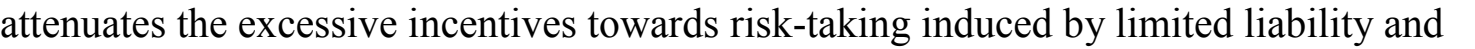

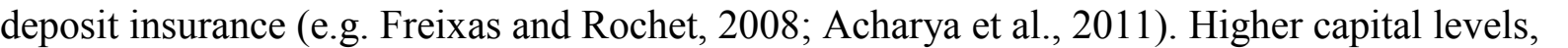
ए

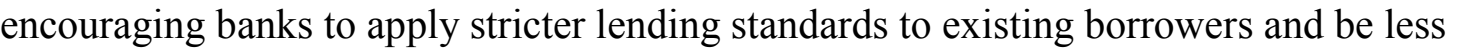

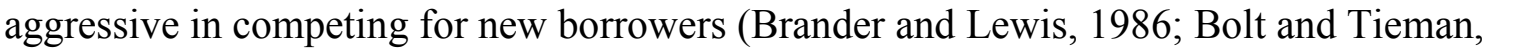

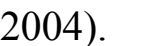

$\square$

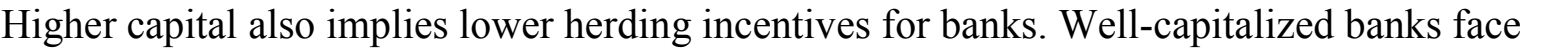

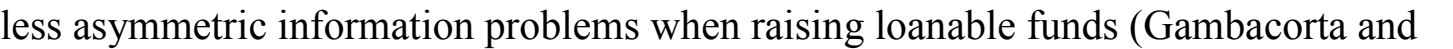

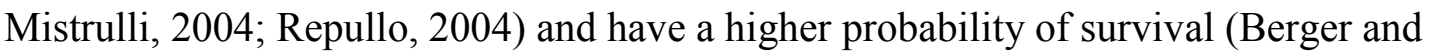

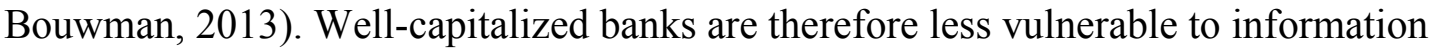

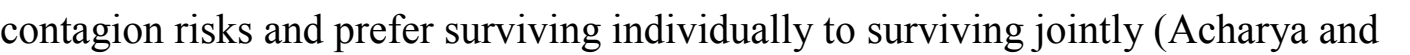

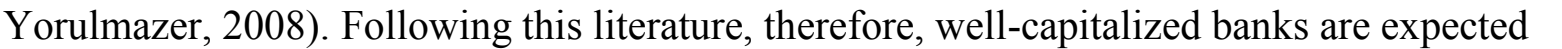

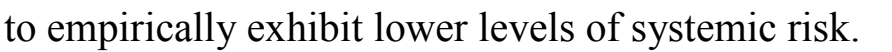

$\square$

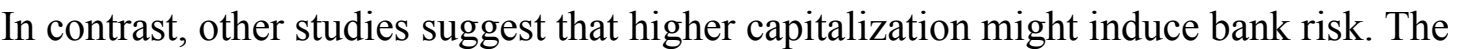

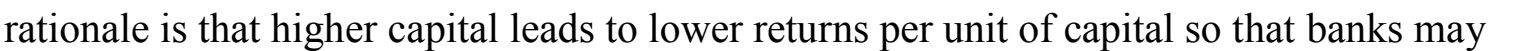

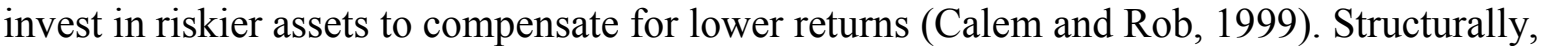

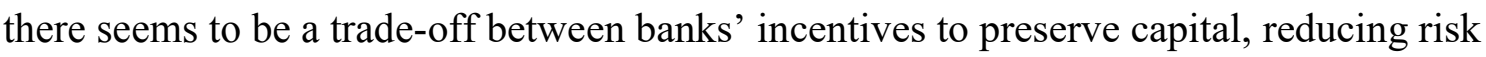

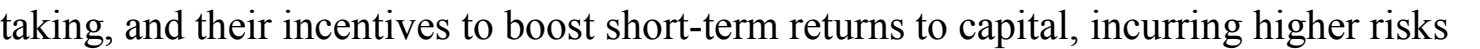

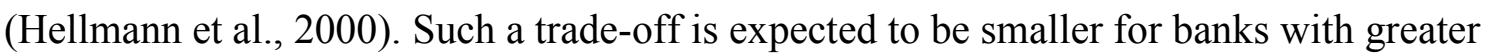

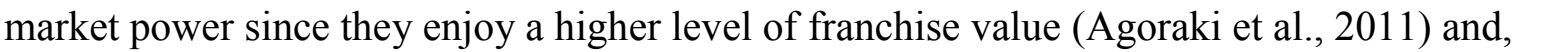

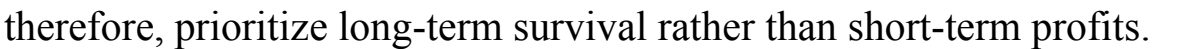

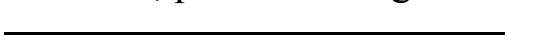

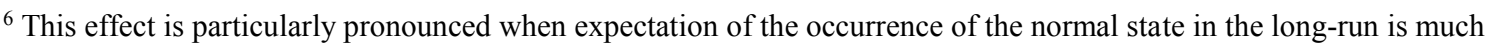

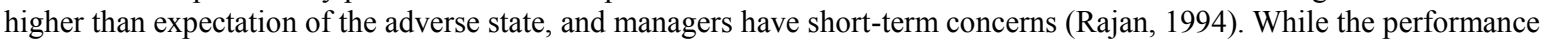

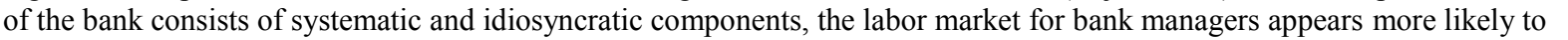
associate better performance with managers' ability in the normal rather than adverse state (Thakor, 2016). $\square$ 


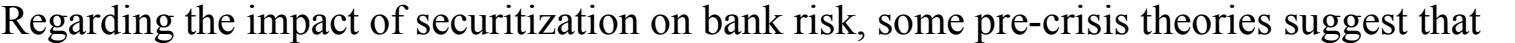

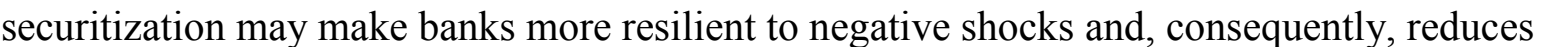

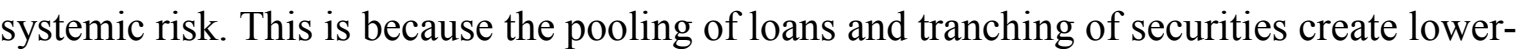
प

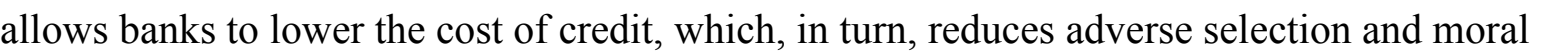

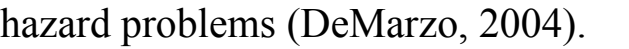

$\square$

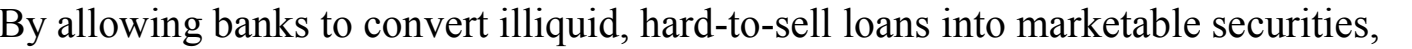

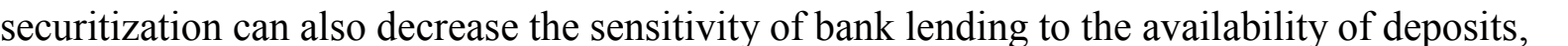

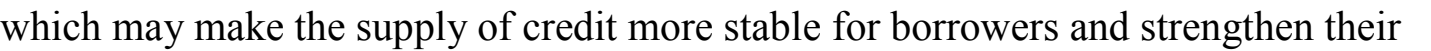

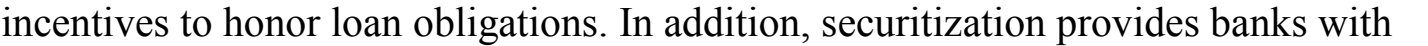

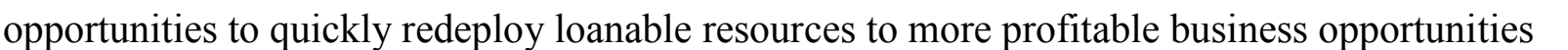

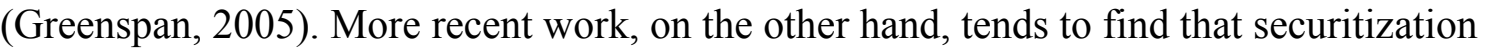

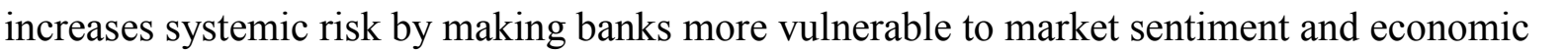

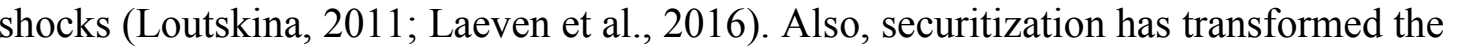

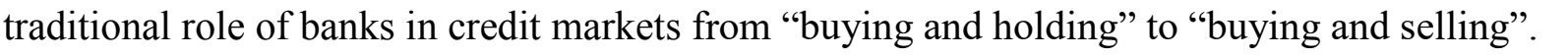

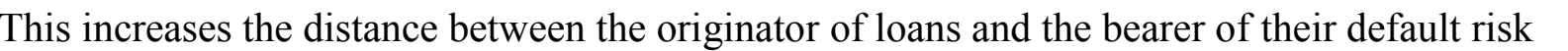

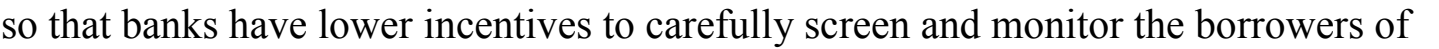

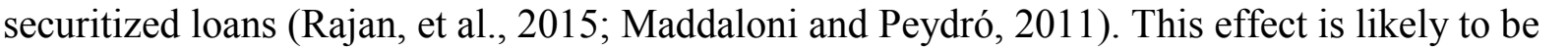

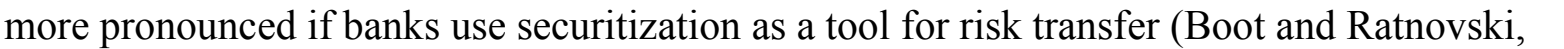

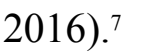

$\square$

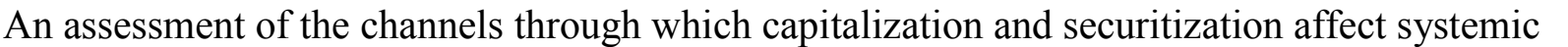

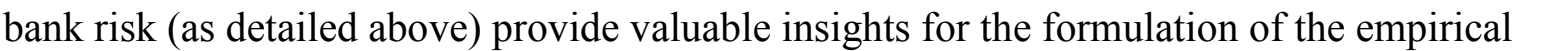

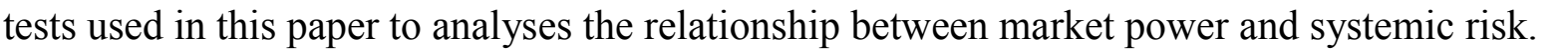

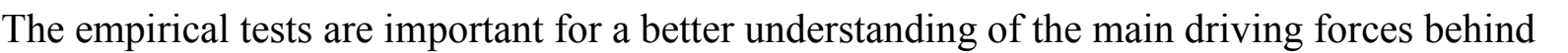

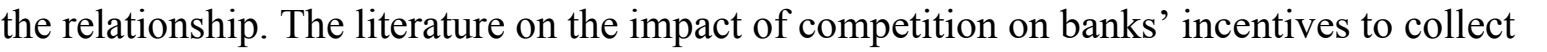

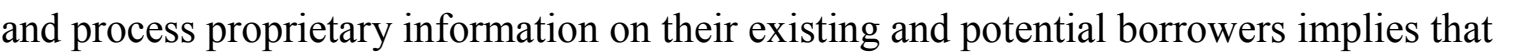

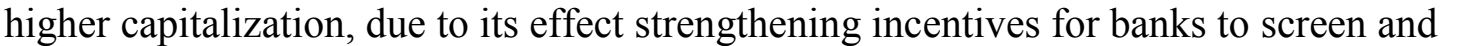

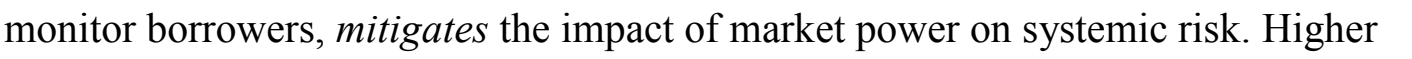

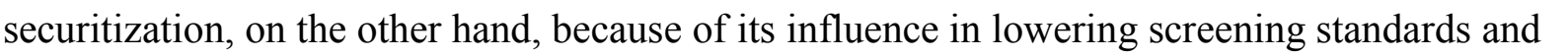

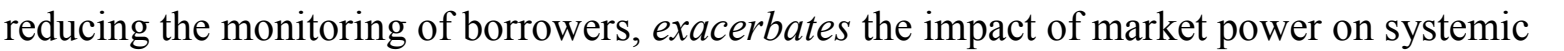

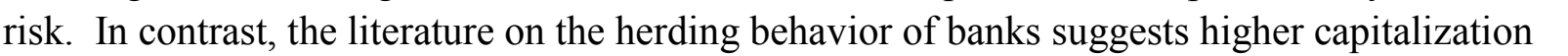

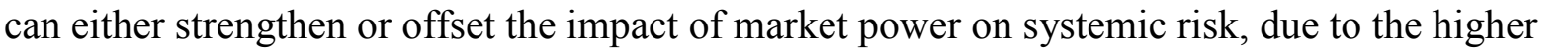

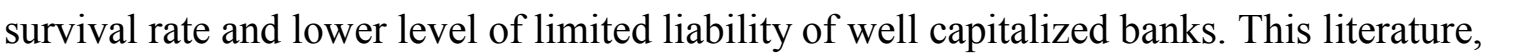

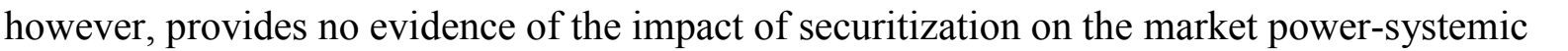

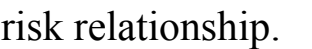

$\square$

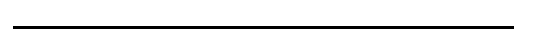

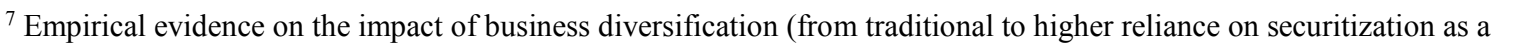
पणतापincome) on banks' soundness and profitability suggest very limited impact during good times (Apergis, 2014).The

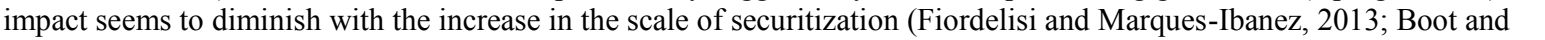

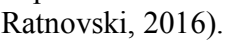




\section{DATA AND MODEL}

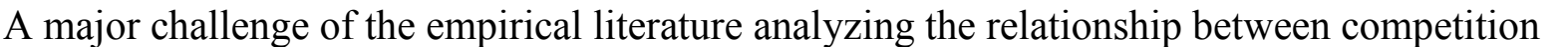

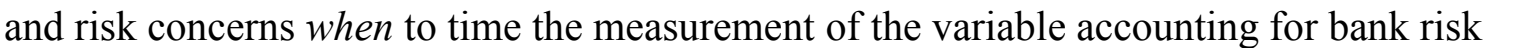

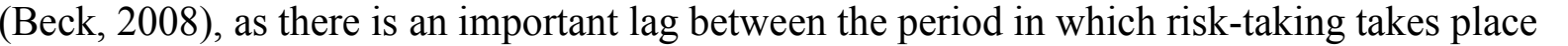

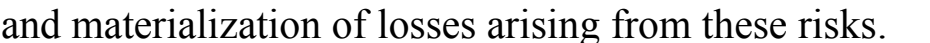

$\square$

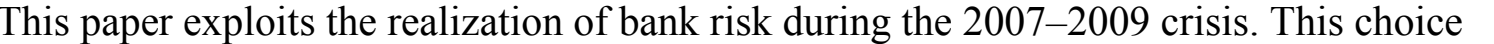

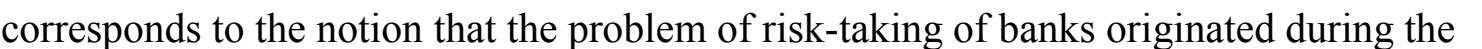

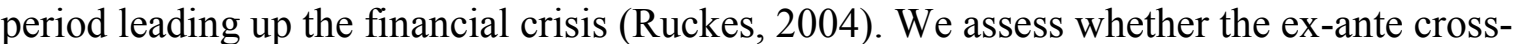

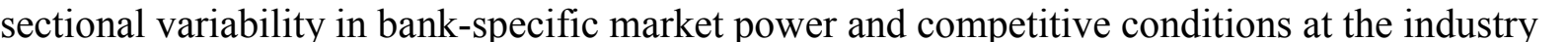

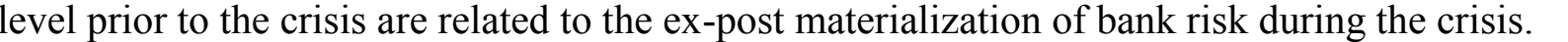

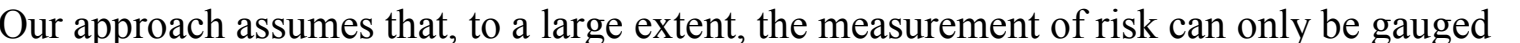

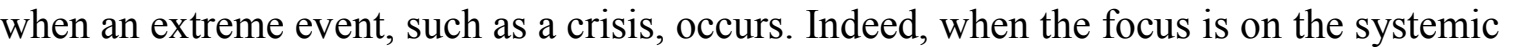

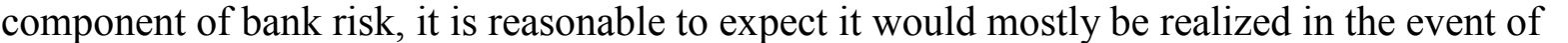

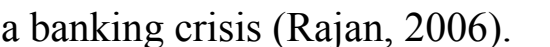

$\square$

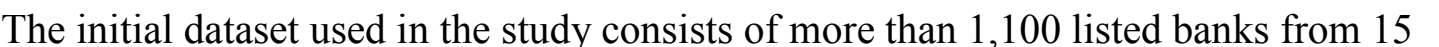

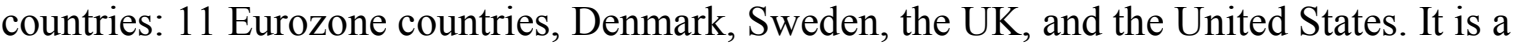

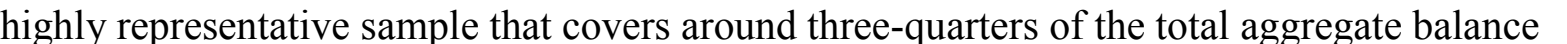

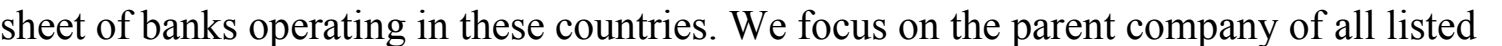

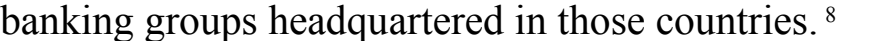

$\square$

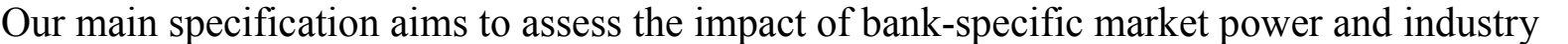

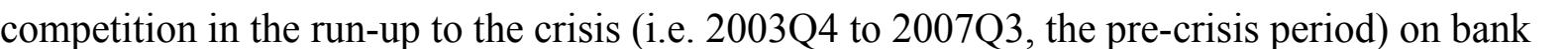

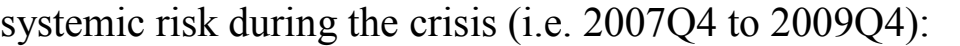

$\square$

$$
\begin{aligned}
& \text { Risk }_{i, k, p o s t}=\text { constant }+\alpha * \text { Lerner }_{i, k, p r e}+\beta * \text { CAPITALIZATION }_{i, k, p r e}+\gamma * \\
& \text { SECURITIZATION }_{i, k, p r e}+\tau * \text { CONTROL }_{i, k, p r e}+b * \text { Lerner }_{k, p r e}+
\end{aligned}
$$

$\varepsilon_{i, k, p o s t}$

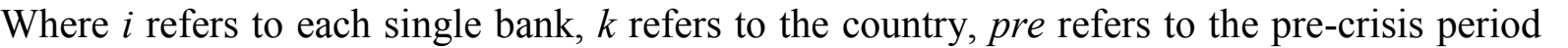

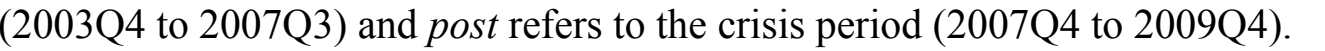

$\square$

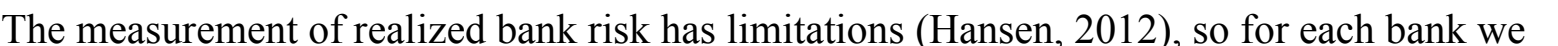

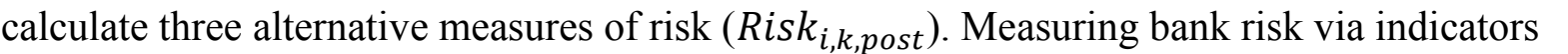

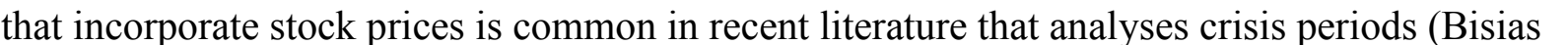

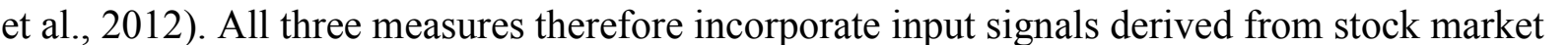

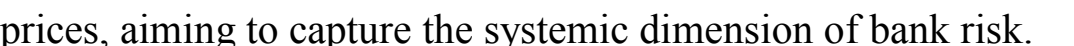

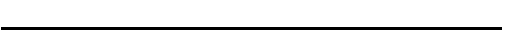

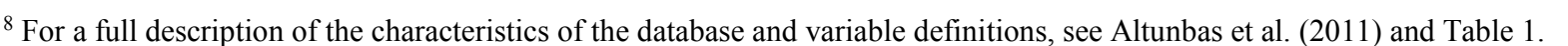




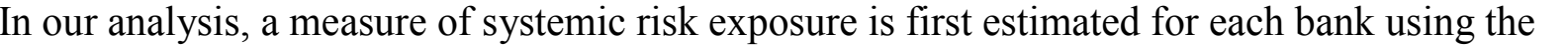

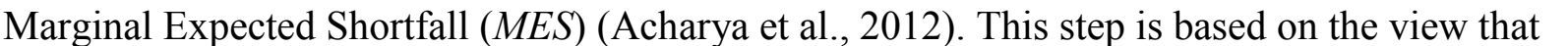

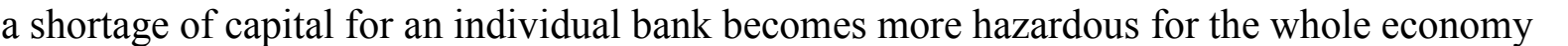

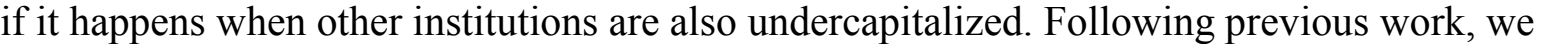

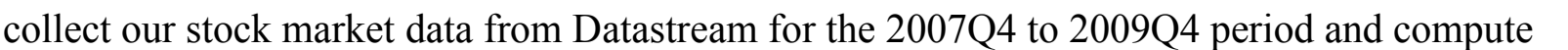

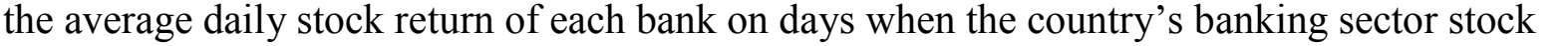

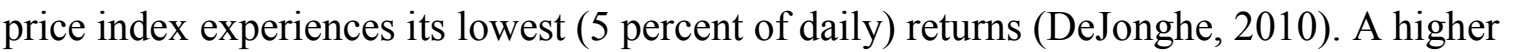

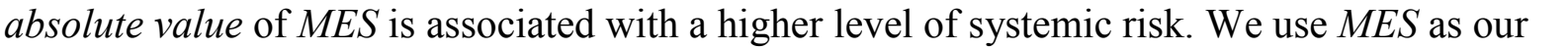

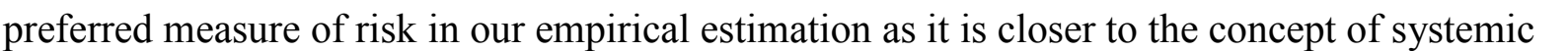
ए

$\square$

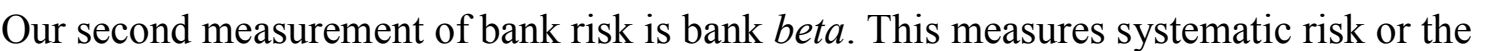

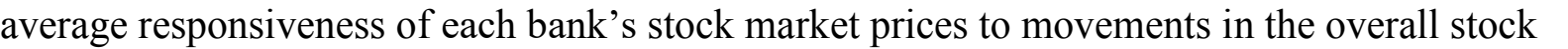

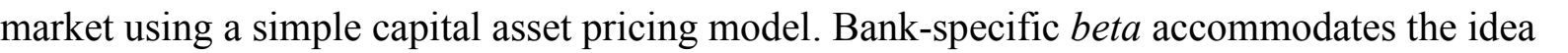

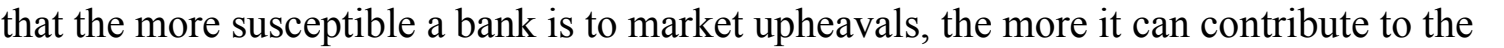

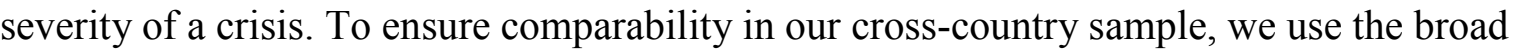

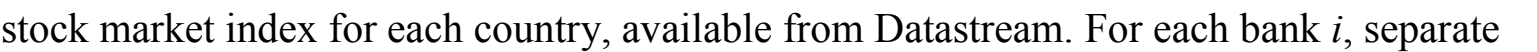

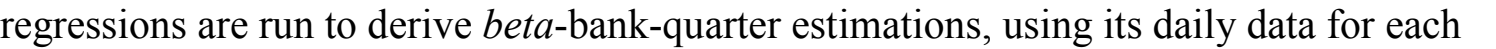

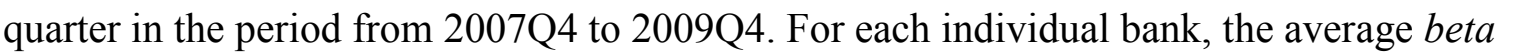

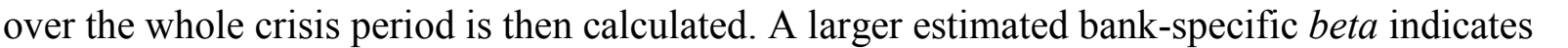

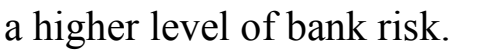

$\square$

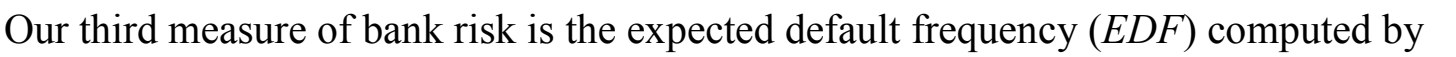

Moody's KMV. The measurement is built on Merton's model (Merton, 1974). $\square \square \square E D F \square$

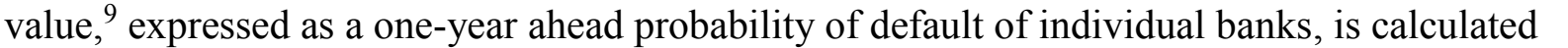

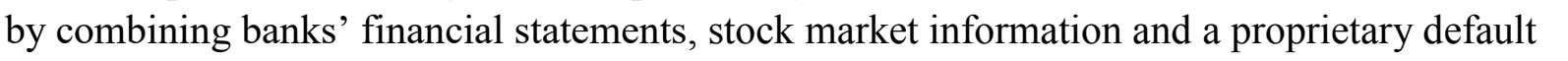

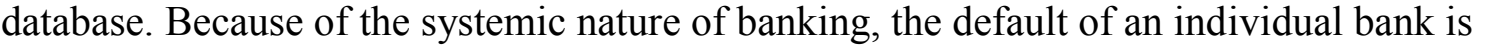

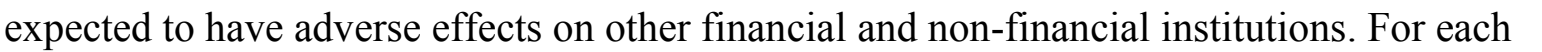

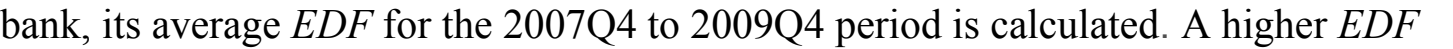
indicates a higher likelihood of bank default in one year's time.

$\square$

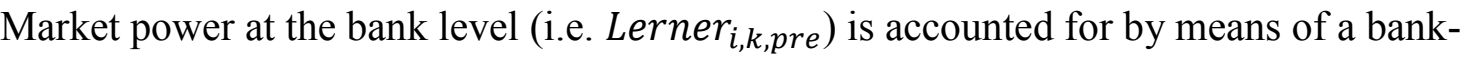

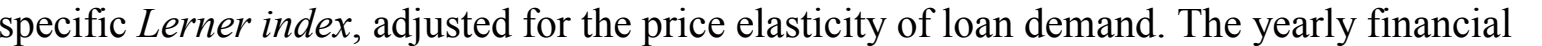

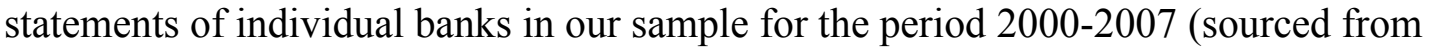

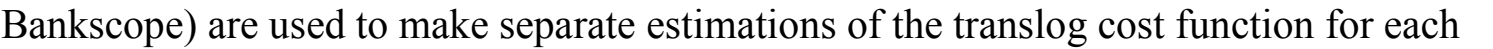

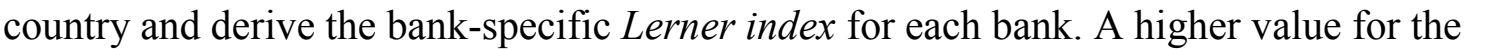

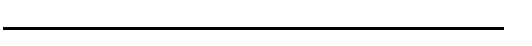

:

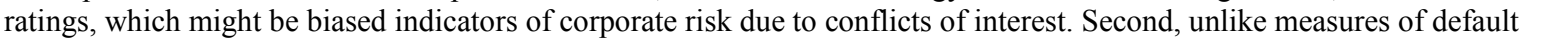

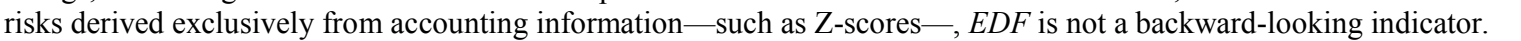

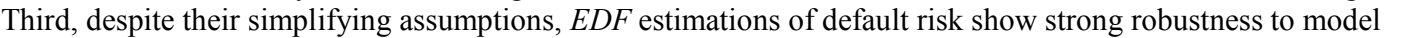

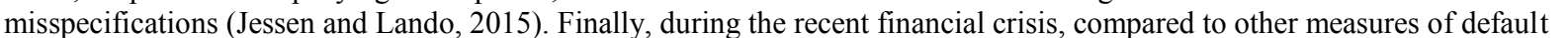

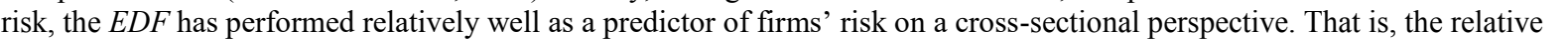

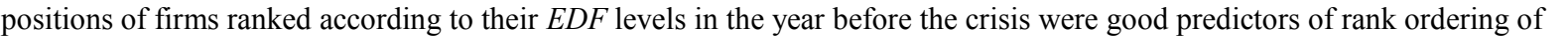

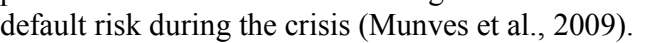




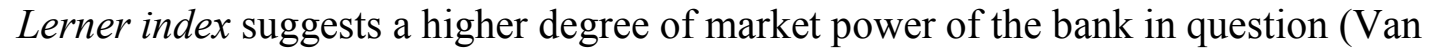

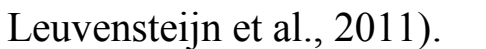

$\square$

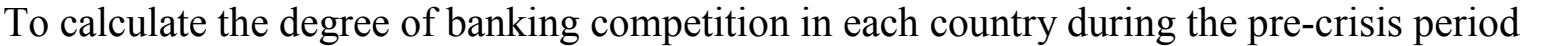

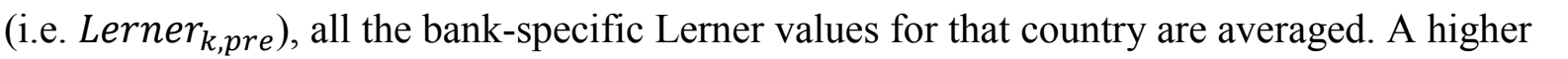

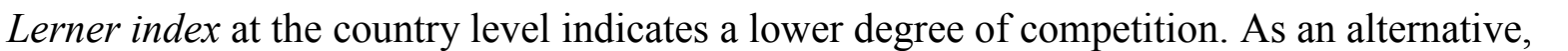

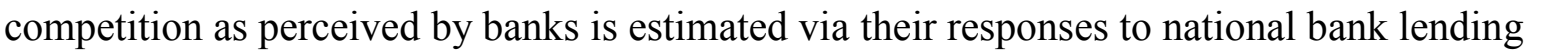

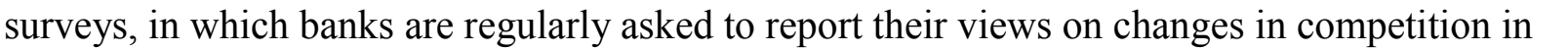

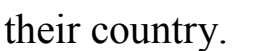

$\square$

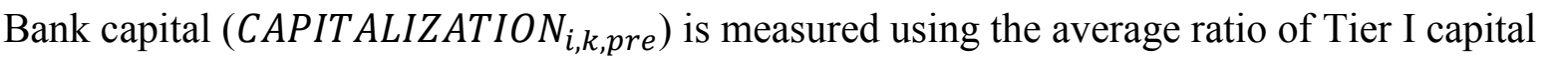

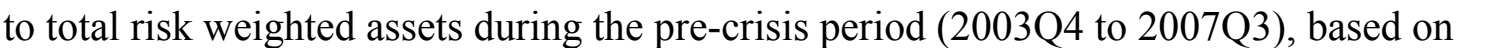

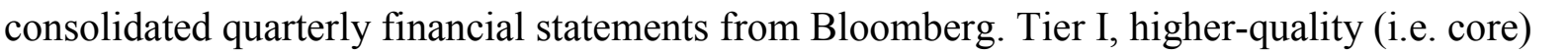

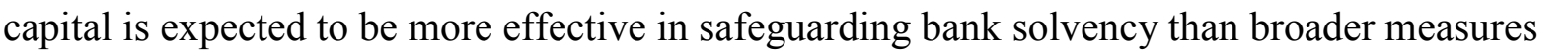

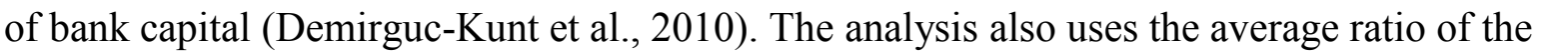

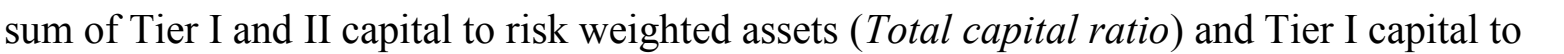

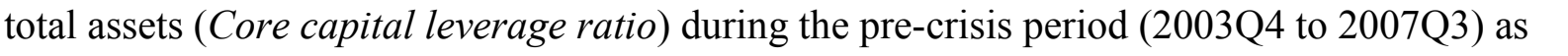

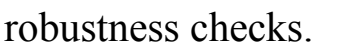

$\square$

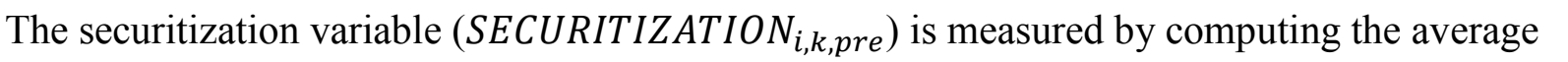

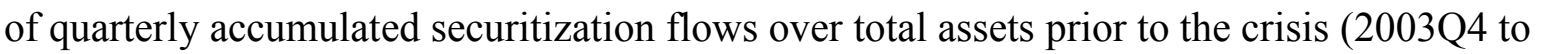

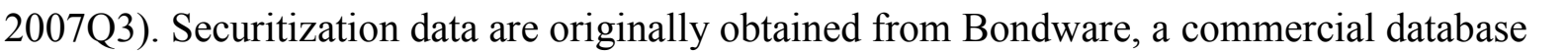

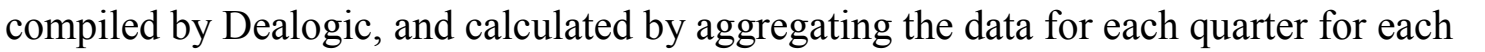

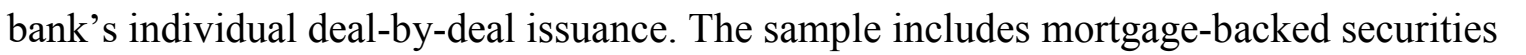

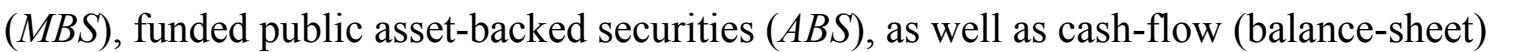

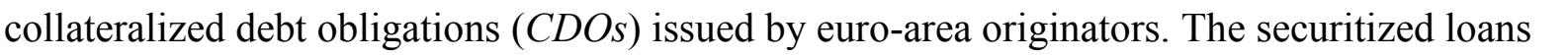

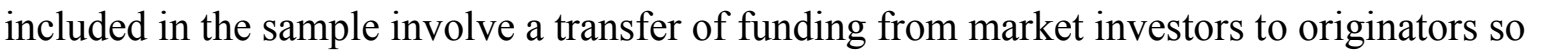

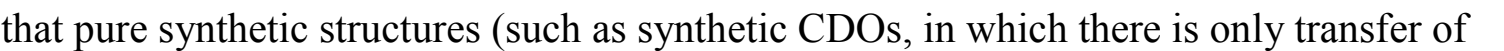

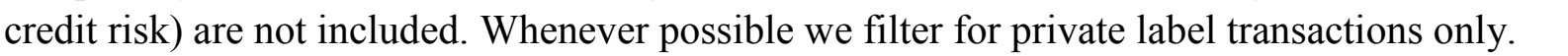
$\square$

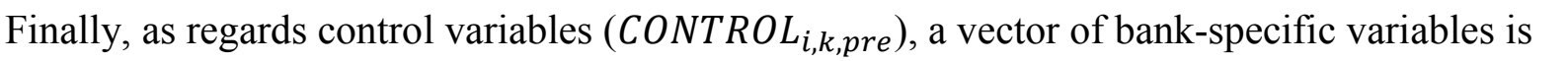

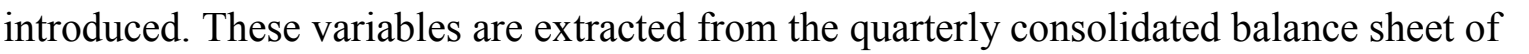

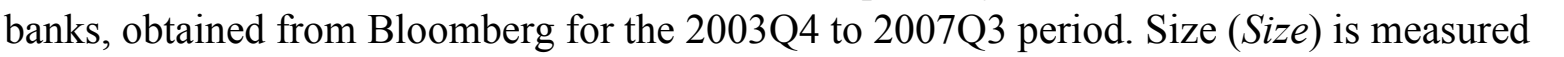

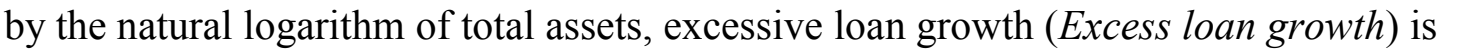

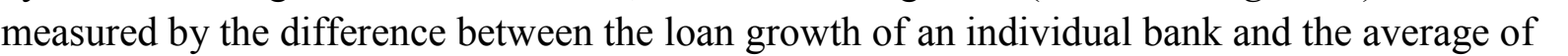

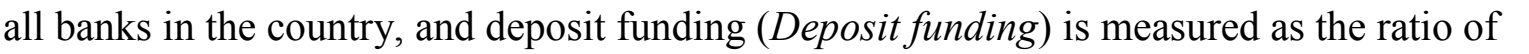

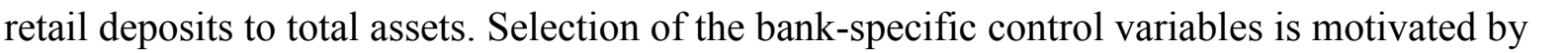
ए

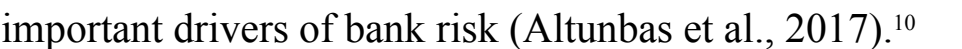

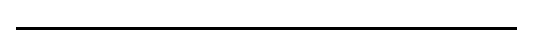

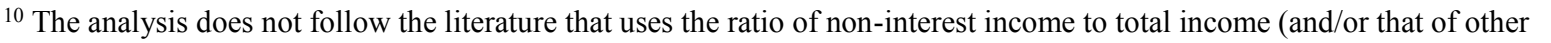

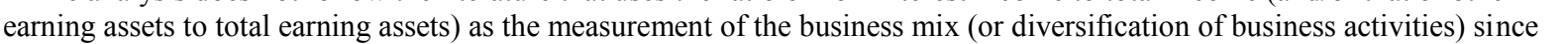
ए ए

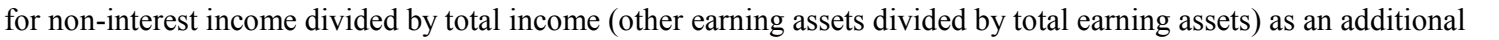

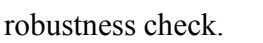




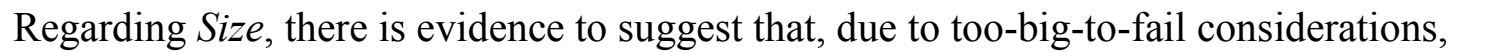

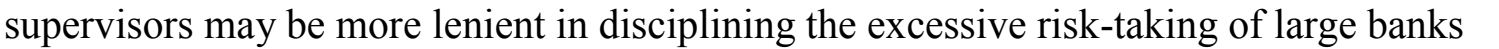

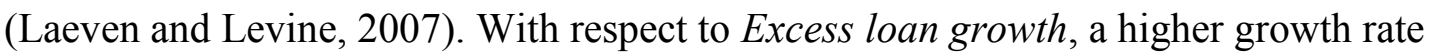

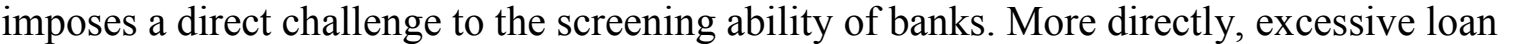

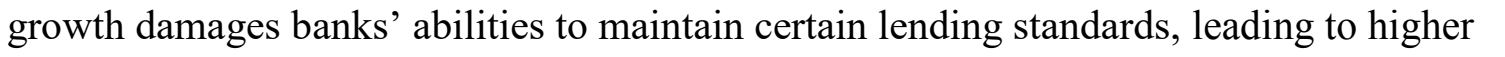

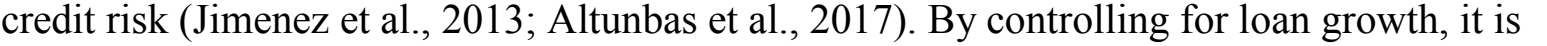

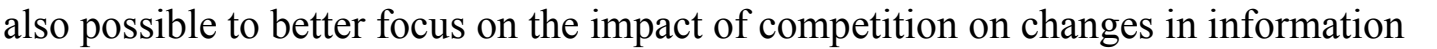

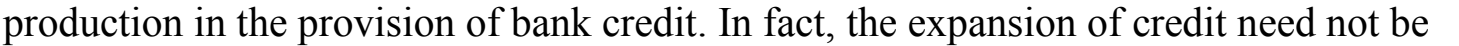

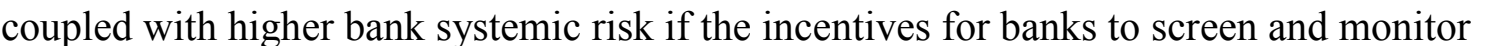

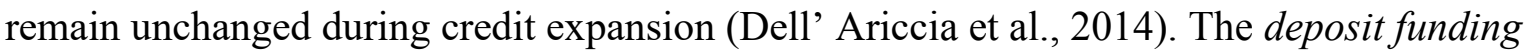

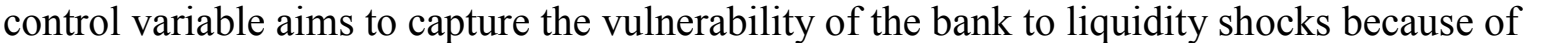

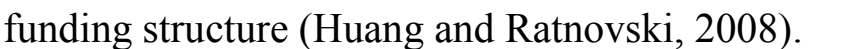

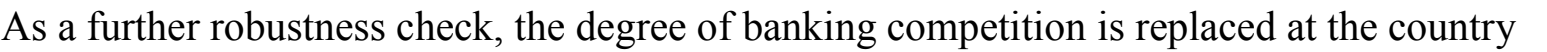

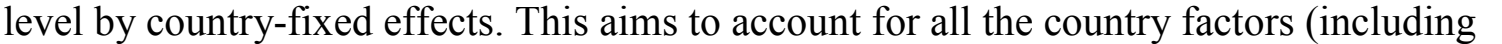

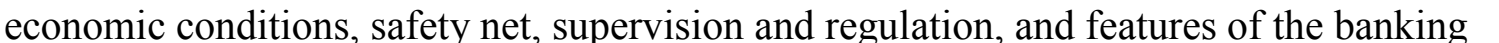

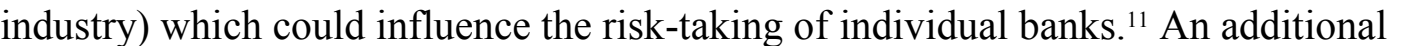

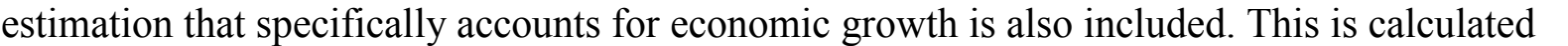

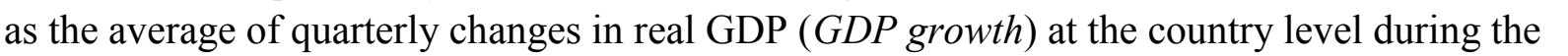

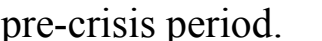

$\square$

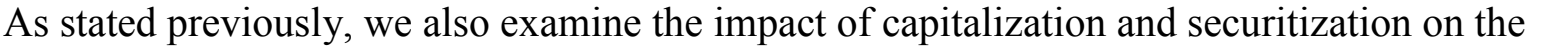

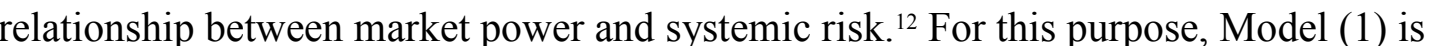

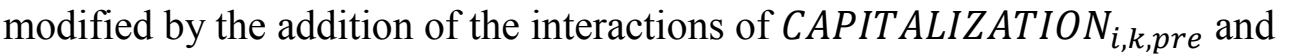

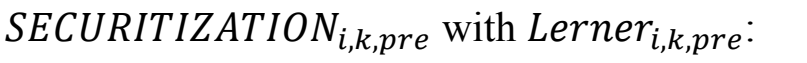

$$
\begin{gathered}
\text { Risk }_{i, k, p o s t}=\text { constant }+\alpha * \text { Lerner }_{i, k, p r e}+\beta * \text { CAPITALIZATION }_{i, k, p r e}+ \\
\gamma * \text { SECURITIZATION }_{i, k, p r e}+\varphi * \text { CAPITALIZATION }_{i, k, p r e} * \text { Lerner }_{i, k, p r e}+\varphi * \\
\text { SECURITIZATION }_{i, k, p r e} * \text { Lerner }_{i . k, p r e}+\tau * \text { CONTROL }_{i, k, p r e}+b * \text { Lerner }_{k, p r e}+
\end{gathered}
$$

$\varepsilon_{i, k, p o s t}$

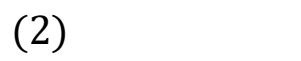

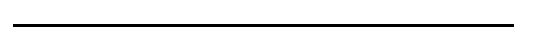

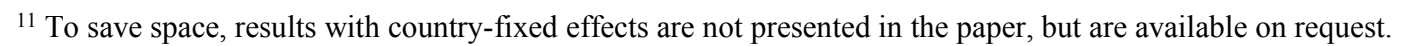

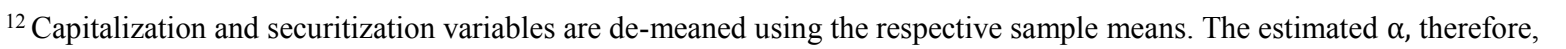

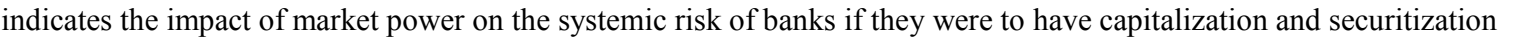

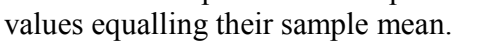




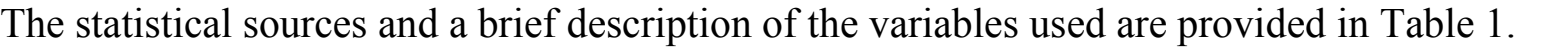

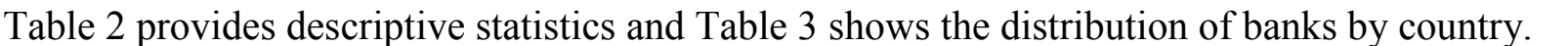

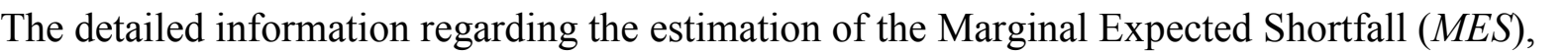

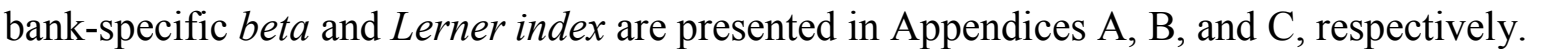
$\square$

\section{RESULTS, ROBUSTNESS TESTS AND ADDITIONAL ANALYSIS}

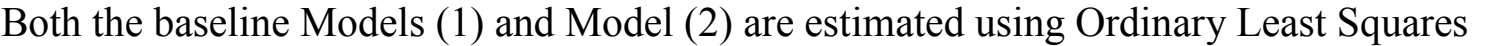

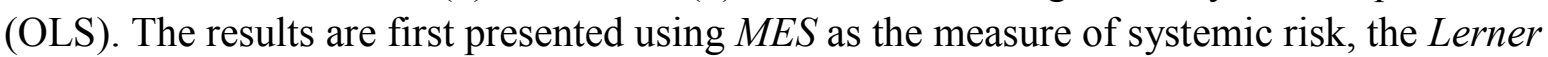

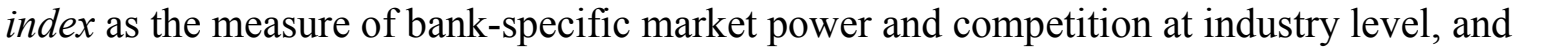

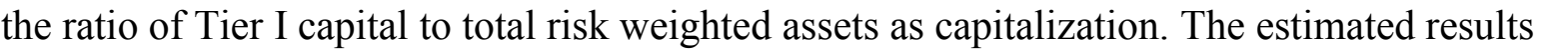

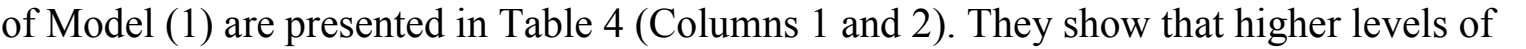

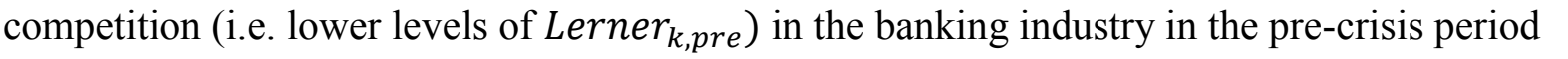

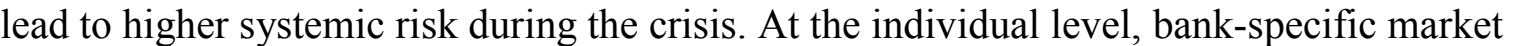

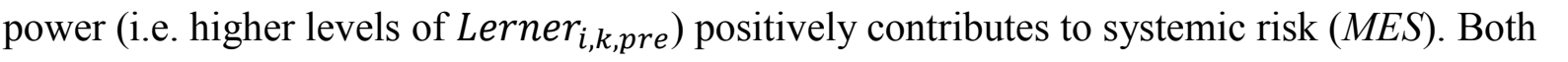

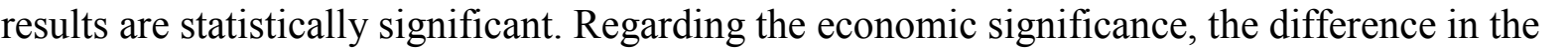

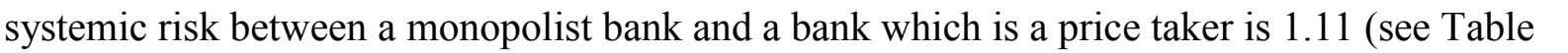

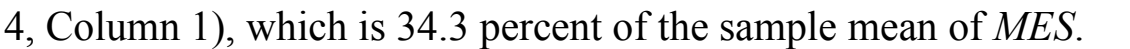

$\square$

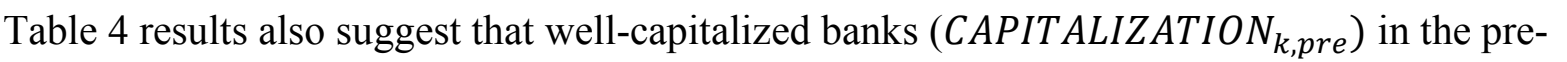

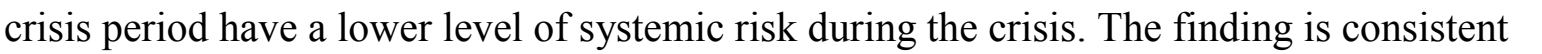

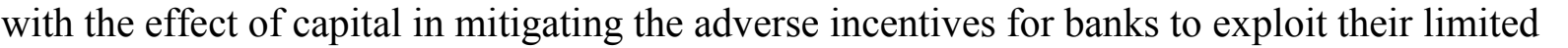

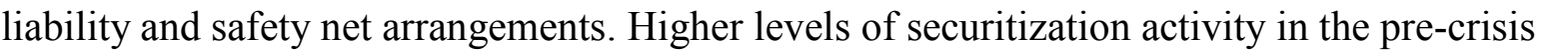

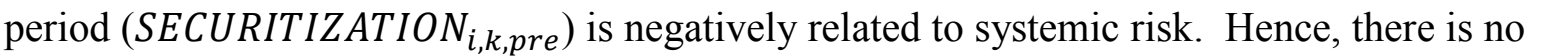

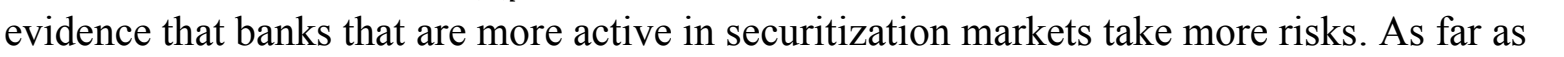

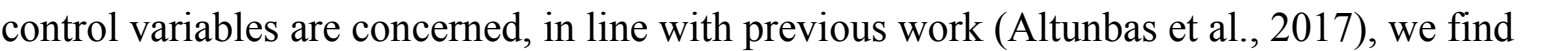

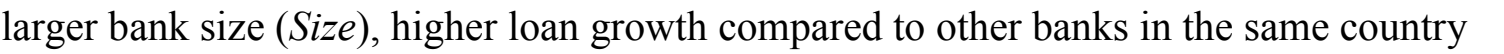

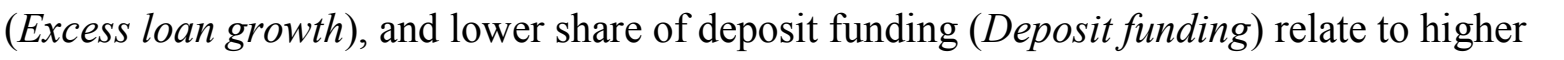

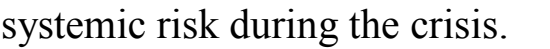

$\square$

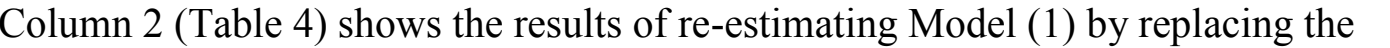

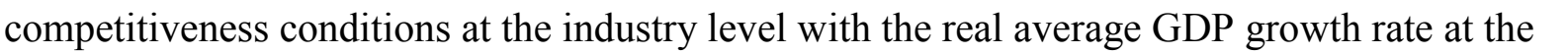

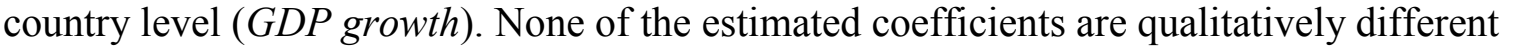

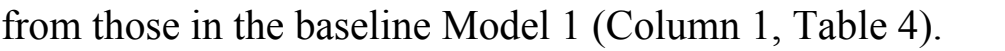

$\square$

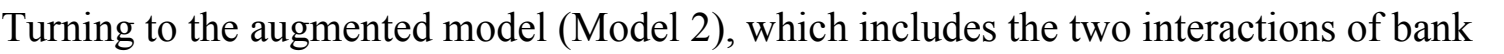

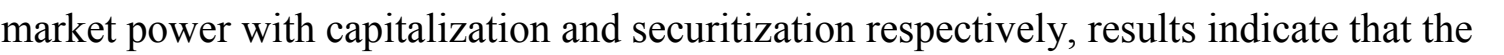
प

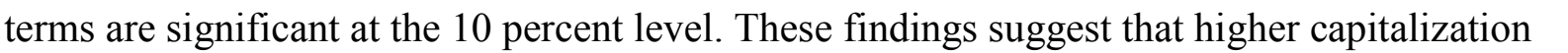

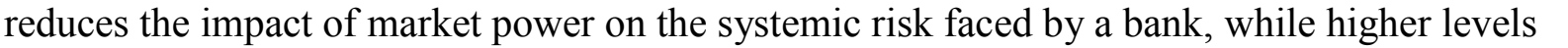

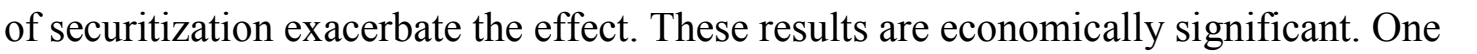

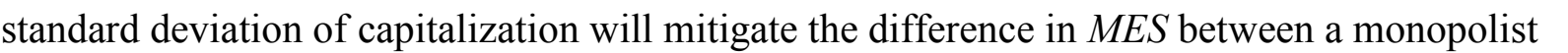

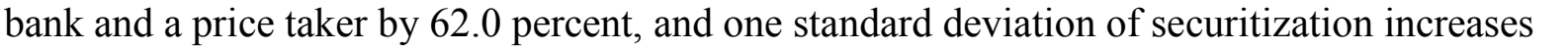

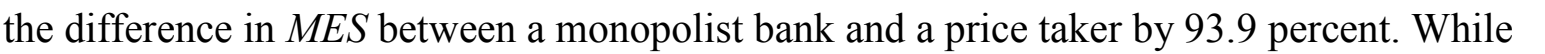

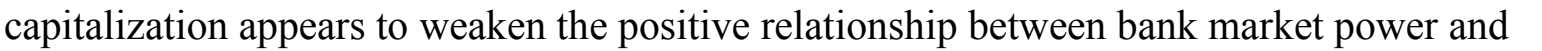




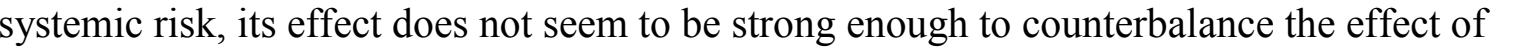

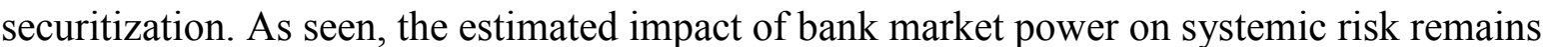

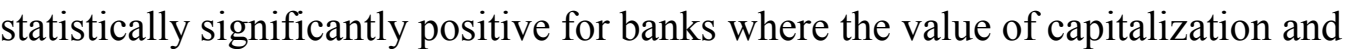

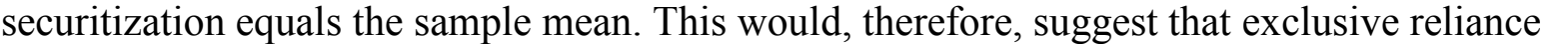

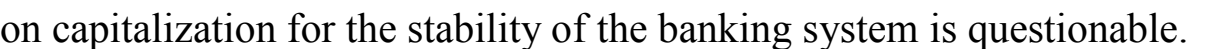

$\square$

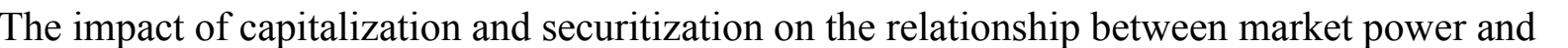

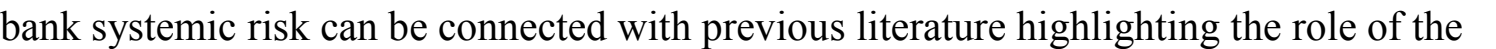

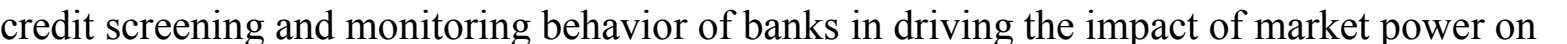

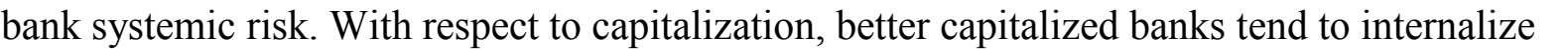

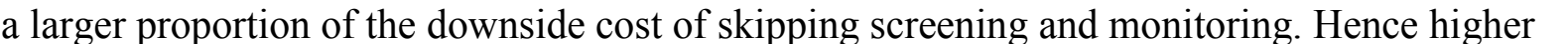

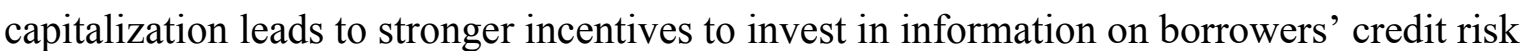

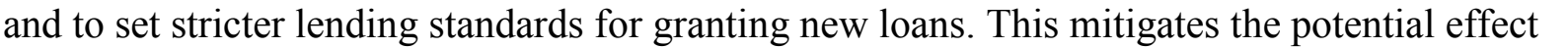

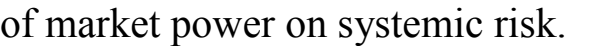

$\square$

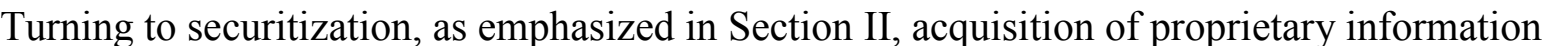

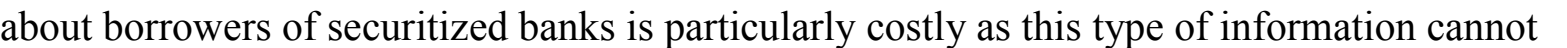

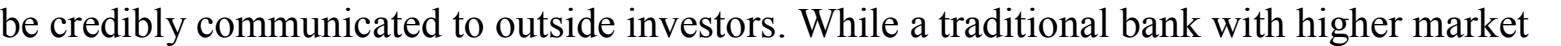

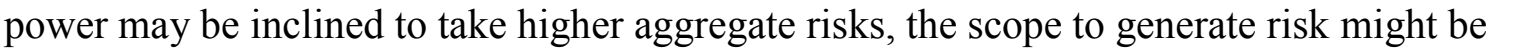

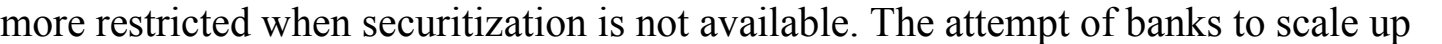

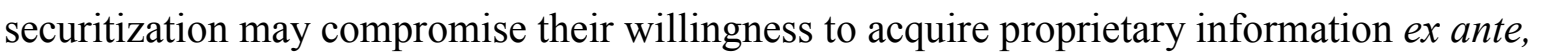
ए

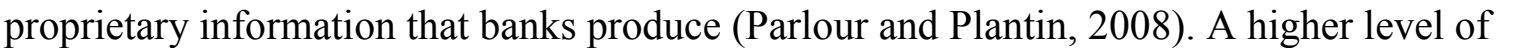

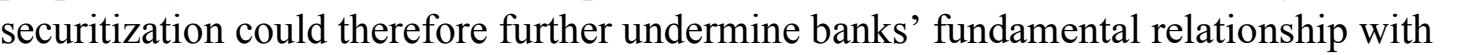

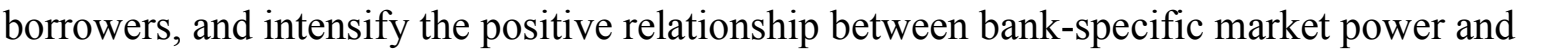

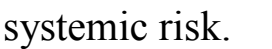

$\square$

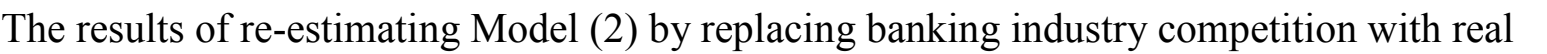

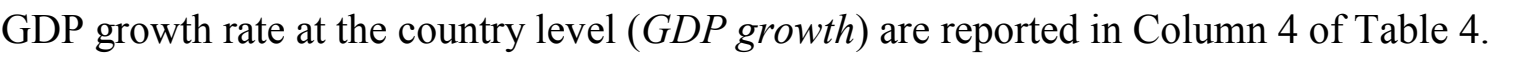

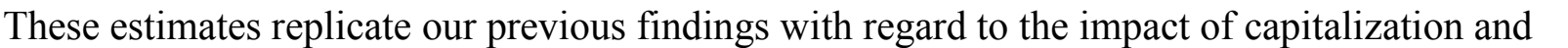

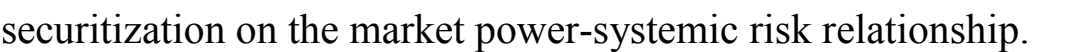
$\square$

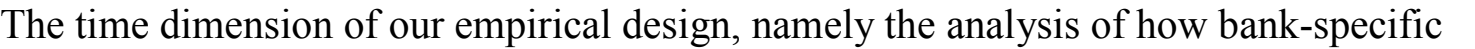

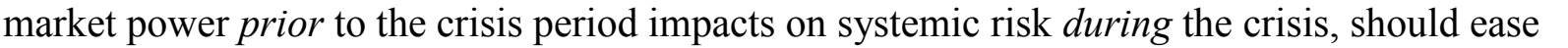

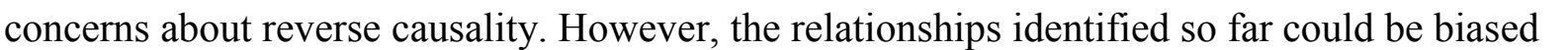

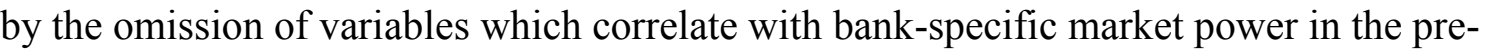

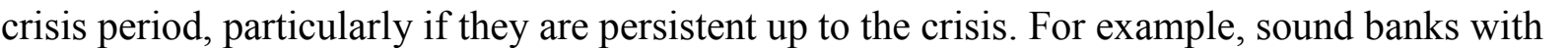

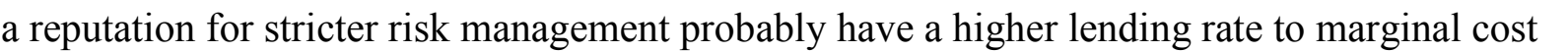

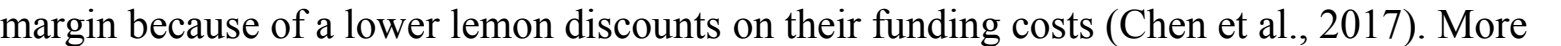

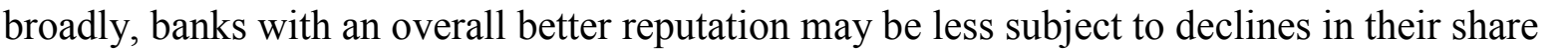

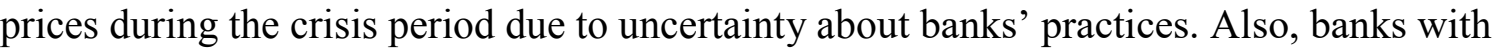

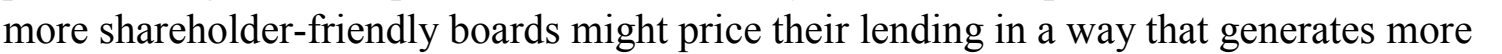

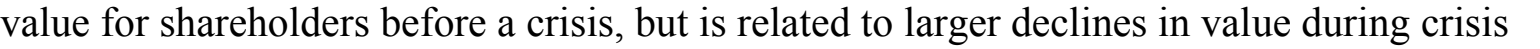

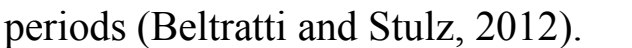

$\square$ 


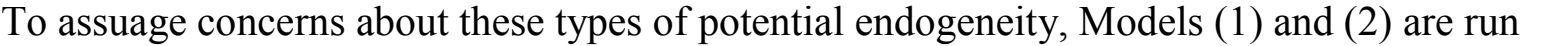

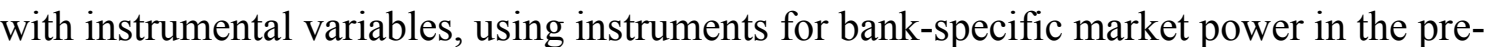

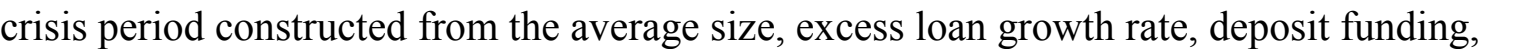

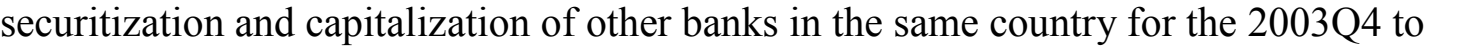

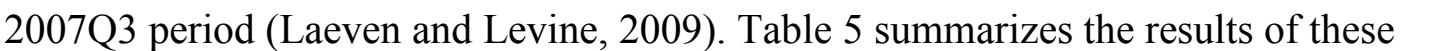

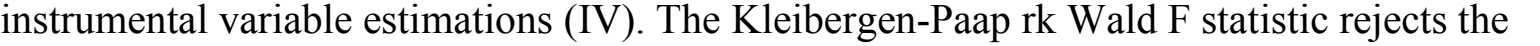

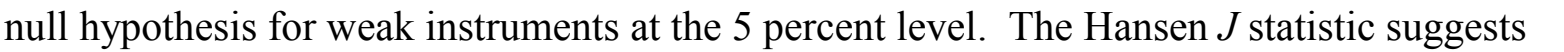
ए

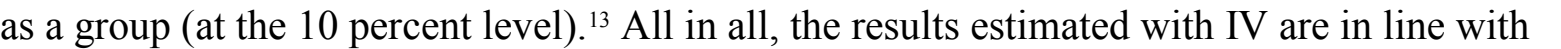

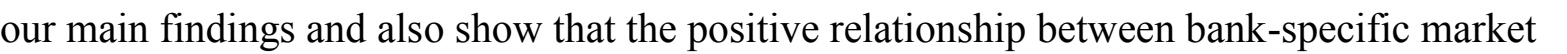

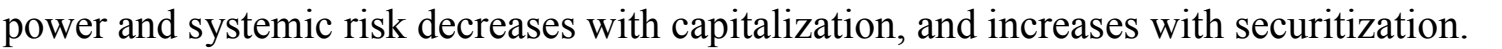
$\square$

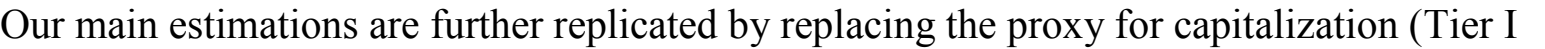

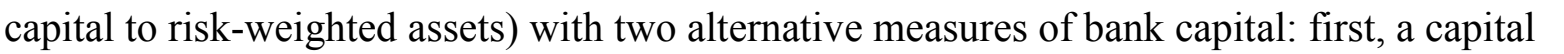

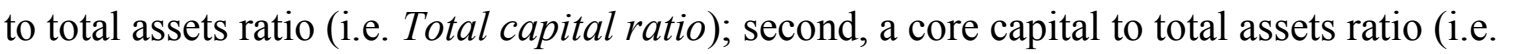

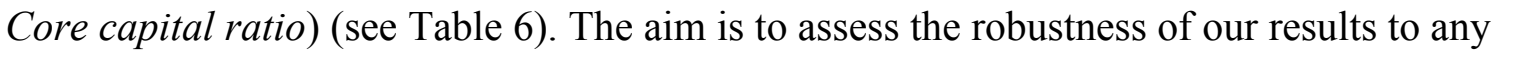

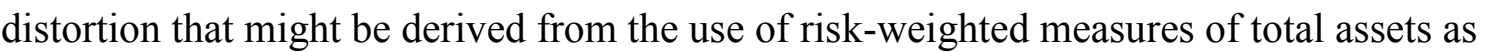

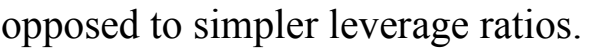

$\square$

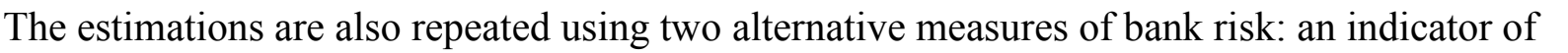

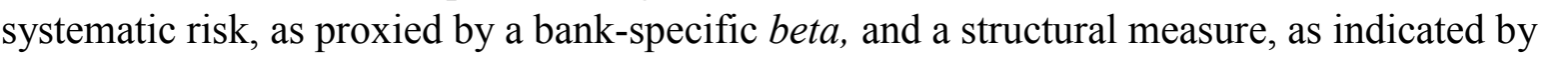

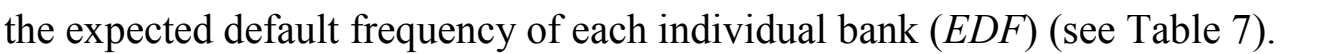

$\square$

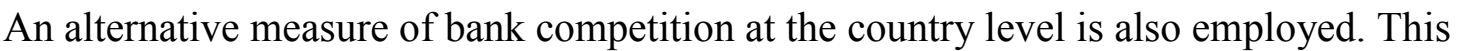

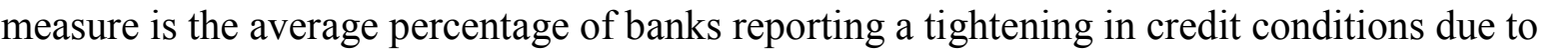

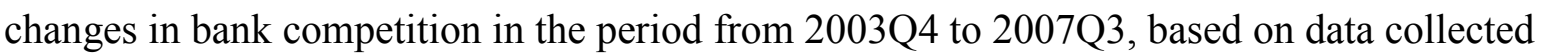

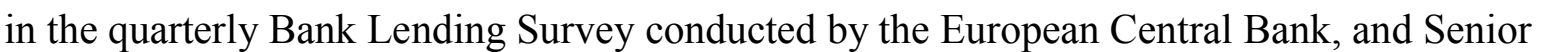

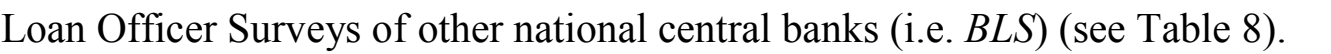

$\square$

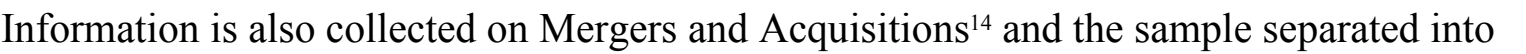

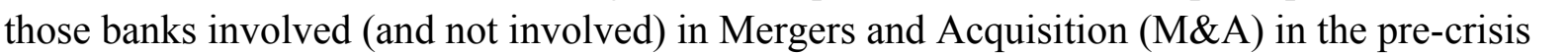

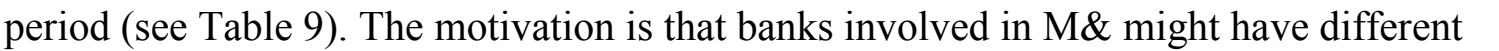

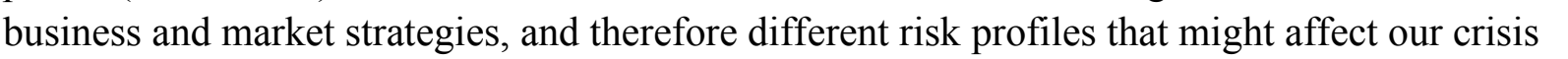

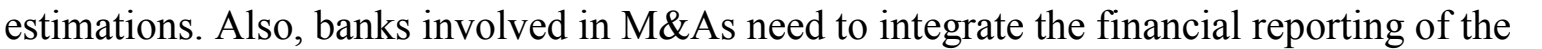

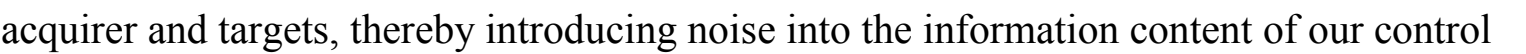
$\square \square\|\|\|\|\|\|$

\section{mmmmmmmmmmmmmmm}

प्र

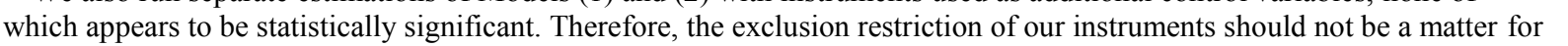
पाणाणा

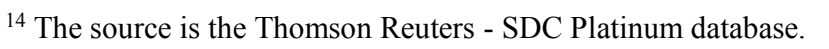




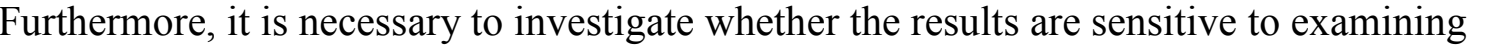

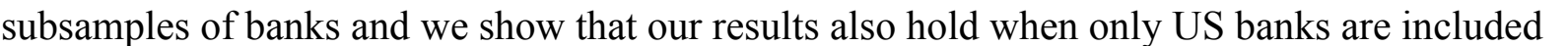

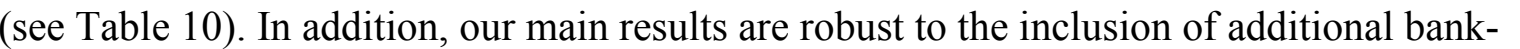

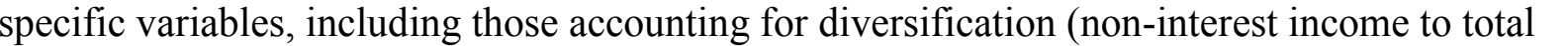

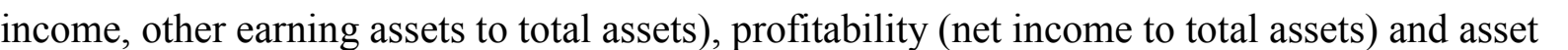

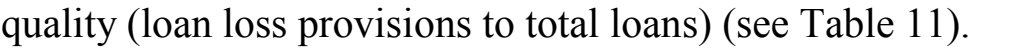

$\square$

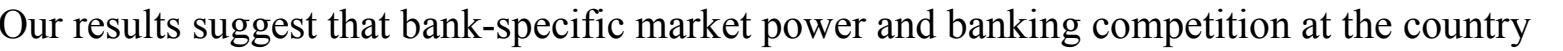
प

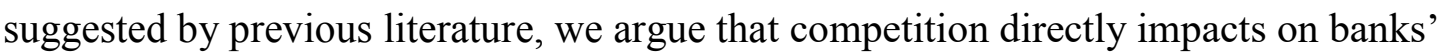
ए

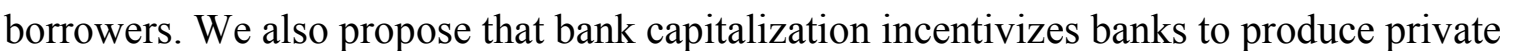

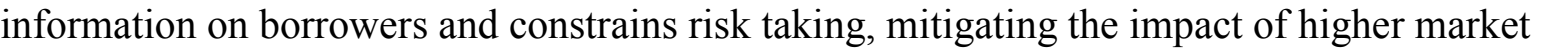

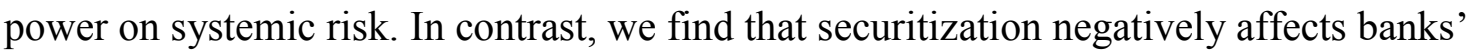

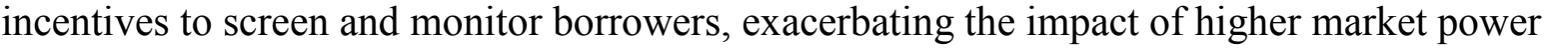

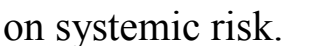

$\square$

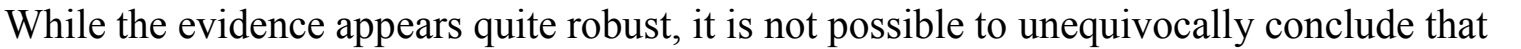

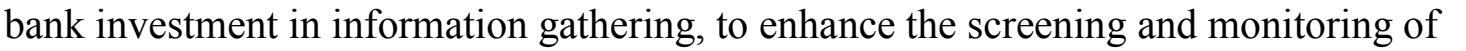

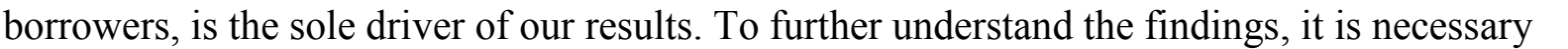

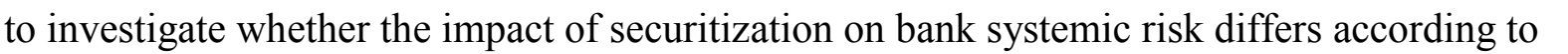

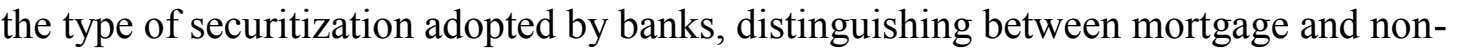

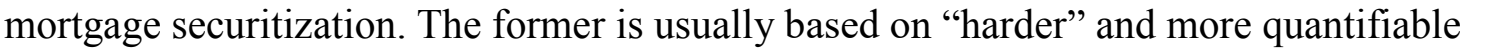

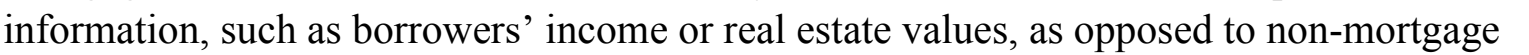
loans, in which “softer" "

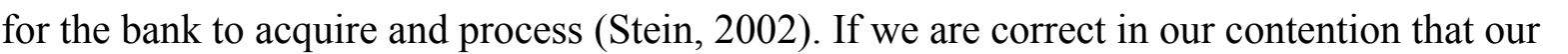
empirical findings can be largely explained by banks' incentives to produce costly $\square\|\square \square \square\| \square \square$

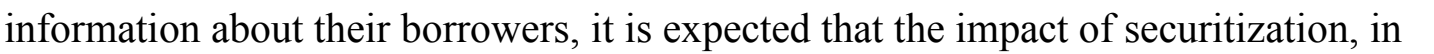

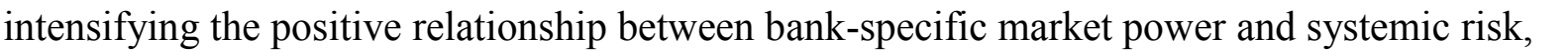

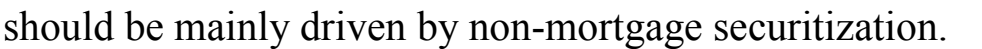

$\square$

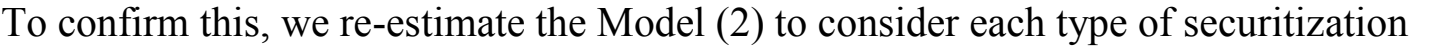

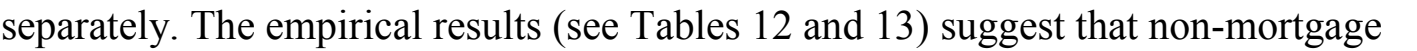

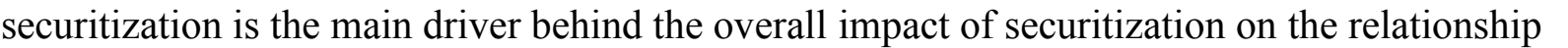

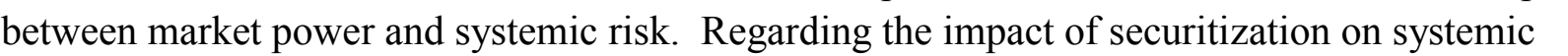

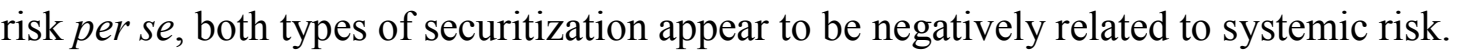

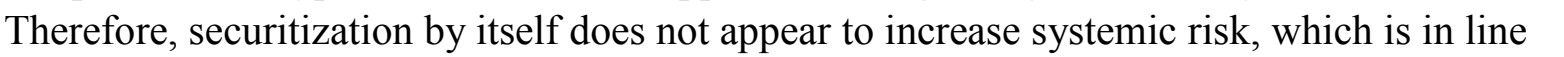

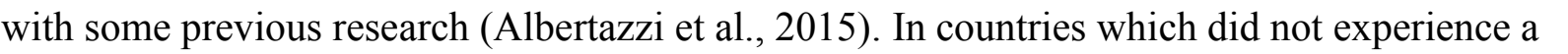

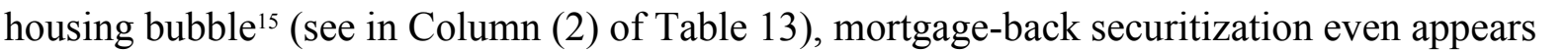

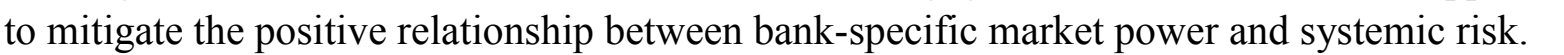

$\square$

m m+m!m

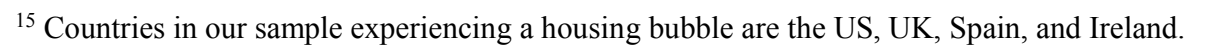




\section{Conclusion}

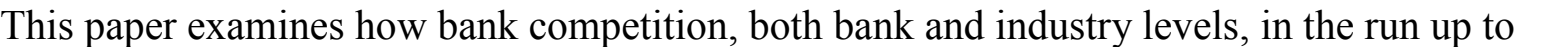

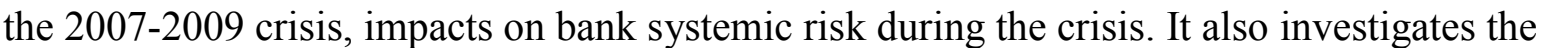

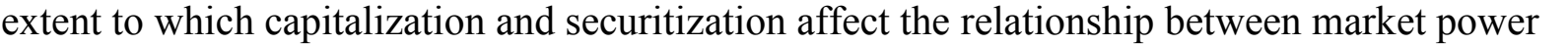

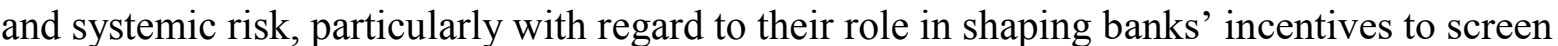

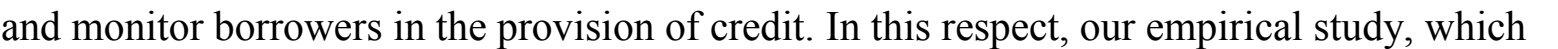

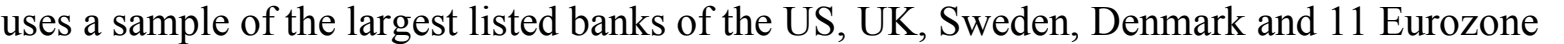

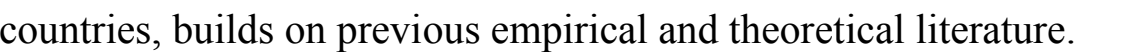

$\square$

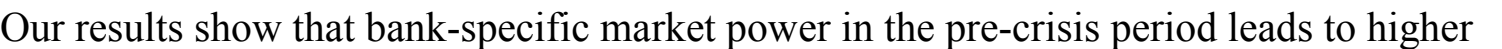

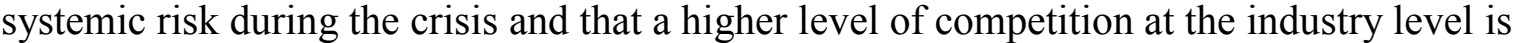

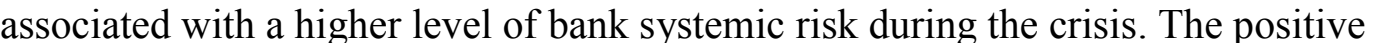

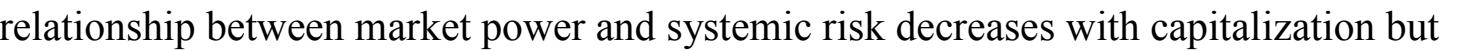

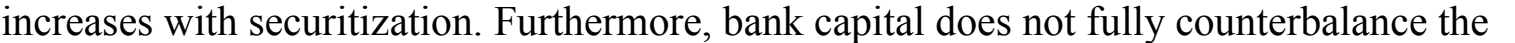

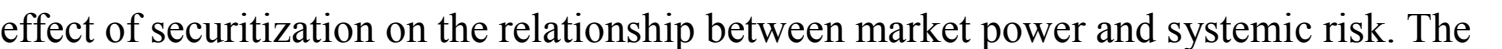

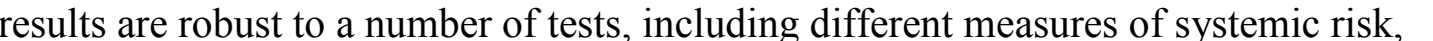

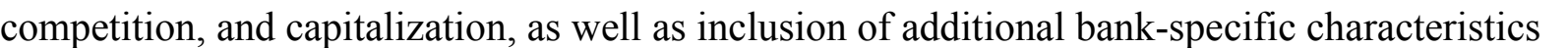

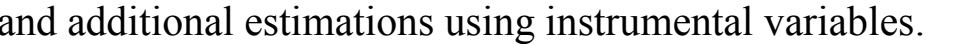

$\square$

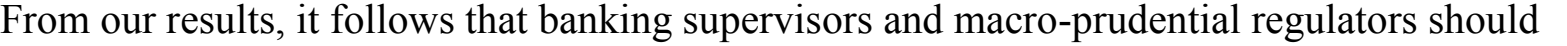

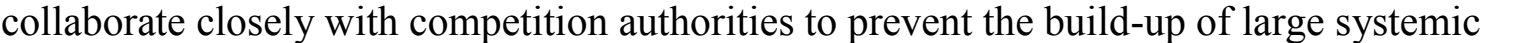

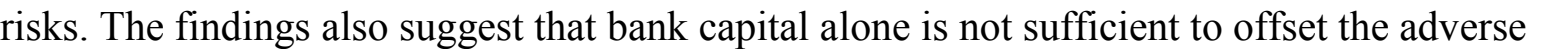

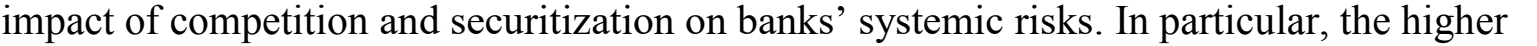

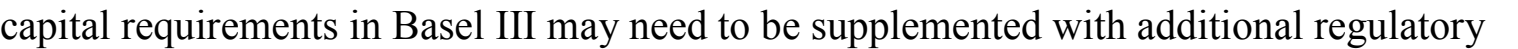
ए

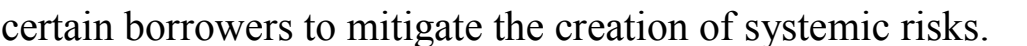




\section{References $\square$}

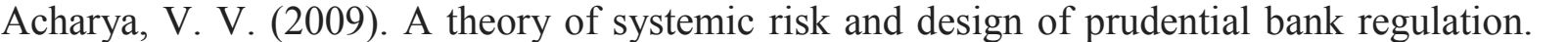

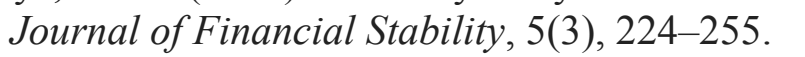

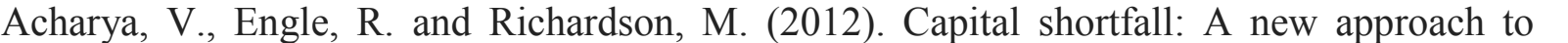

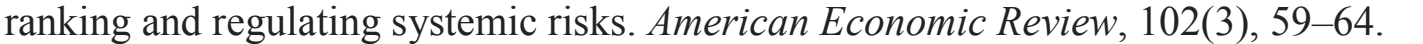

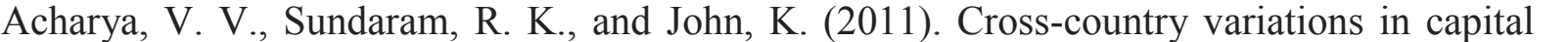

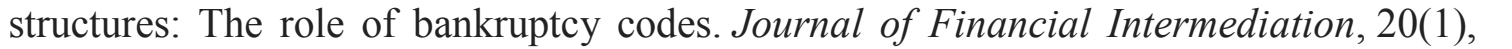
$\square-\square \square \square$

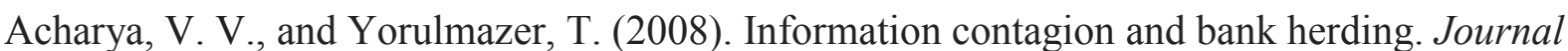
of Money, Credit and Banking $\square||\||\|||-\square| \square$

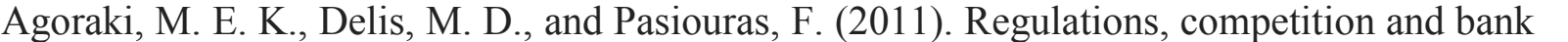

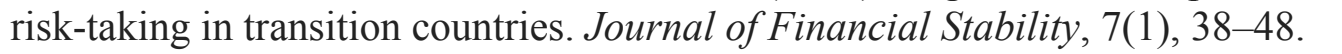

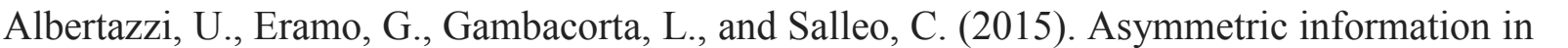

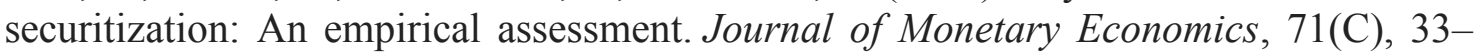
$\square \square$

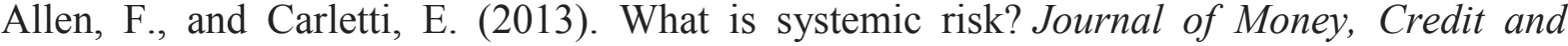

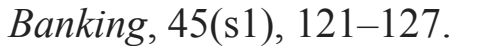

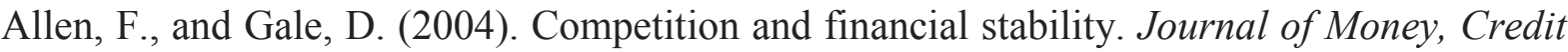

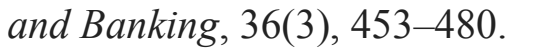

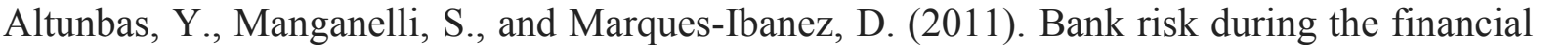

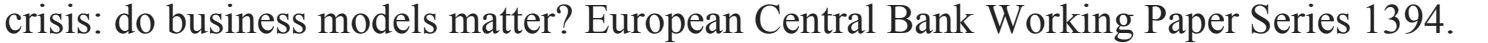

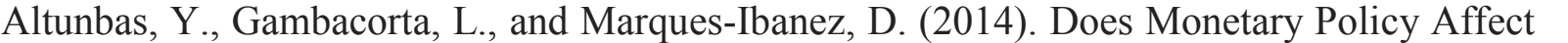

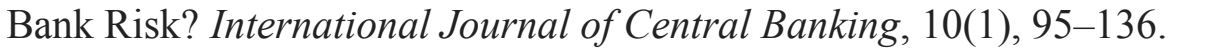

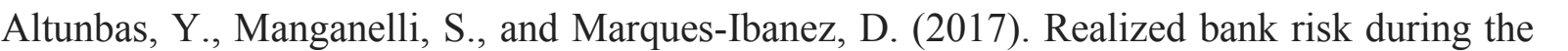

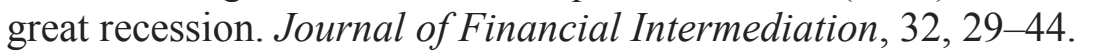

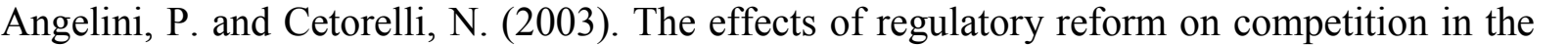

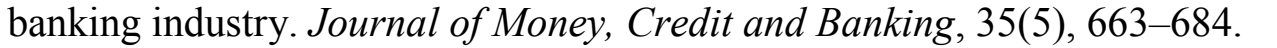

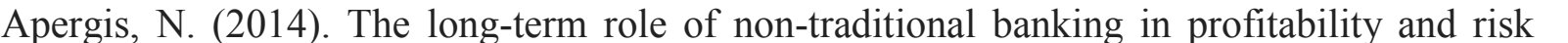

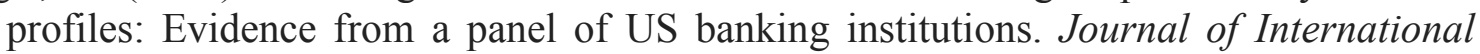
Money and Finance $\square \square|\Pi|-\square \square$

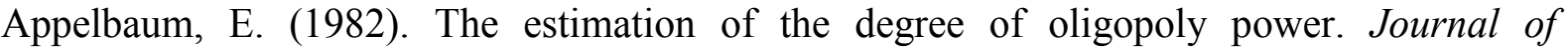

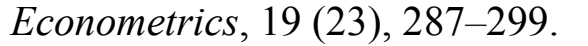

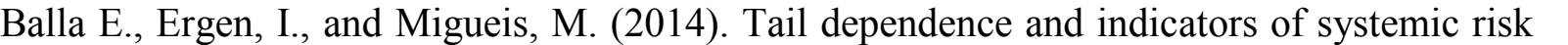

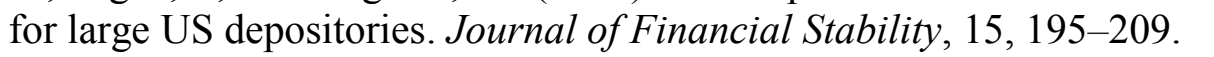

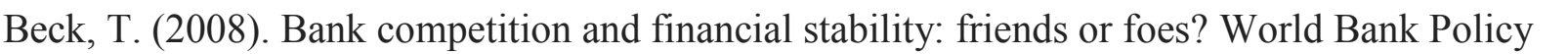

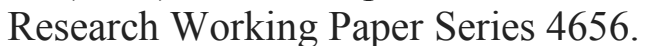

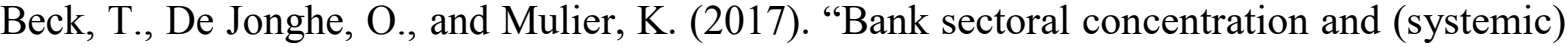

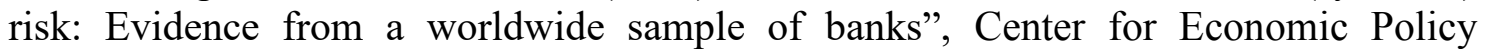

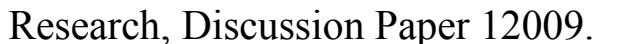

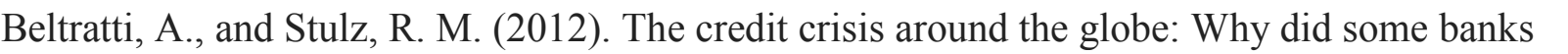

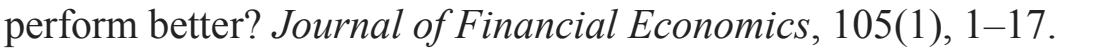




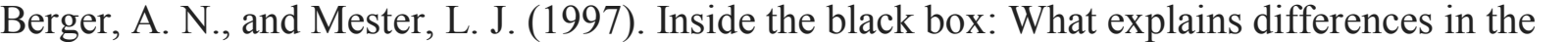

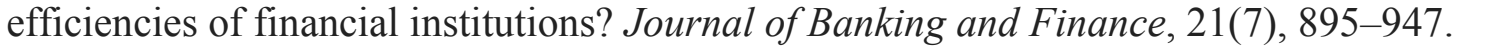

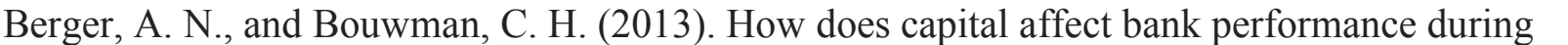

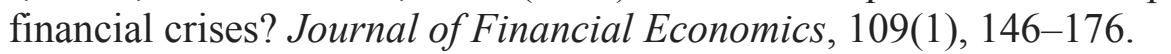

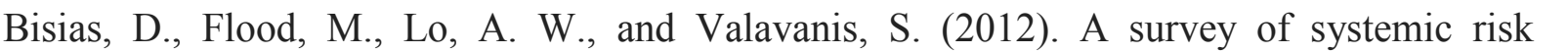

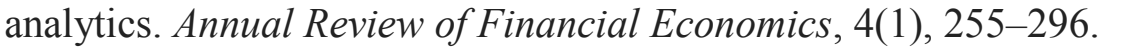

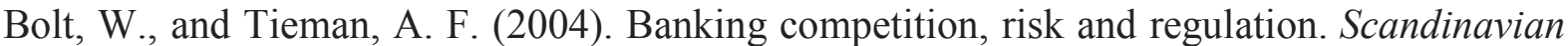
Journal of Economics $\square\|\|\|\| \| \square-\square \square \square$

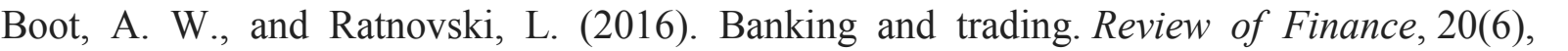
$\square \square-\square \square \square \square$

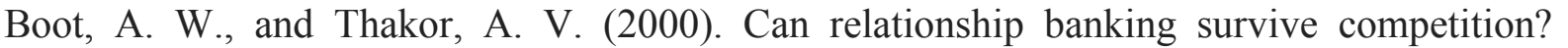

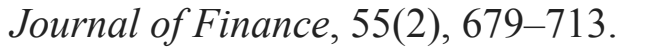

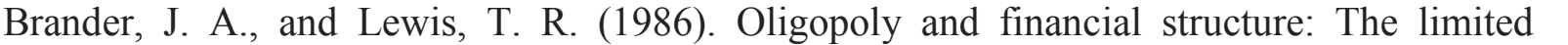

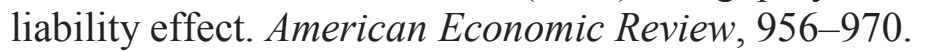

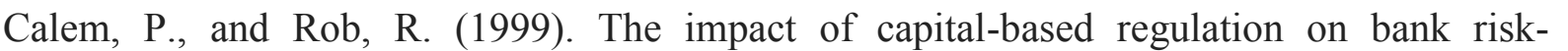

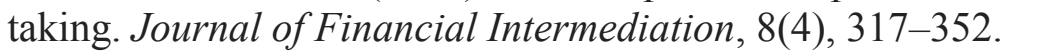

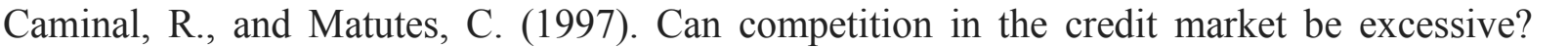

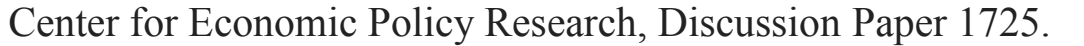

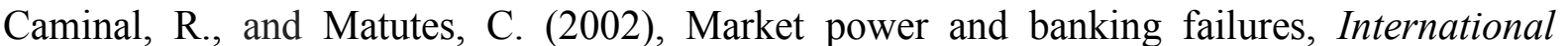

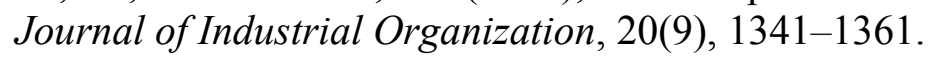

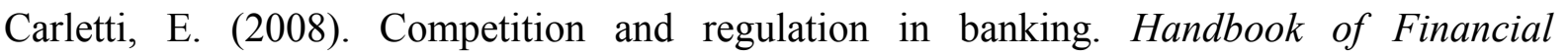

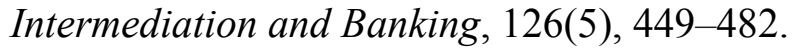

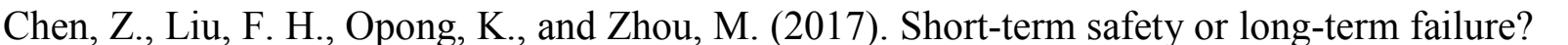

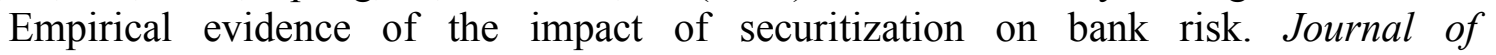
International Money and Finance $\square \square \square-\square \square$

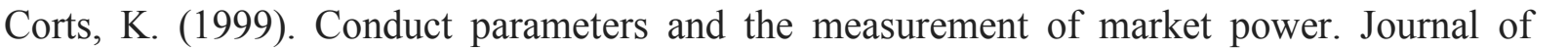

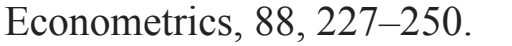

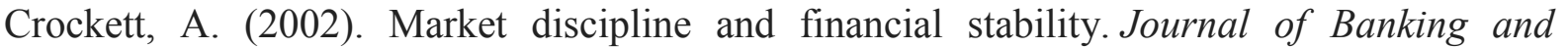

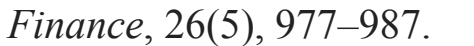

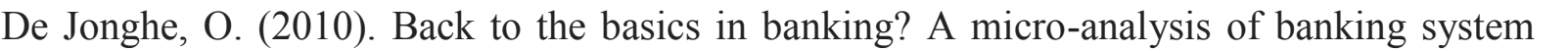

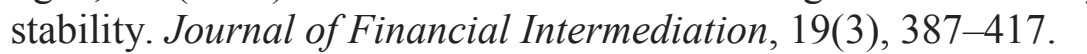

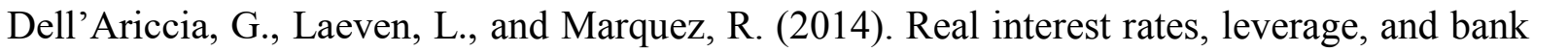

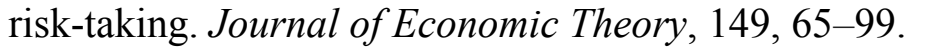

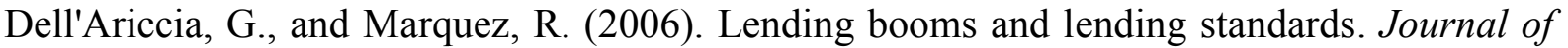

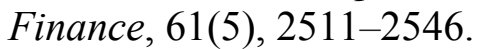

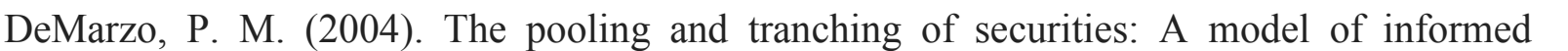

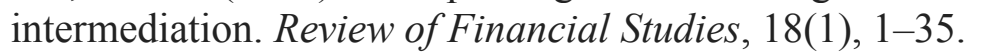

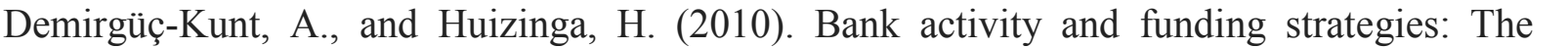

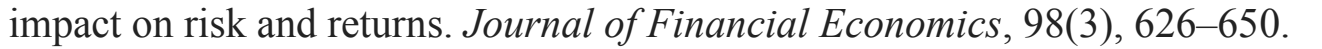

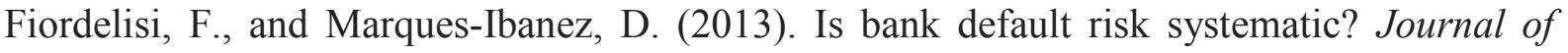

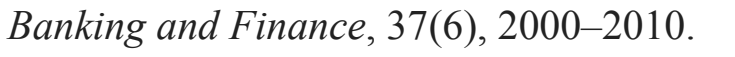




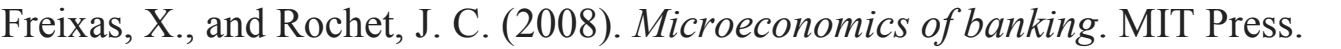

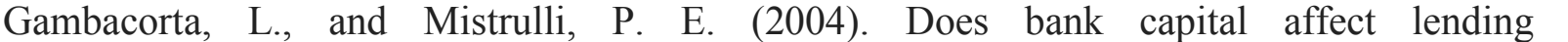

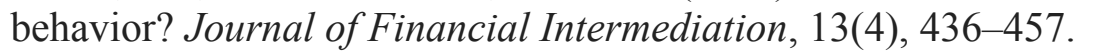

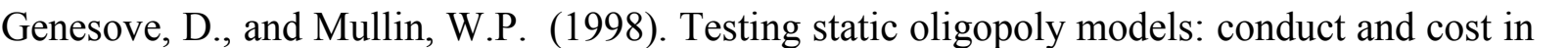

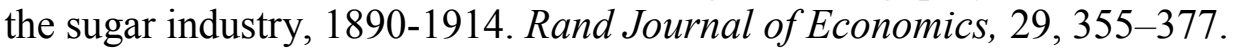

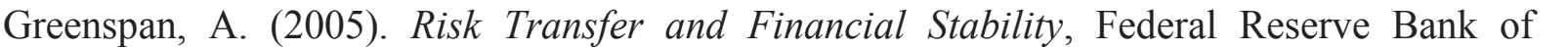

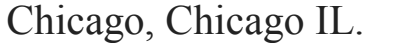

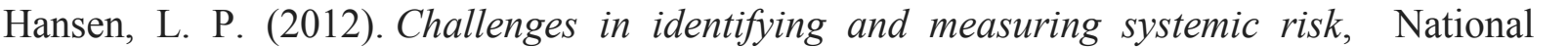

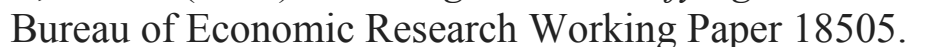

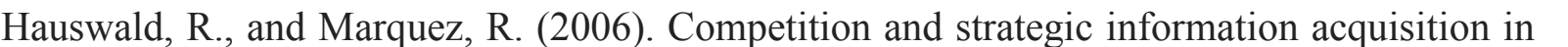

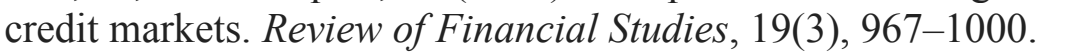

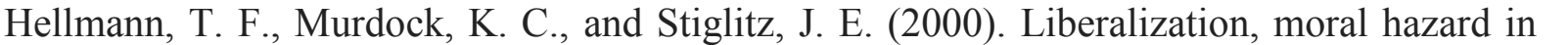

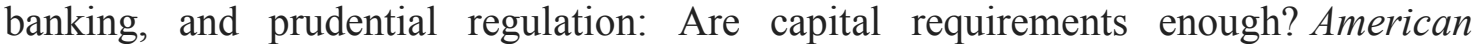
Economic Review $\square \square|\Pi \| m|-\square \square \square$

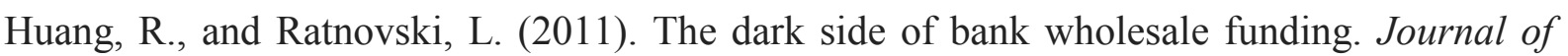
Financial Intermediation $\square \square\|\square\| m \mid-\square \square \square$

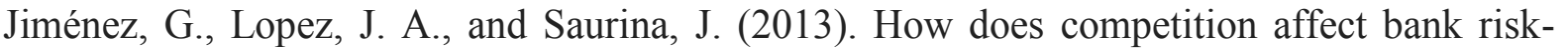

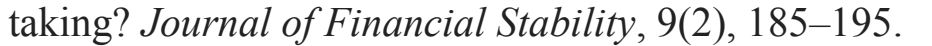

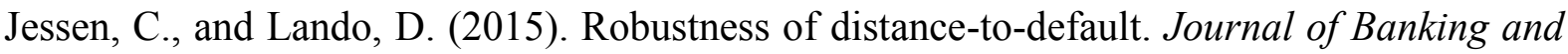
Finance $\square|\||||-\square \mid \square$

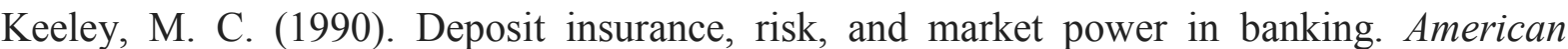

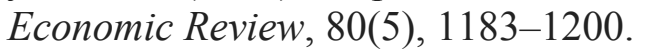

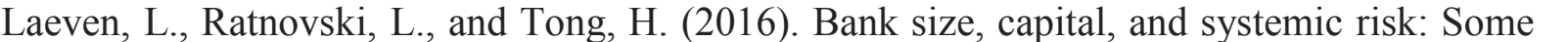

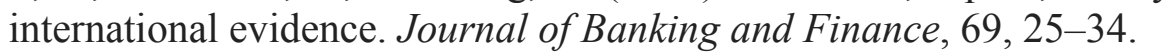

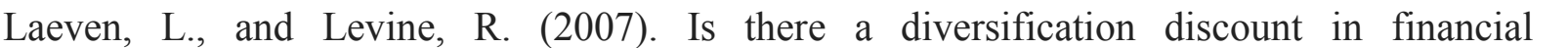

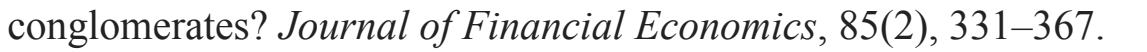

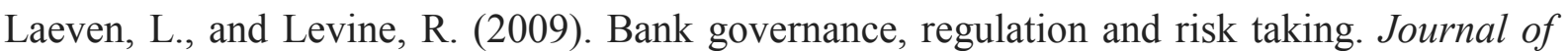

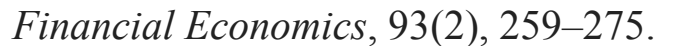

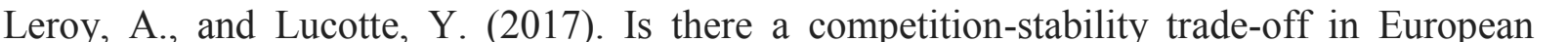

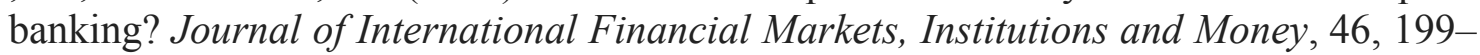
$\square \square \mid \square$

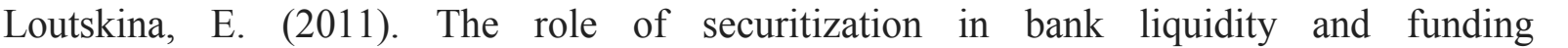

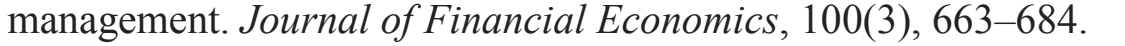

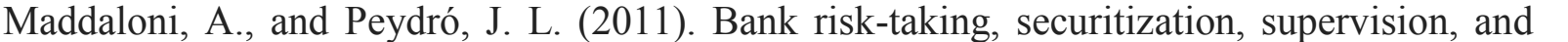

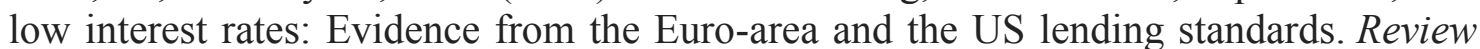

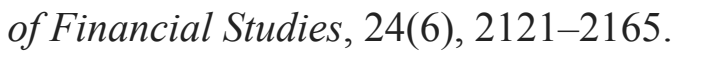

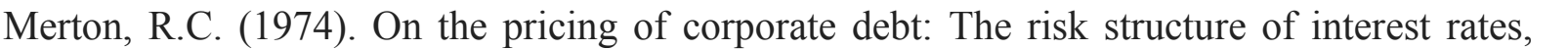

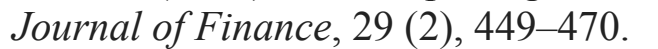

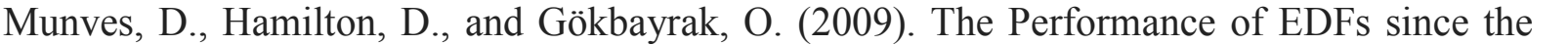

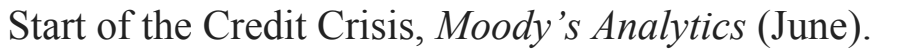

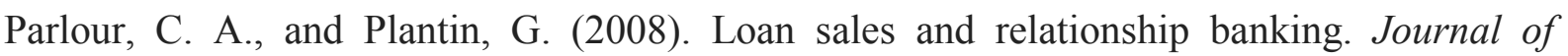

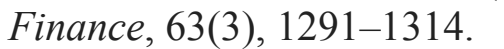




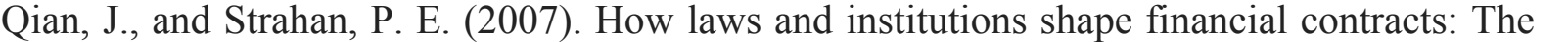

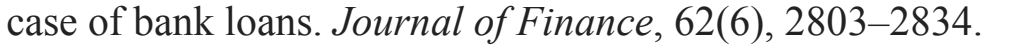

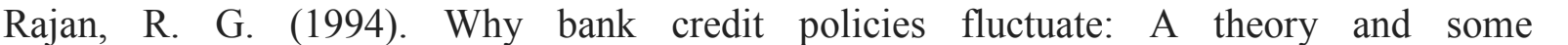

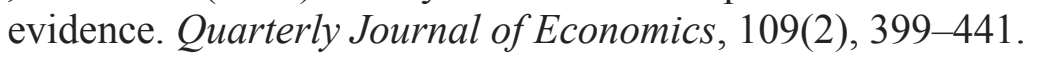

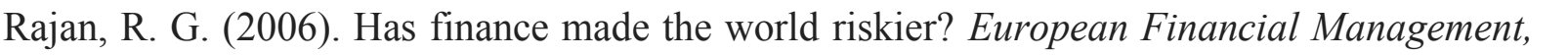

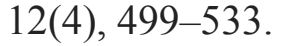

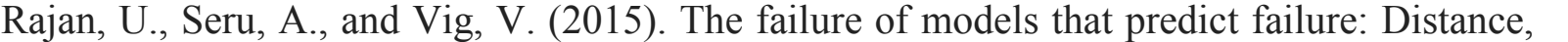

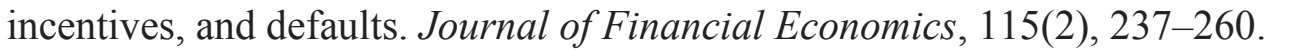

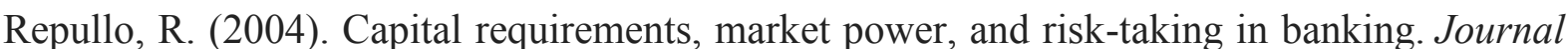

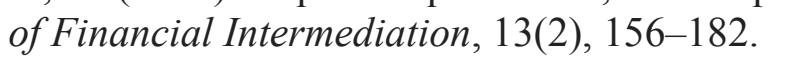

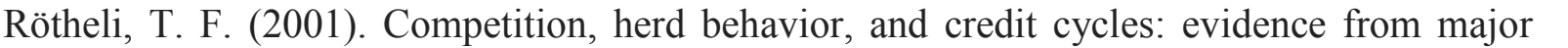

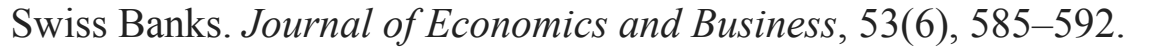

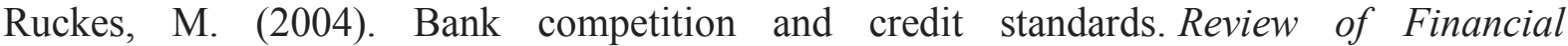

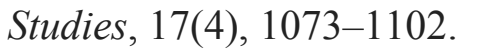

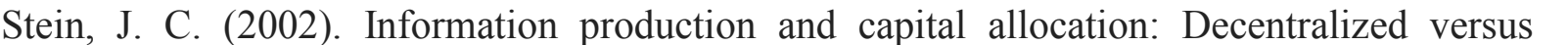

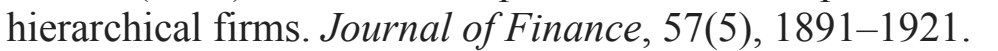

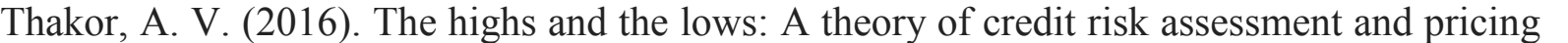

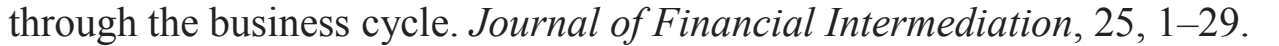

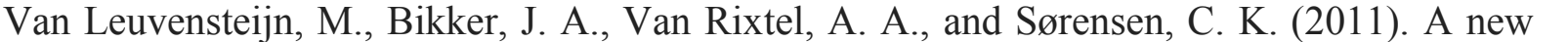

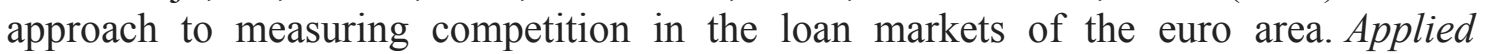
Economics $\square \square \square\|\square\| \square \mid-\square \square \square \square$ 


\section{Appendix A: Marginal expected shortfall (MES)}

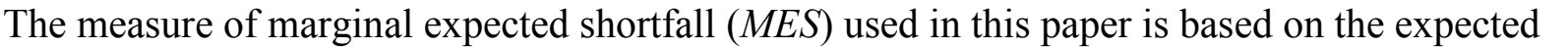

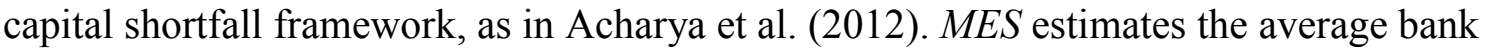
ए पाणाएणाए

$\square$

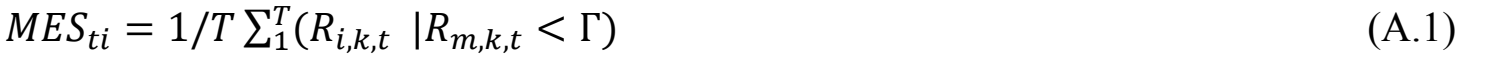

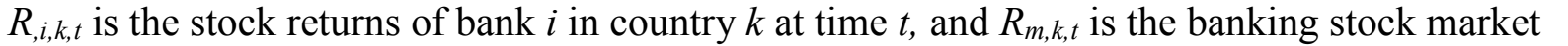

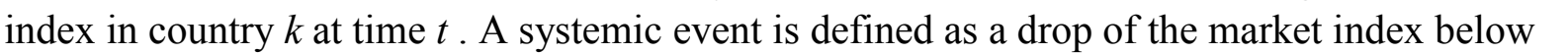

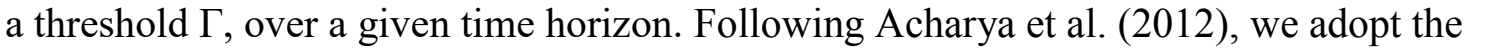
ए

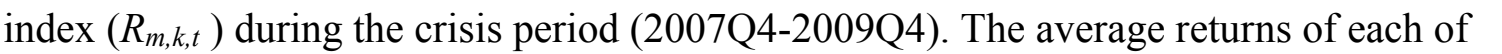

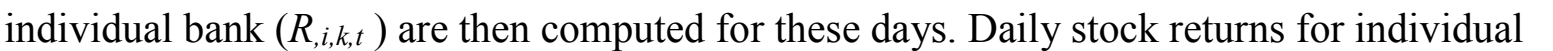

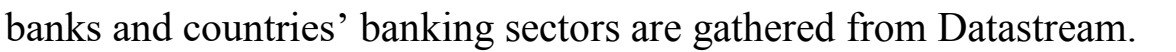

\section{Appendix B: Bank-specific beta}

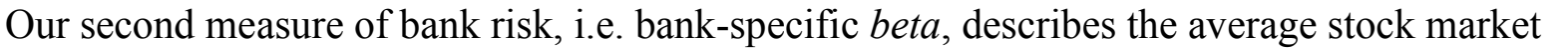

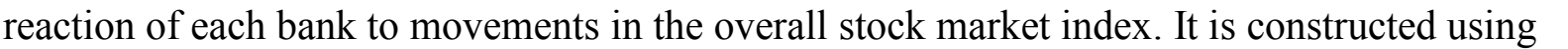

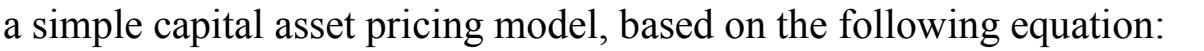
$\square$

$R_{i, k, t}=\beta_{i, k, t} * R_{m, k, t}+\varepsilon_{i, k, t}$

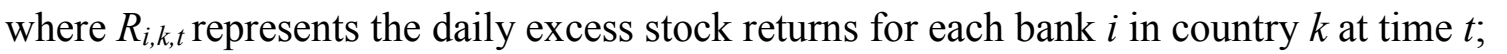

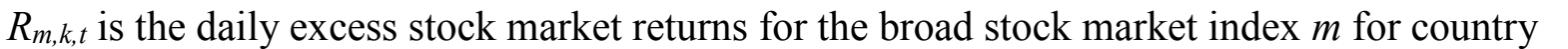

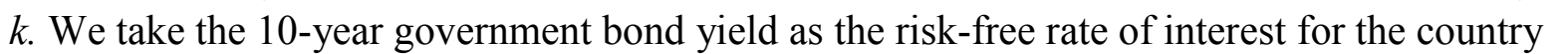

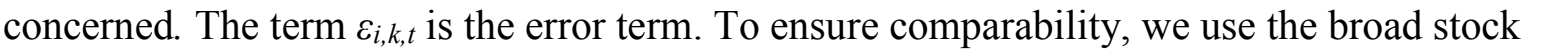

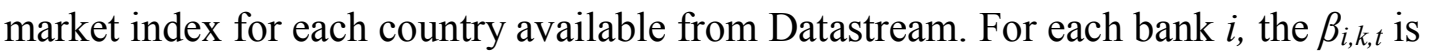

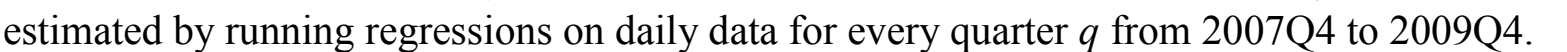

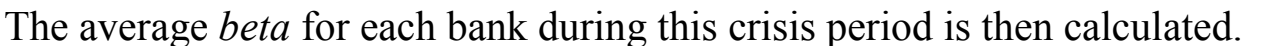

\section{Appendix C: Calculating the elasticity adjusted Lerner Index $\square$}

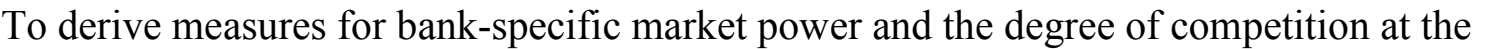
ए

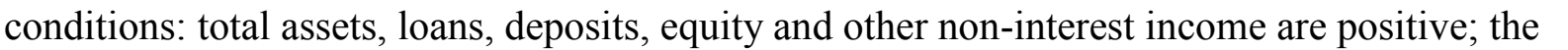

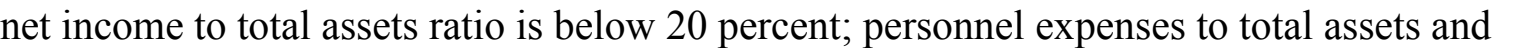

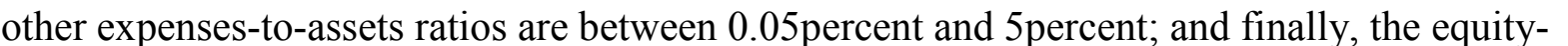

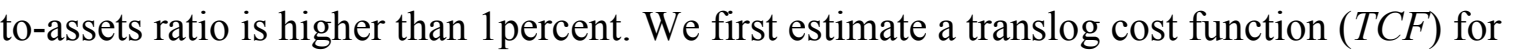

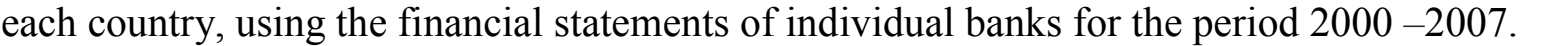

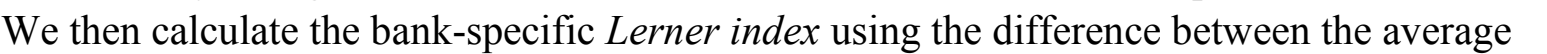

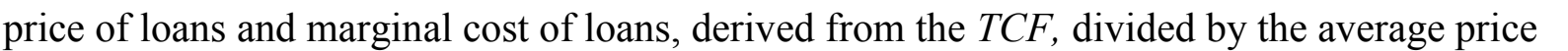

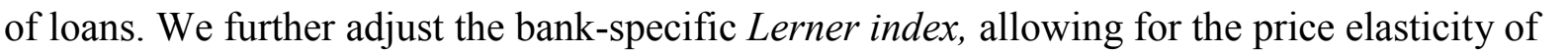

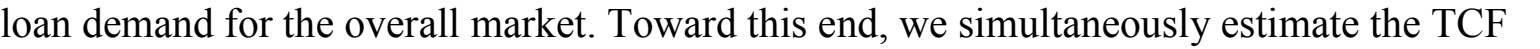




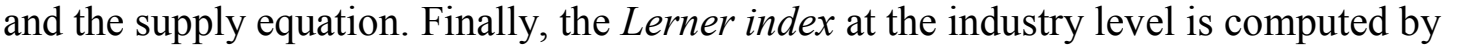

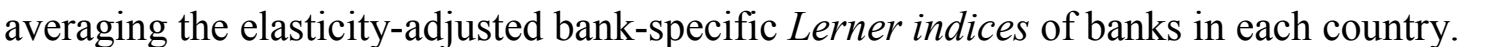
$\square$

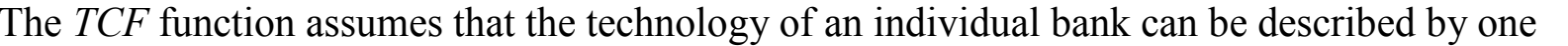

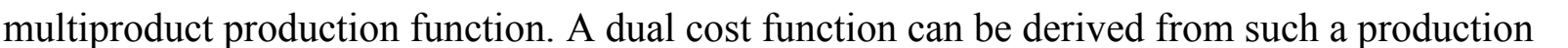

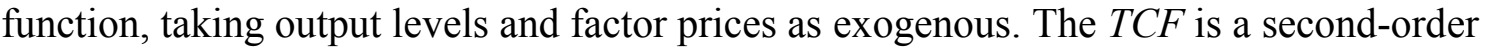

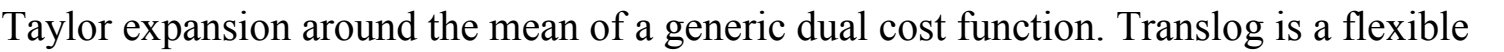

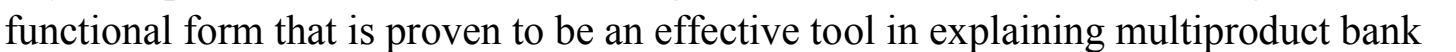

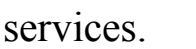

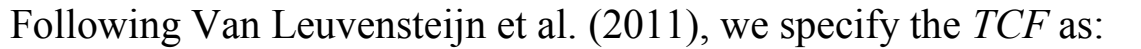

$\ln c_{i t}=\alpha_{0}+\sum_{t=1}^{T-1} \gamma_{t} d_{t}+\sum_{j=1}^{K} \delta_{j} \ln x_{i j t}+\sum_{j=1}^{K} \sum_{k=1}^{K} \epsilon_{j k} \ln x_{i j t} \ln x_{i k t}+v_{i t} \mathbb{\square}$ $\square$

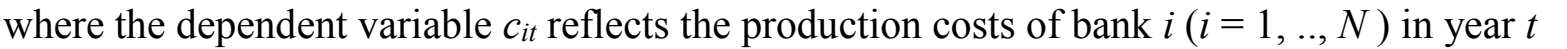

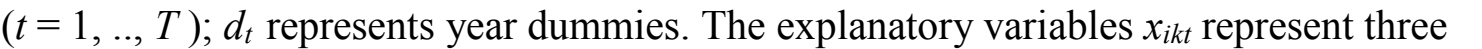

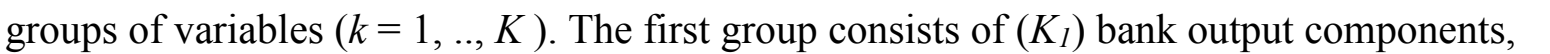

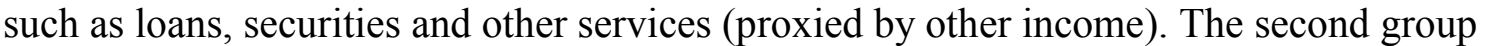

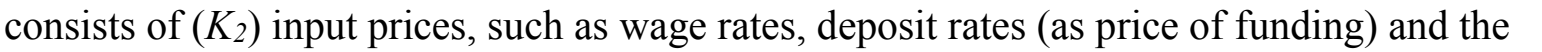

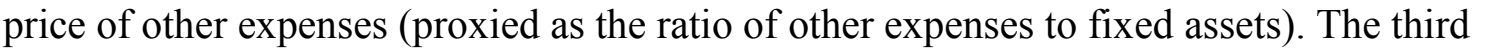

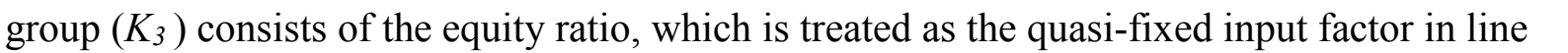

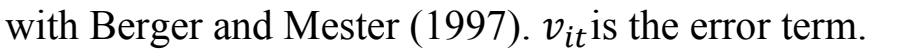
$\square$

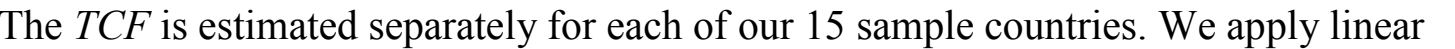

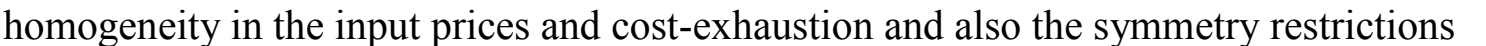

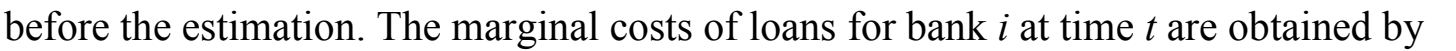

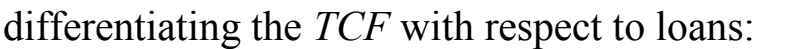
$\square$

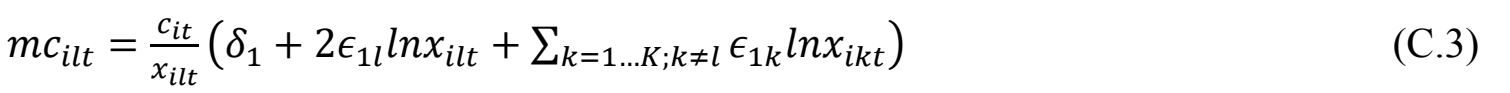

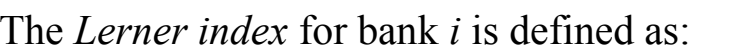

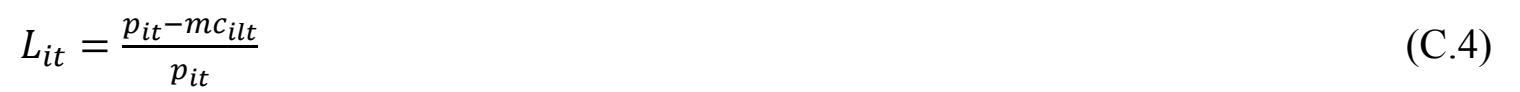
$\square$

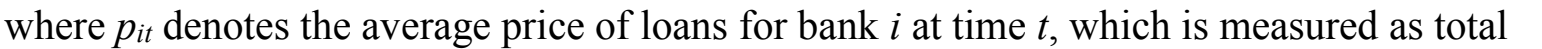

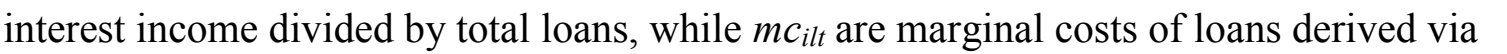

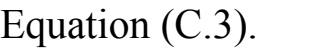

$\square$

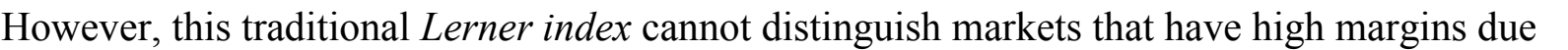
प

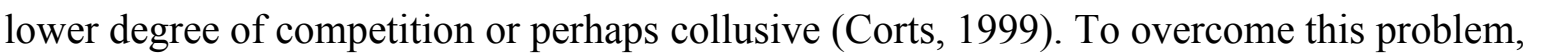

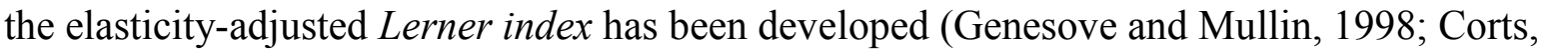

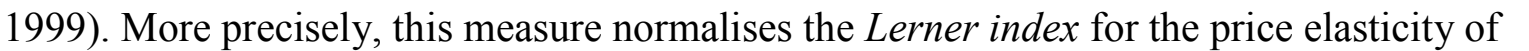




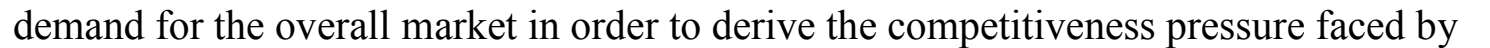

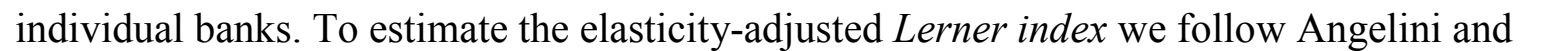

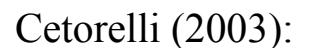

$\square$

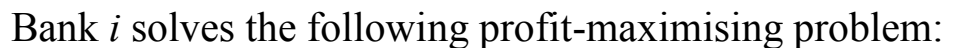

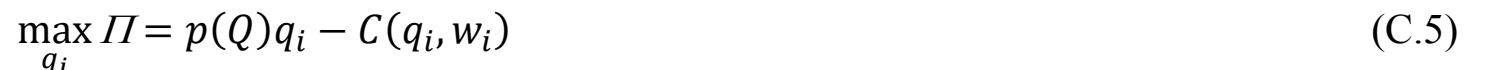
$\square$

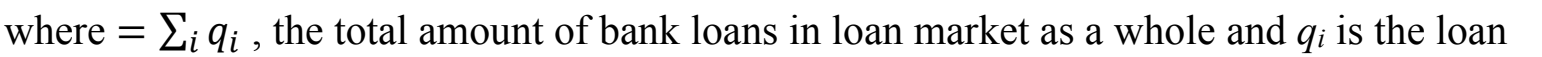

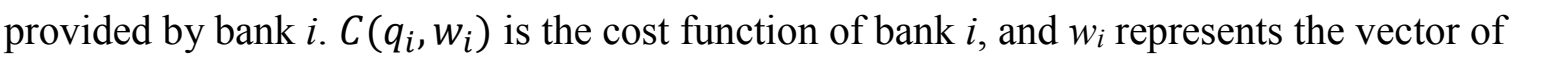

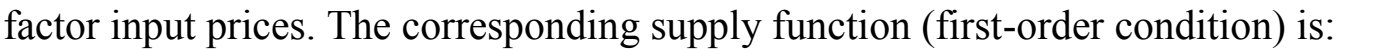

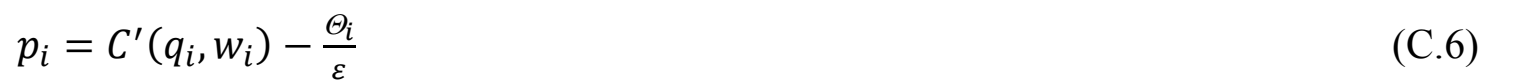

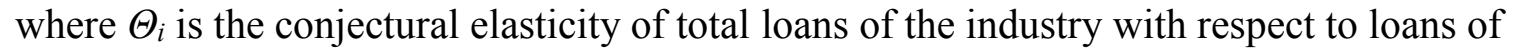

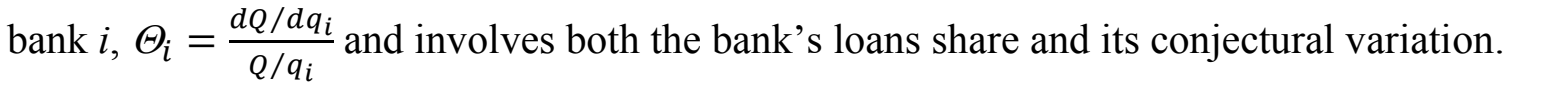
$\varepsilon=\frac{d Q / d p}{Q}<0$ पा

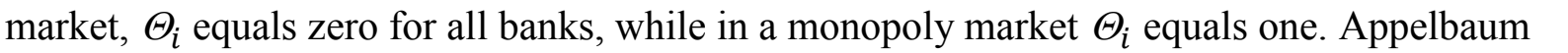

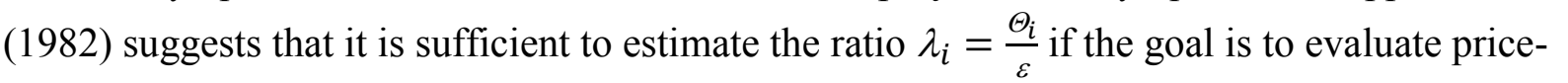

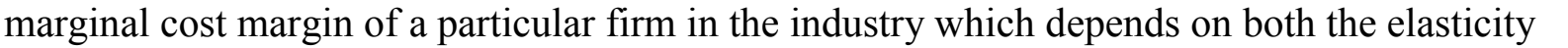

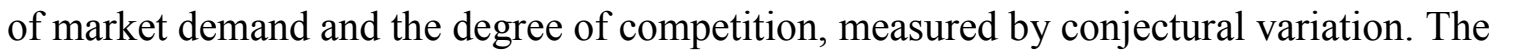

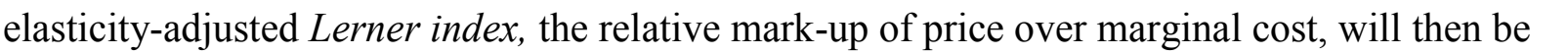

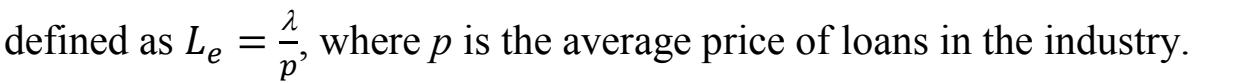

$\square$

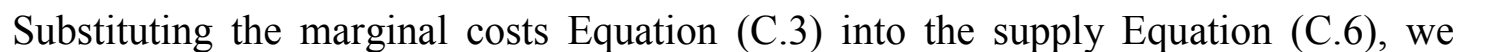

पाणाणाए

$p_{i t}=\frac{c_{i t}}{x_{i l t}}\left(\delta_{1}+2 \epsilon_{1 l} \ln x_{i l t}+\sum_{k=1 \ldots K ; k \neq l} \epsilon_{1 k} \ln x_{i k t}\right)+\sum_{t=1 \ldots T-1} \lambda_{t} d_{t}+\varepsilon_{i t}$ एाणाणाणाएण

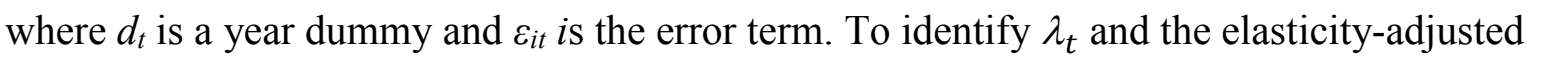

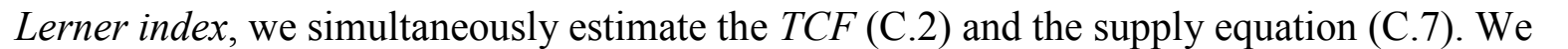

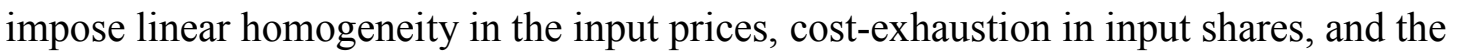

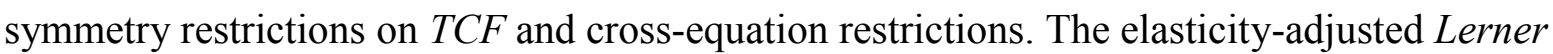
index $\square$ 
$L_{e, i t}=\mu_{t} \frac{p_{i t}-m c_{i l t}}{p_{i t}} \square \quad \square \quad \square \quad \square \quad \square \quad \square \quad \square \quad \square \quad \square \quad \square \quad \square m m \square$

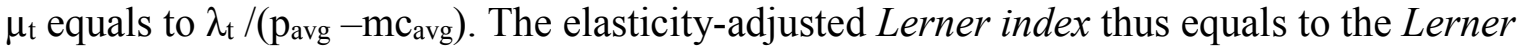

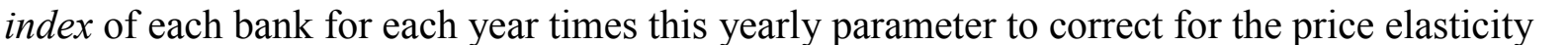

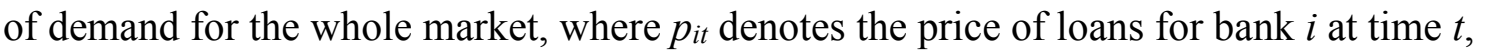

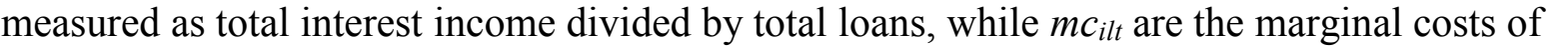

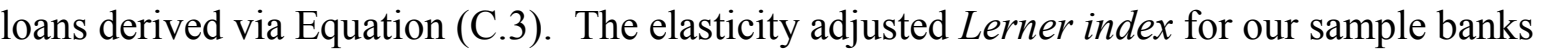

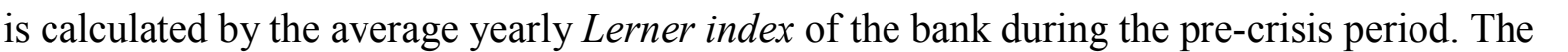

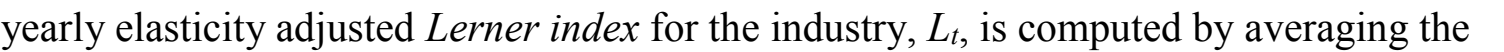

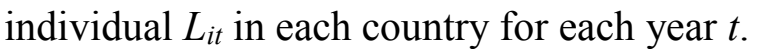


Table 1: Definitions, data sources and the description of main variables

\begin{tabular}{|c|c|c|}
\hline Variable & Source & Description \\
\hline Panel A: Bank risk variables & & $\square$ \\
\hline Marginal expected shortfall (MES) & 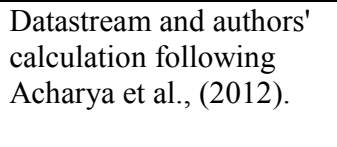 & 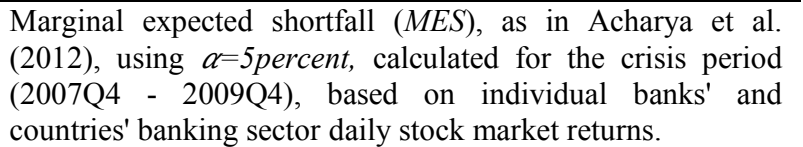 \\
\hline Bank-specific beta & 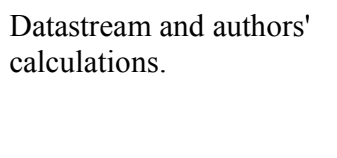 & 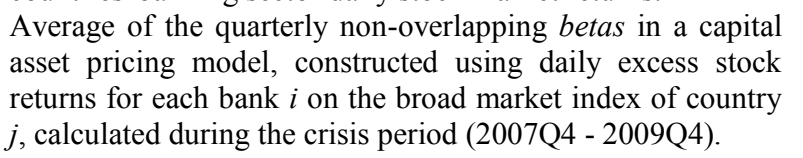 \\
\hline Expected default frequency (EDF) & $\square \square\|\| \| \square \square \square$ & 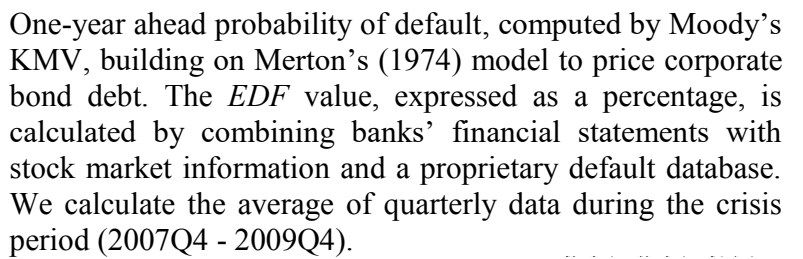 \\
\hline
\end{tabular}

Panel B: Bank competition variables

\begin{tabular}{|c|c|}
\hline Lerner (firm level) & 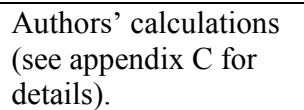 \\
\hline
\end{tabular}

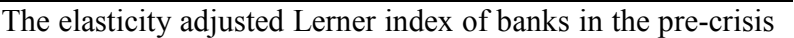

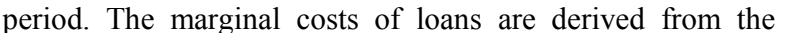

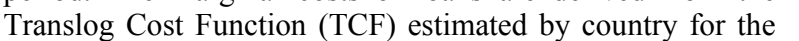

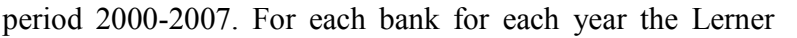

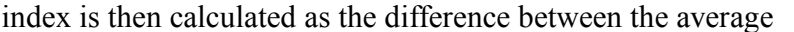

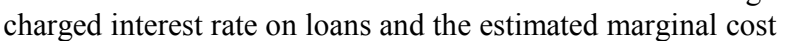

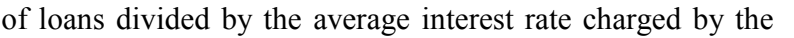

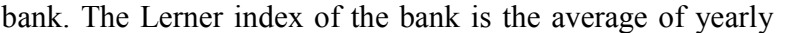

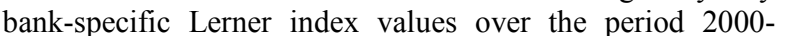

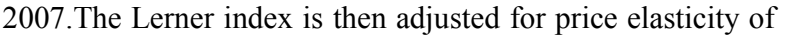
$\square \square \square \square \square$

Lerner (industry level)

$B L S$

Panel C: Balance sheet variables

Size

Capitalization (percent)

पापापापा

Total capital ratio (percent)

पणापणाण

Core capital ratio (percent)

पाणमाणा

Securitization (percent)

Non-mortgage backed securitization (percent)

Mortgage backed securitization (percent)

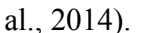

पामापाण
पणाणाणा

पणाणाणा प्णाणाणा
Author's calculation. $\square$

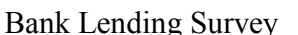

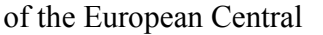

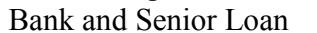

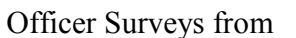

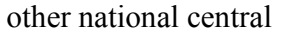

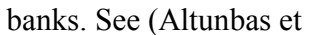

ए1]

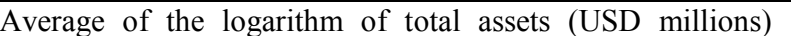

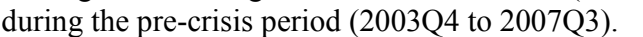

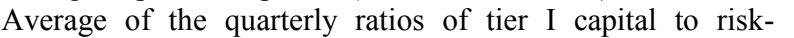

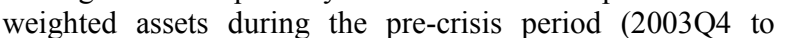
$\square \square \square \square \square$

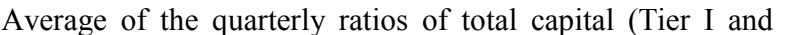

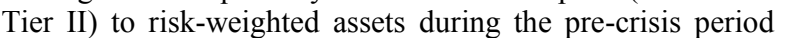

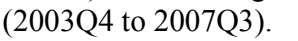

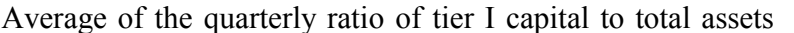

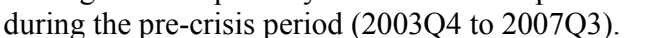

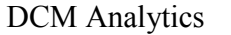

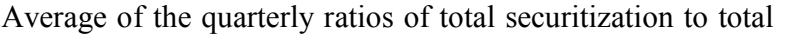

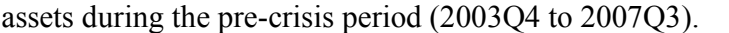

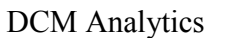

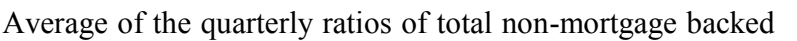

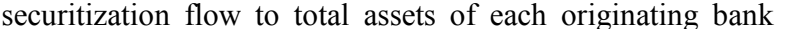

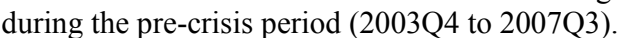

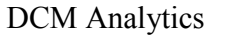




\begin{tabular}{|c|c|c|}
\hline Variable & Source & Description \\
\hline & & $\square|\|\||\|\| \|$ \\
\hline Deposit funding (percent) & யாणாயா & 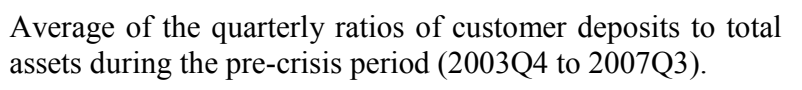 \\
\hline Excessive loan growth & 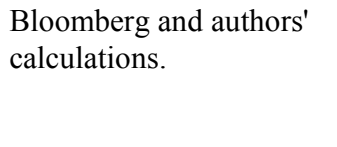 & 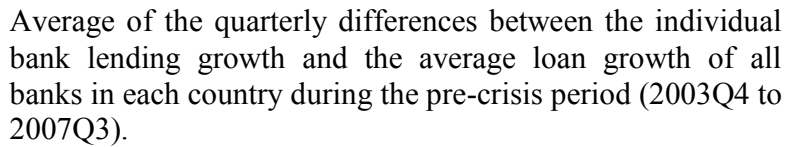 \\
\hline $\begin{array}{l}\text { Other earning assets ratio } \\
\text { (percent) }\end{array}$ & पामापाप & 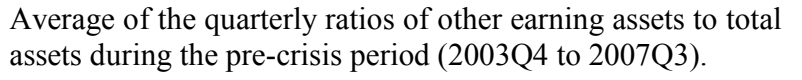 \\
\hline Profitability (percent) & पणमाणा & 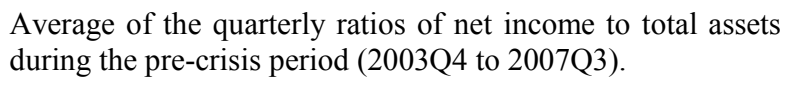 \\
\hline Asset quality (percent) & पणापणाप & 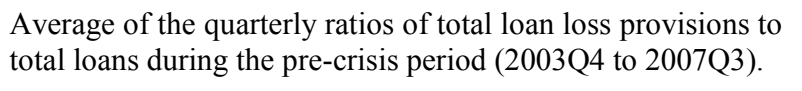 \\
\hline Non-Interest Income (percent) & पण口णाण & 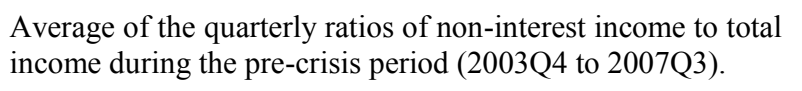 \\
\hline Panel D: Other Control variable & & ए \\
\hline Housing bubble dummy & 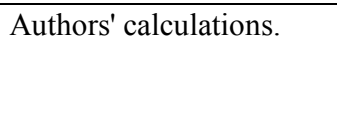 & 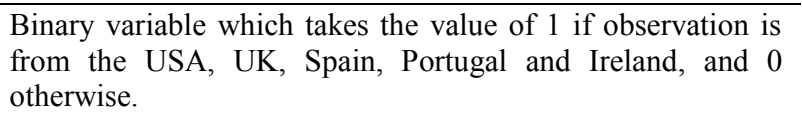 \\
\hline GDP growth & 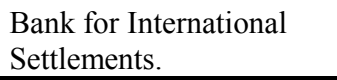 & 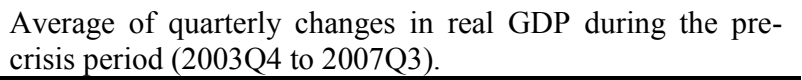 \\
\hline
\end{tabular}

Note: This table presents the names of the variables employed in our empirical analysis, indicates the data sources and gives a brief description of each variable. More detailed information, plus all publicly available data, are available upon request. 
Table 2: Sample distribution across countries

\begin{tabular}{|c|c|c|}
\hline Country & $\begin{array}{c}\text { Number of banks: } \\
\text { Systemic risk/bank- } \\
\text { specific beta }\end{array}$ & $\begin{array}{c}\text { Number of banks: } \\
\qquad E F\end{array}$ \\
\hline Eurozone countries & $\square$ & $\square$ \\
\hline Austria $(A T)$ & $\square$ & $\square$ \\
\hline Belgium (BE) & $\square$ & $\square$ \\
\hline Germany (DE) & $\square \square$ & $\square \square$ \\
\hline $\operatorname{Spain}(E S)$ & $\square$ & $\square \square$ \\
\hline Finland (FI) & $\square$ & $\square$ \\
\hline France (FR) & $\square \square$ & $\square$ \\
\hline Greece (GR) & $\square$ & $\square$ \\
\hline Ireland (IE) & $\square$ & $\square$ \\
\hline Italy (IT) & $\square \square$ & $\square$ \\
\hline The Netherlands (NL) & $\square$ & $\square$ \\
\hline \multirow[t]{2}{*}{ Portugal (PT) } & $\square$ & $\square$ \\
\hline & $\square$ & $\square$ \\
\hline Non-Eurozone countries & $\square$ & $\square$ \\
\hline Denmark $(D K)$ & $\square \square$ & $\square \square$ \\
\hline Sweden (SE) & $\square$ & $\square$ \\
\hline United Kingdom (GB) & $\square$ & $\square$ \\
\hline United States (US) & $\square \square$ & $\square \square \square$ \\
\hline Total & 546 & 545 \\
\hline
\end{tabular}

Note: This table provides information regarding the distribution of the sample banks in each of our 15 sample countries. 
Table 3: Descriptive Statistics

\begin{tabular}{|c|c|c|c|c|c|c|}
\hline Variables & $\mathbf{N}$ & Average & Median & $\begin{array}{l}\text { Standard } \\
\text { Deviation } \\
\end{array}$ & Q1 & Q3 \\
\hline \multicolumn{7}{|l|}{ Panel A: Bank Risk } \\
\hline Marginal expected shortfall (MES) & $\square \square$ & 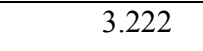 & 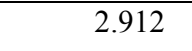 & $\square \square \square$ & $\square \square \square$ & $\square \square \square$ \\
\hline Bank-specific beta & $\square \square$ & $\square \square 1 \square$ & $\square \square$ & 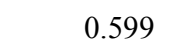 & $\square \square \square$ & $\square \square$ \\
\hline Expected default frequency $(E D F)$ & $\square \square$ & $\square \square 11$ & $\square \square \square$ & $\square \square \square$ & $\square \square \square$ & $\square \square \square$ \\
\hline Panel B: Bank competition variables & $\square$ & ए1 & 匹 & $\square$ & $\square$ & $\square$ \\
\hline Lerner (firm level) & $\square \square$ & 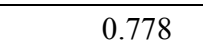 & $\square \square \square$ & $\square \square \square$ & $\square \square \square$ & $\overline{\square \square \square}$ \\
\hline Lerner (industry level) & $\square \square$ & पणाए & $\square \square ा$ & 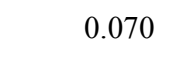 & $\square ण \square$ & $\square ण$ \\
\hline$B L S$ & $\square \square$ & एणाएा & एणाप & $\square \| \square$ & पाणाप & एापाए \\
\hline \multicolumn{7}{|l|}{ Panel C: Balance Sheet Variables } \\
\hline Size & $\square \square$ & 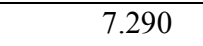 & 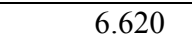 & 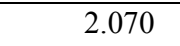 & 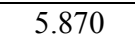 & $\overline{\square \square \square}$ \\
\hline Capitalization (percent) & $\square$ & $\square ण 11$ & $\square \amalg$ & $\square \amalg$ & $\square \| ा$ & 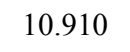 \\
\hline Total capital ratio (percent) & $\square$ & 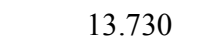 & $\square \square \square$ & $\square \amalg$ & $\square \square \square$ & $\square \amalg \amalg$ \\
\hline Core capital ratio (percent) & $\square$ & एणाए & $\square \square \square$ & $\square \amalg$ & एणा & $\square \square \square$ \\
\hline Securitization (percent) & $\square$ & एणाए & $\square \amalg$ & $\square \amalg$ & $\square \square \square$ & $\square \square$ \\
\hline $\begin{array}{l}\text { Non-mortgage backed securitization } \\
\text { (percent) }\end{array}$ & $\square \square$ & 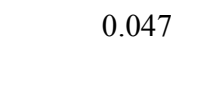 & $\square \square$ & $\square \amalg \square$ & $\square \square \square$ & $\square \square \square$ \\
\hline $\begin{array}{l}\text { Mortgage backed securitization } \\
\text { (percent) }\end{array}$ & $\square \square$ & एणाए & $\square \square \square$ & $\square \square \square$ & $\square \square \square$ & $\square \amalg$ \\
\hline Deposit funding (percent) & $\square$ & $\square \square \square$ & $\square \amalg \square$ & $\square \square \square$ & $\square \square \square$ & $\square \amalg \square$ \\
\hline Excessive loan growth & $\square$ & पामा & $\square \square$ & $\square \square$ & $\square \square$ & $\square \square$ \\
\hline Other earning assets ratio (percent) & $\square \square$ & 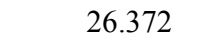 & $\square \square \square$ & $\square \square \square$ & $\square \square \square$ & $\square \| \square$ \\
\hline Profitability (percent) & $\square$ & एणा & $\square \square$ & $\square \square$ & 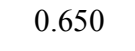 & एवाए \\
\hline Asset quality (percent) & $\square$ & 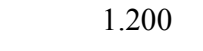 & $\square \square$ & $\square \square \square$ & $\square \square \square$ & $\square \square$ \\
\hline Non-Interest Income (percent) & $\square \square$ & $\square \square \square$ & $\square \amalg$ & $\square \square \square$ & पणा & $\square \square \square$ \\
\hline Panel D: Other Control Variables & 四 & III & $\mathbb{\square}$ & $\mathbb{1 1}$ & $\mathbb{I I}$ & 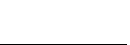 \\
\hline Housing bubble dummy & $\overline{\square \square}$ & 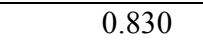 & 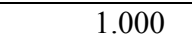 & 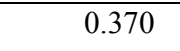 & 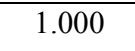 & $\overline{\square \square \square \square}$ \\
\hline GDP growth & $\square \square$ & $\square \square \square$ & $\square \square \square$ & $\square \amalg \square$ & $\square \square \square$ & $\square \square \square$ \\
\hline
\end{tabular}

Note: The average MES over the post-crisis period (2007Q4-2009Q4) was 3.22 percent, which is in line with the marginal expected shortfall (MES) of 2.094, reported for US banks in Balla et al. (2014, p. 201). 
Table 4: Impact of bank level market power (Lerner) and industry competition on systemic risk and the impact of capitalization and securitization on this relationship

\begin{tabular}{|c|c|c|c|c|c|c|c|c|}
\hline \multirow{2}{*}{$\begin{array}{l}\text { Variable } \\
\square\end{array}$} & \multicolumn{2}{|l|}{$\begin{array}{l}\text { Systemic } \\
\text { risk }\end{array}$} & $\begin{array}{l}\text { Systemic } \\
\text { risk } \\
\end{array}$ & \multicolumn{2}{|r|}{$\begin{array}{l}\text { Systemic } \\
\text { risk }\end{array}$} & \multicolumn{3}{|c|}{$\begin{array}{l}\text { Systemic } \\
\text { risk }\end{array}$} \\
\hline & $\begin{array}{lll}\square(110 \\
\end{array}$ & $\square$ & $\square \square$ & $\square$ & $\square 10$ & $\bar{\square}$ & $\square \mathbb{1 0}$ & 四 \\
\hline Lerner (firm level) & $1.1071^{* *} \square$ & $\square$ & $1.8536^{* * *} \square$ & $\square$ & $1.3075^{* *} \square$ & $\square$ & $1.1162^{* *} \square$ & $\square$ \\
\hline$\square$ & पाणाएा & $\square$ & पाणाएण & $\square$ & पणाएण & $\square$ & पाणाएा & $\square$ \\
\hline Securitization & $-0.7781^{* * *} \sqsubset$ & $\square$ & $-0.7773^{* *} \square$ & $\square$ & $-0.7513^{* * *} \sqsubset$ & $\square$ & $-0.7153^{* *} \square$ & $\square$ \\
\hline$\square$ & पाणा1ा & $\square$ & पाயा1ण & $\square$ & पाणा1ण & $\square$ & पाणामा & $\square$ \\
\hline Capitalization & $-0.1262^{* *} \square$ & $\square$ & $-0.1419^{* * *} \square$ & $\square$ & $-0.1363^{* * *} \sqsubset$ & $\square$ & $-0.1181^{* * *} \sqsubset$ & $\square$ \\
\hline$\square$ & पाणा1ाप & $\square$ & पाणा1ाप & $\square$ & पाणा1ा & $\square$ & पाणा1ा & $\square$ \\
\hline Size & $0.4644^{* * *} \square$ & $\square$ & $0.5614^{* * *} \square$ & $\square$ & $0.5686^{* * *} \square$ & $\square$ & $0.6359^{* * *} \square$ & $\square$ \\
\hline$\square$ & पाणाएा & $\square$ & एणामा & $\square$ & पाणाएा & $\square$ & पाणापा & $\square$ \\
\hline Excessive loan growth & $0.4076^{* *} \square$ & $\square$ & $0.3597^{*} \square$ & $\square$ & $0.2968^{*} \square$ & $\square$ & 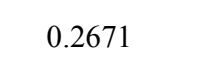 & $\square$ \\
\hline$\square$ & पणाएण & $\square$ & पाणाएण & $\square$ & पाणा1ण & $\square$ & पाणा1ा & $\square$ \\
\hline Deposit funding & $-0.0342^{*} \square$ & $\square$ & $-0.0484^{* * *} \sqsubset$ & $\square$ & $-0.0406^{* * *} \sqsubset$ & $\square$ & $-0.0515^{* * *} \sqsubset$ & $\square$ \\
\hline 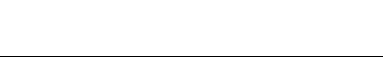 & $\square\|\| ा \|$ & $\square$ & पाणामाप & $\mathbb{1}$ & पणायाए & 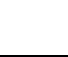 & 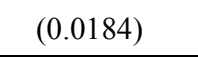 & $\mathbb{1}$ \\
\hline Macro-Economic variables & 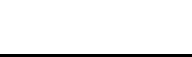 & $\square$ & $\square$ & $\square$ & II & $\square$ & II & $\square$ \\
\hline Lerner (industry level) & $-0.1027^{* * *} \sqsubset$ & $\square$ & $\square$ & $\square$ & $-0.0924^{* * *} \sqsubset$ & $\square$ & $\square$ & $\square$ \\
\hline$\square$ & पाणा1ा & $\square$ & $\square$ & $\square$ & एणाएा & $\square$ & $\square$ & $\square$ \\
\hline GDP growth & & $\square$ & $2.3427^{* *} \square$ & $\square$ & $\square$ & $\square$ & $3.0223^{* * *} \square$ & $\square$ \\
\hline$\square$ & $\square$ & $\square$ & पाणा1ए & $\square$ & $\square$ & $\square$ & पाणा1ए & $\square$ \\
\hline Competition interactions & $\mathbb{\square}$ & $\square$ & $\mathbb{1 1}$ & 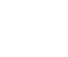 & II & $\square$ & II & 四 \\
\hline $\begin{array}{l}\text { Capitalization * Lerner (firm } \\
\text { level) }\end{array}$ & & $\square$ & $\square$ & $\square$ & $-0.0845^{* * *} \sqsubset$ & $\square$ & $-0.0941^{* * *} \sqsubset$ & $\square$ \\
\hline$\square$ & $\square$ & $\square$ & $\square$ & $\square$ & पणागा & $\square$ & पाणा1ए & $\square$ \\
\hline $\begin{array}{l}\text { Securitization * Lerner (firm } \\
\text { level) }\end{array}$ & & $\square$ & $\square$ & $\square$ & $0.7054^{* * *} \square$ & $\square$ & $0.6986^{* * *} \square$ & $\square$ \\
\hline$\square$ & $\square$ & $\square$ & & $\square$ & एणामाण & $\square$ & एाणाएण & $\square$ \\
\hline Constant & $-4.3572^{* *} \square$ & $\square$ & $-7.2602^{* * *} \sqsubset$ & $\square$ & $4.0853^{*} \square$ & $\square$ & $-6.8198^{* * *} \sqsubset$ & $\square$ \\
\hline$\square$ & $\square[1110$ & $\square$ & 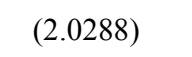 & $\square$ & पणाणाएा & $\square$ & 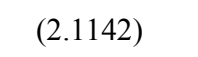 & $\square$ \\
\hline$\square$ & $\square$ & $\square$ & $\square$ & $\square$ & 四 & $\square$ & 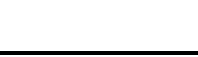 & $\square$ \\
\hline 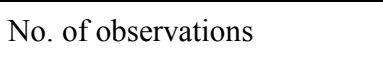 & $\square \square$ & $\square$ & $\square \square$ & $\square$ & $\square \square$ & $\square$ & $\square \square$ & $\square$ \\
\hline$\square^{\square} \square$ & $\square \square \square \square$ & $\square$ & $\square \Pi 11 \square$ & $\square$ & $\square \square \square \square$ & $\square$ & $\square \square \square \square$ & $\mathbb{1}$ \\
\hline
\end{tabular}

Note: This table provides the estimated results of Model (1) and Model (2). Systemic risk is measured by the MES. Columns (1)-(2) show the estimated results of Model (1). Column (1) shows the effect of bank balance sheet variables, Lerner (firm level) and Lerner (industry level) on systemic risk. Column (2) replaces Lerner (industry level) with real GDP growth. Columns (3)-(4) introduce the interaction terms of Securitization and Capitalization with bank-specific market power and present the estimated results of Model (2). The dependent variable is calculated during the crisis period (2007Q4 to 2009Q4). Regressors are calculated as averages of quarterly data for individual banks during the pre-crisis period (2003Q4 to 2007Q3) unless otherwise indicated. Robust standard errors are in parentheses. ${ }^{*},{ }^{* *}$ and ${ }^{* * *}$ indicate statistical significance at the 10 percent, 5 percent and 1 percent levels, respectively. The definition of variables can be found in Table 1. 
Table 5: Estimated results via IV approach

\begin{tabular}{|c|c|c|c|c|c|c|c|c|}
\hline Variable & \multicolumn{2}{|c|}{ Systemic risk } & \multicolumn{2}{|l|}{ Systemic risk } & \multicolumn{2}{|c|}{ Systemic risk } & \multicolumn{2}{|c|}{ Systemic risk } \\
\hline$\square$ & 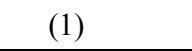 & & एापाणाण & & 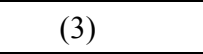 & & एापाणाण & \\
\hline Lerner (firm level) & $2.9082^{* *} \square$ & $\bar{\square}$ & $2.5658^{* *} \square$ & $\overline{7}$ & $2.7888^{* *} \square$ & $\bar{\square}$ & $2.7477^{* *} \square$ & \\
\hline$\square$ & पाणा1ा & $\square$ & पाणामा & $\square$ & पाणा1ा & $\square$ & एाயा1ा & $\square$ \\
\hline Securitization & $-0.9291^{* * *} \square$ & $\square$ & $-0.7338^{* * *} \square \square$ & $\square$ & $-0.6955^{* * *} \sqsubset$ & $\square$ & $-0.6677^{* * *} \sqsubset$ & \\
\hline$\square$ & एापाएा & $\square$ & एणामा & $\square$ & पाणा1ா & $\square$ & एणामा & $\square$ \\
\hline Capitalization & $-0.0586^{* *} \square$ & $\square$ & $-0.1967^{* *} \square \square$ & $\square$ & $-0.1603^{*} \square$ & $\square$ & $-0.1536^{*} \square$ & \\
\hline$\square$ & पणाएण & $\square$ & एणाएण & $\square$ & पाणा1ण & $\square$ & एणाणाप & $\square$ \\
\hline Size & $0.5437^{* * *} \square$ & $\square$ & $0.5197^{* * *} \square \quad \square$ & $\square$ & $0.5479^{* * *} \square$ & $\square$ & $0.6754^{* * *} \square$ & \\
\hline$\square$ & एणाणा & $\square$ & पाणाएा & $\square$ & 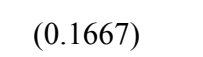 & $\square$ & एणापाए & $\square$ \\
\hline Excessive loan growth & $0.3083^{* *} \square$ & $\square$ & $0.3878^{* *} \square \quad \square$ & $\square$ & $0.3038^{* *} \square$ & $\square$ & $0.2244^{*} \square$ & \\
\hline$\square$ & पाणा1ाए & $\square$ & एवागाण & $\square$ & पाणाए & $\square$ & एणामाप & $\square$ \\
\hline Deposit funding & $-0.0479^{* *} \square$ & $\square$ & $-0.0479^{* * *} \square \square$ & $\square$ & $-0.0403^{* *} \square$ & $\square$ & $-0.0487^{* * *} \sqsubset$ & \\
\hline 四 & $\square|\square| \mid \square$ & $\square$ & एणामाप & $\square$ & पायापाए & $\square$ & 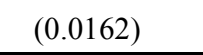 & $\square$ \\
\hline Macro-Economic variables & 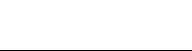 & 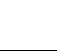 & $\mathbb{4} \square$ & $\square$ & $\mathbb{I}$ & 四 & $\mathbb{I}$ & 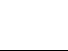 \\
\hline Lerner (industry level) & $-0.1066^{* * *} \square$ & $\square$ & $\square$ & $\square$ & $-0.0937^{* * *} \sqsubset$ & $\bar{\square}$ & $\square$ & \\
\hline$\square$ & पणागा & $\square$ & $\square$ & $\square$ & पाणामा & $\square$ & $\square$ & $\square$ \\
\hline GDP growth & & $\square$ & $2.4449^{* * *} \square \quad \square$ & $\square$ & $\square$ & $\square$ & $3.4920^{* * *} \square$ & \\
\hline$\square$ & $\square$ & $\square$ & 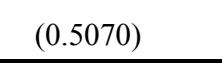 & $\square$ & $\square$ & $\square$ & एणा।110 & $\square$ \\
\hline Competition interactions & 田 & $\square$ & पा प & $\overline{11}$ & II & W & $\overline{I I}$ & 田 \\
\hline Capitalization * Lerner (firm level) & & $\square$ & $\square$ & $\square$ & $-0.0746^{*} \square$ & $\square$ & $-0.0944^{* * *} \sqsubset$ & $\square$ \\
\hline$\square$ & $\square$ & $\square$ & $\square$ & $\square$ & एणाएा & $\square$ & एाणाएण & $\square$ \\
\hline Securitization * Lerner (firm level) & & $\square$ & $\square$ & $\square$ & $0.7371^{* * *} \square$ & $\square$ & $0.7658^{* * *} \square$ & $\square$ \\
\hline$\square$ & $\square$ & $\square$ & $\square$ & $\square$ & पाणामा & $\square$ & एणाएाए & $\square$ \\
\hline Constant & $4.1756^{* *} \square$ & $\square$ & $-7.8448^{* * *} \sqsubset$ & $\square$ & $2.9956^{*} \square$ & $\square$ & $-8.7299^{* * *} \sqsubset$ & $\square$ \\
\hline$\square$ & $\square \square|\square| \square$ & $\square$ & 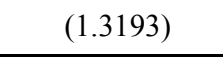 & $\square$ & पणाएाए & $\square$ & $\square\|1\| \mathbb{~}$ & $\square$ \\
\hline Capitalization $*$ Lerner (firm level) & $\bar{\square}$ & $\square$ & $\square \square$ & $\overline{7}$ & $\overline{\square\|\| ा \| ा}$ & $\bar{\square}$ & $\overline{\square\|\|\|\| \| ा \mid ~}$ & $\square$ \\
\hline$\square$ & $\square$ & $\square$ & $\square \square$ & $\square$ & एामाएा & $\square$ & एामापा & $\square$ \\
\hline Securitization * Lerner (firm level) & & $\square$ & $\square \square$ & $\square$ & $\square \square \square \square \square$ & $\square$ & $\square \square \Pi \Pi \square \square$ & $\square$ \\
\hline$\square$ & $\square$ & $\square$ & $\square \square$ & $\square$ & एवाणाए & $\square$ & 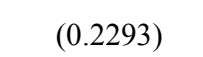 & $\square$ \\
\hline Constant & $\square \square ा 11 \square$ & $\square$ & एायाएा $\square$ & ] & $\square \square ा \Pi$ & $\square$ & एणामापा & $\square$ \\
\hline$\square$ & $\square|\square||| \square$ & $\square$ & 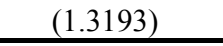 & $\square$ & पाणा।ाI & $\square$ & पाणामाप & $\square$ \\
\hline 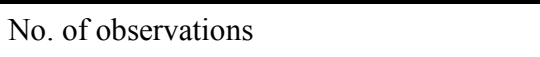 & $\square \square$ & & $\square \square$ & & $\square \square$ & & $\square \square$ & \\
\hline 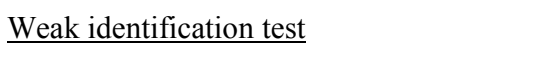 & & & & & & & & \\
\hline 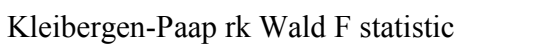 & 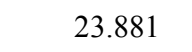 & & 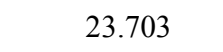 & & 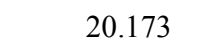 & & $\square \mid \Pi 1 \square$ & \\
\hline 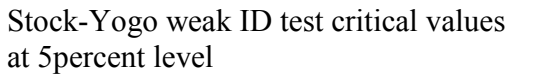 & $\square \square \square$ & & $\square \square \square$ & & 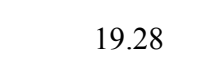 & & एण口 & \\
\hline 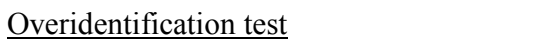 & & & & & & & & \\
\hline 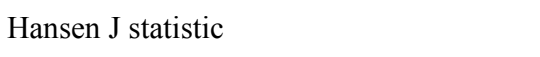 & $\square \square \square$ & & $\square \square \square$ & & $\square ण \square$ & & $\square[1 \square$ & \\
\hline पणाणाய & पणाए & & $\square ण 11$ & & एणाए & & $\square[110$ & \\
\hline$\square \square$ & 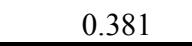 & & $\square \square 11$ & & 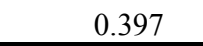 & & 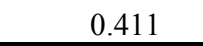 & \\
\hline
\end{tabular}

Note: The table contains the estimated results of Model (1) (Columns (1)-(2)) and Model (2) (Column (3)-(4)) using the IV approach. Systemic risk is measured by the MES. The dependent variable is calculated during the crisis period (2007Q4 to 2009Q4). Regressors are calculated as averages of quarterly data for individual banks during the pre-crisis period (2003Q4 to 2007Q3) unless otherwise indicated. Columns (1) and (2) present the estimated results of Model (1). Column (1) shows the effect of bank balance sheet variables and Lerner (firm level) and Lerner (industry level) on systemic risk. Column (2) replaces Lerner (industry level) with real GDP growth. Columns (3) and (4) introduce the interaction terms of securitization and capitalization with bank-specific market power and show the estimated results of Model (2). The instruments used for bankspecific market power are: Size, Excessive loan growth, Deposit funding, Capitalization, Securitization of other banks in the 
same country during the pre-crisis period in the estimation of Model (1) and also include the product of capitalization of other banks in the same country during the pre-crisis period, the bank-specific Lerner index during the pre-crisis period, and the product of securitization of other banks in the same country during the pre-crisis and bank-specific Lerner index during the precrisis period in the estimation of Model (2). Robust standard errors are in parentheses. ${ }^{*}{ }^{* *}$ and ${ }^{* * *}$ indicate statistical significance at the 10percent, 5 percent and 1 percent levels, respectively. The definition of other variables can be found in Table 1.

Table 6: Estimated results using alternative measurements of capitalization

\section{Variable} Systemic risk Systemic risk

Systemic risk

Systemic risk

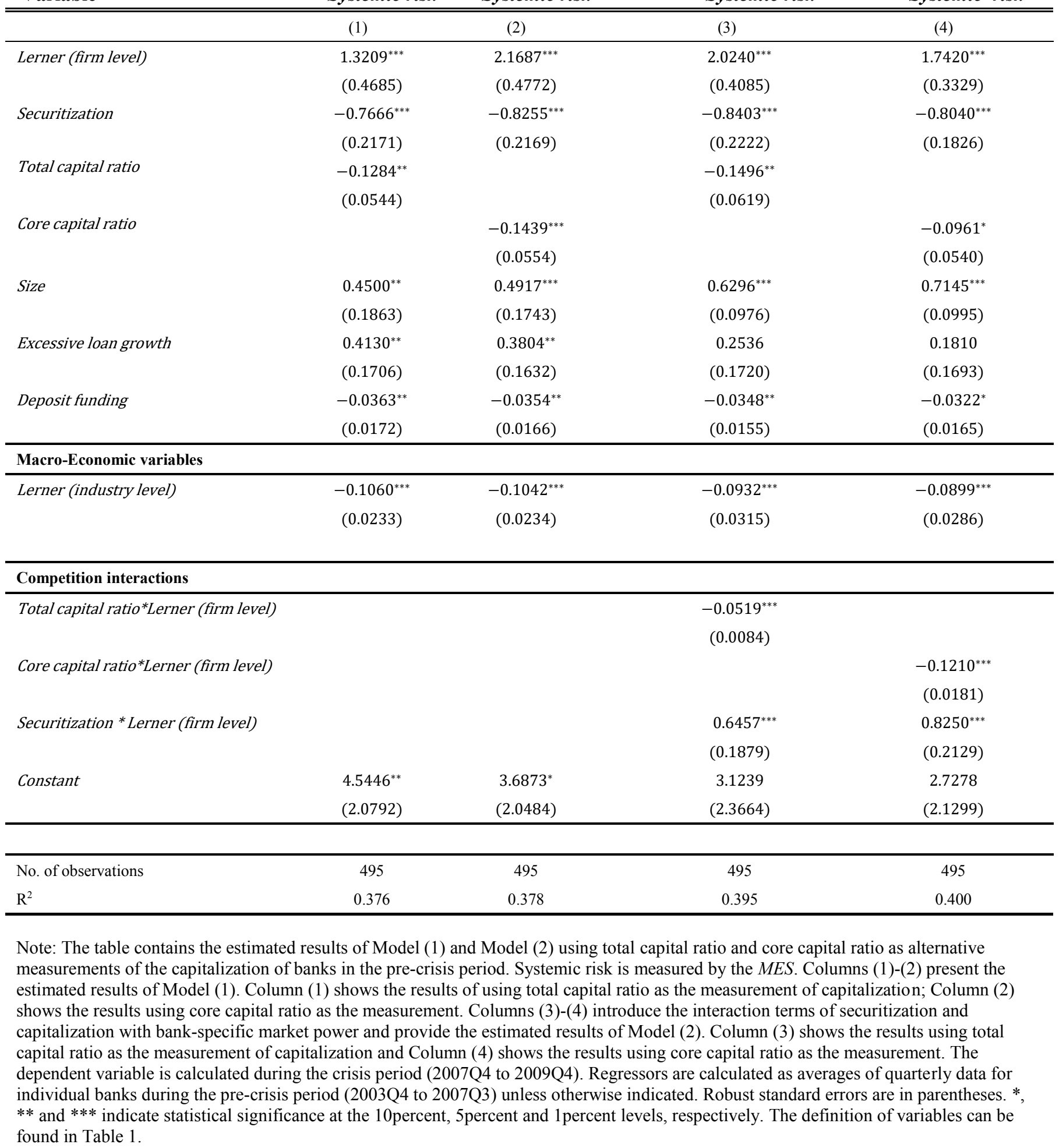


Table 7: Estimated results using alternative measurement of bank risk

\begin{tabular}{|c|c|c|}
\hline Variable & Bank-specific betc & $E D F$ \\
\hline $\mathbb{1 1}$ & 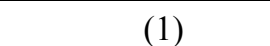 & 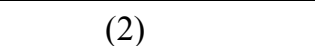 \\
\hline \multirow[t]{2}{*}{ Lerner (firm level) } & $0.4675^{* * *}$ & $5.5974^{* * *}$ \\
\hline & $(0.1320)$ & $(0.1371)$ \\
\hline \multirow[t]{2}{*}{ Securitization } & $-0.2189^{* * *}$ & $-1.2587^{*}$ \\
\hline & $(0.0825)$ & $(0.6646)$ \\
\hline \multirow[t]{2}{*}{ Capitalization } & $-0.0776^{* * *}$ & $-0.0545^{* * *}$ \\
\hline & $(0.0106)$ & $(0.0061)$ \\
\hline \multirow[t]{2}{*}{ Size } & $0.0922^{* * *}$ & $-0.1965^{* * *}$ \\
\hline & $(0.0269)$ & $(0.0305)$ \\
\hline \multirow[t]{2}{*}{ Excessive loan growth } & $0.1492^{* * *}$ & $-0.1436^{* * *}$ \\
\hline & $(0.0421)$ & $(0.0143)$ \\
\hline \multirow[t]{2}{*}{ Deposit funding } & $-0.0108^{* * *}$ & $-0.0098^{* *}$ \\
\hline & $(0.0018)$ & $(0.0039)$ \\
\hline Macro-Economic variables & & एा \\
\hline \multirow[t]{2}{*}{ Lerner (industry level) } & $-0.0209^{* *}$ & $-0.0134^{*}$ \\
\hline & $(0.0090)$ & $(0.0073)$ \\
\hline Competition interactions & & $\llbracket \square$ \\
\hline Capitalization * Lerner (firm level) & $-0.0114^{* * *}$ & $-0.1744^{* * *}$ \\
\hline$\square$ & $(0.0025)$ & $(0.0092)$ \\
\hline Securitization * Lerner (firm level) & $0.1640^{* *}$ & $1.2876^{*}$ \\
\hline$\square$ & $(0.0675)$ & $(0.7268)$ \\
\hline Constant & 0.4592 & $2.6905^{* * *}$ \\
\hline 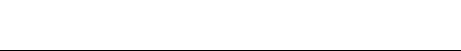 & $(0.5533)$ & $(0.5967)$ \\
\hline 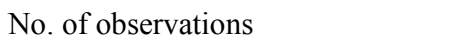 & $\square \square$ & $\square \square$ \\
\hline$\square^{\square} \square$ & 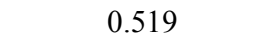 & $\square ण \square$ \\
\hline
\end{tabular}

Note: This table provides the estimated results of Model (2). Systemic risk is measured by bank-specific beta (Column (1)) and EDF (Column (2)), respectively. The dependent variable is calculated during the crisis period (2007Q4 to 2009Q4). Regressors are calculated as averages of quarterly data for individual banks during the pre-crisis period (2003Q4 to 2007Q3) unless otherwise indicated. Robust standard errors are in parentheses. * ${ }^{* *}$ and ${ }^{* *}$ indicate statistical significance at the 10percent, 5 percent and 1 percent levels, respectively. The definition of variables can be found in Table 1. 
Table 8: Estimated results using alternative measurement of competition at the country level

\begin{tabular}{|c|c|c|c|c|}
\hline Variable & Systemic risk & & Systemic risk & \\
\hline m & 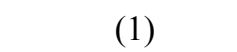 & $\mathbb{\square}$ & 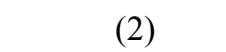 & पा \\
\hline Lerner (firm level) & $2.1774^{* * *}$ & & $2.1091^{* * *}$ & \\
\hline$\square$ & $(0.3994)$ & & $(0.7182)$ & \\
\hline Securitization & $0.2019^{* *}$ & & $-0.5564^{* * *}$ & \\
\hline$\square$ & $(0.0936)$ & & $(0.1771)$ & \\
\hline Capitalization & $-0.0822^{* * *}$ & & $-0.0654^{*}$ & \\
\hline$\square$ & $(0.0094)$ & & $(0.0389)$ & \\
\hline Size & $1.1842^{* * *}$ & & $0.6331^{* * *}$ & \\
\hline$\square$ & $(0.0708)$ & & $(0.0806)$ & \\
\hline Excessive loan growth & 0.0960 & & $0.2706^{*}$ & \\
\hline$\square$ & $(0.0816)$ & & $(0.1502)$ & \\
\hline Deposit funding & $-0.0293^{* *}$ & & $-0.0302^{*}$ & \\
\hline 四 & $(0.0116)$ & & $(0.0159)$ & \\
\hline Macro-Economic variables & & $\square \square$ & $\square$ & $\square$ \\
\hline $\begin{array}{l}B L S \\
\square\end{array}$ & $\begin{array}{c}-0.0628^{* * *} \\
(0.0025)\end{array}$ & & $\begin{array}{c}-0.0209^{* *} \\
(0.0090)\end{array}$ & \\
\hline Competition interactions & & एख & ए1) & 四 \\
\hline Capitalization $*$ Lerner (firm level) & & & $-0.0556^{* * *}$ & \\
\hline$\square$ & & & & \\
\hline Securitization * Lerner(firm level) & & & $0.5176^{* * *}$ & \\
\hline$\square$ & & & $(0.1619)$ & \\
\hline Constant & $-11.1850^{* * *}$ & & $-5.3942^{* * *}$ & \\
\hline 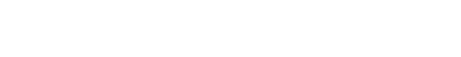 & $(0.6131)$ & & $(1.4620)$ & \\
\hline$\square$ & 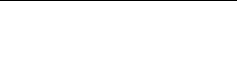 & $\square$ & ए & $\square$ \\
\hline 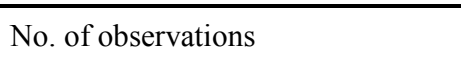 & $\square \square$ & $\square$ & $\square \square$ & $\bar{\square}$ \\
\hline$\square^{\square} \square$ & $\square \square \square$ & 四 & $\square \square \square$ & 四 \\
\hline
\end{tabular}

Note: This table provides the estimated results of Model (1) and Model (2). Systemic risk is measured by the MES. The results use the answers in Bank Lending Surveys $(B L S)$ from each country to the question of whether banks report a tightening (or loosening) of credit conditions due to competition during the pre-crisis period as the measurement of competition. Column (1) reports the estimated results of Model (1). Columns (2) introduces the interaction terms of securitization and capitalization with bank-specific market power and provides the estimated results of Model (2). The dependent variable is calculated during the crisis period (2007Q4 to 2009Q4). Regressors are calculated as averages of quarterly data for individual banks during the pre-crisis period (2003Q4 to 2007Q3) unless otherwise indicated. Robust standard errors are in parentheses. ${ }^{*},{ }^{* *}$ and ${ }^{* * *}$ indicate statistical significance at the 10 percent, 5 percent and 1 percent levels, respectively. The definition of variables can be found in Table 1. 
Table 9: Estimated results for banks involved/ not involved in Merger and Acquisition in the pre-crisis period

\begin{tabular}{|c|c|c|c|c|}
\hline & $\begin{array}{l}\text { MandA } \\
\text { Involved }\end{array}$ & $\begin{array}{l}\text { MandA Non- } \\
\text { involved }\end{array}$ & MandA Involved & $\begin{array}{l}\text { MandA Non- } \\
\text { involved }\end{array}$ \\
\hline \multirow[t]{2}{*}{ पमाणाण } & Systemic risk & Systemic risk & Systemic risk & Systemic risk \\
\hline & (1) & $(2)$ & (3) & (4) \\
\hline Lerner (firm level) & $\begin{array}{l}2.8102^{* *} \\
(1.2811)\end{array}$ & $\begin{array}{c}0.9581^{* * *} \\
(0.3032)\end{array}$ & $\begin{array}{l}2.8652^{* *} \\
(1.3086)\end{array}$ & $\begin{array}{l}1.3552^{* * *} \\
(0.4979)\end{array}$ \\
\hline Securitization & $\begin{array}{c}-0.6626^{* *} \\
(0.2654)\end{array}$ & $\begin{array}{c}-0.6971^{* *} \\
(0.2709)\end{array}$ & $\begin{array}{c}-0.7273^{* *} \\
(0.2852)\end{array}$ & $\begin{array}{c}-0.7458^{* * *} \\
(0.2547)\end{array}$ \\
\hline Capitalization & $\begin{array}{c}-0.0671^{* *} \\
(0.0282)\end{array}$ & $\begin{array}{c}-0.0314^{* *} \\
(0.0152)\end{array}$ & $\begin{array}{c}-0.1610^{* *} \\
(0.0679)\end{array}$ & $\begin{array}{c}-0.0277^{*} \\
(0.0151)\end{array}$ \\
\hline Size & $\begin{array}{c}0.5449 \\
(0.3731)\end{array}$ & $\begin{array}{l}0.7511^{* * *} \\
(0.1276)\end{array}$ & $\begin{array}{l}0.7583^{* *} \\
(0.3425)\end{array}$ & $\begin{array}{c}0.7992^{* * *} \\
(0.1014)\end{array}$ \\
\hline Excessive loan growth & $\begin{array}{l}-0.0004 \\
(0.4507)\end{array}$ & $\begin{array}{l}0.3679^{* * *} \\
(0.0430)\end{array}$ & $\begin{array}{l}-0.1212 \\
(0.4291)\end{array}$ & $\begin{array}{c}0.3063^{* * *} \\
(0.0482)\end{array}$ \\
\hline Deposit funding & $\begin{array}{c}0.0036 \\
(0.0146)\end{array}$ & $\begin{array}{c}-0.0782^{* * *} \\
(0.0113)\end{array}$ & $\begin{array}{c}0.0130 \\
(0.0142)\end{array}$ & $\begin{array}{c}-0.0728^{* * *} \\
(0.0112)\end{array}$ \\
\hline \multicolumn{5}{|l|}{ Macro-Economic variables } \\
\hline Lerner (industry level) & $\begin{array}{c}-0.1071^{* *} \\
(0.0446)\end{array}$ & $\begin{array}{c}-0.0977^{* * *} \\
(0.0261)\end{array}$ & $\begin{array}{c}-0.0909^{* *} \\
(0.0406)\end{array}$ & $\begin{array}{c}-0.0888^{* * *} \\
(0.0264)\end{array}$ \\
\hline \multicolumn{5}{|l|}{ Competition interactions } \\
\hline $\begin{array}{l}\text { Capitalization }{ }^{*} \text { Lerner (firm } \\
\text { level) }\end{array}$ & & & $\begin{array}{c}-0.1225^{* * *} \\
(0.0267)\end{array}$ & $\begin{array}{c}-0.0898^{* * *} \\
(0.0196)\end{array}$ \\
\hline $\begin{array}{l}\text { Securitization * Lerner (firm } \\
\text { level) }\end{array}$ & & & $\begin{array}{l}1.2758^{* * *} \\
(0.3777)\end{array}$ & $\begin{array}{l}0.3801^{* *} \\
(0.1802)\end{array}$ \\
\hline Constant & $\begin{array}{c}6.0070^{*} \\
(3.3494)\end{array}$ & $\begin{array}{c}3.0903 \\
(1.9118)\end{array}$ & $\begin{array}{c}3.9195 \\
(2.8390)\end{array}$ & $\begin{array}{c}1.9840 \\
(2.0543)\end{array}$ \\
\hline No. of observations & 193 & 302 & 193 & 302 \\
\hline $\mathrm{R}^{2}$ & 0.363 & 0.385 & 0.440 & 0.390 \\
\hline
\end{tabular}

Note: This table provides the estimated results of Model (1) and Model (2) for banks involved in Merger and Acquisition (Columns (1) and (3)) and those not involved (Columns (2) and (4)) in the pre-crisis period. Systemic risk is measured by the MES. The dependent variable is calculated during the crisis period (2007Q4 to 2009Q4). Regressors are calculated as averages of quarterly data for individual banks during the pre-crisis period (2003Q4 to 2007Q3) unless otherwise indicated. ${ }^{*},{ }^{* *}$ and ${ }^{* * *}$ indicate statistical significance at the 10percent, 5percent and 1percent levels, respectively. Robust standard errors are in parentheses. The definition of variables can be found in Table 1. The information regarding Merger and Acquisition is gathered from the Thomson Reuters - SDC Platinum database. 


\section{Table 10: Estimated results for U.S. banks in the sample}

\begin{tabular}{|c|c|c|c|c|c|c|c|c|c|c|c|c|}
\hline \multirow{2}{*}{$\begin{array}{l}\text { Variable } \\
\square\end{array}$} & \multicolumn{2}{|l|}{ MES } & \multicolumn{2}{|c|}{$\begin{array}{c}\text { Bank-specific } \\
\text { beta } \\
\end{array}$} & \multicolumn{2}{|l|}{$E D F$} & \multicolumn{2}{|l|}{ MES } & \multicolumn{2}{|c|}{$\begin{array}{c}\text { Bank-specific } \\
\text { beta } \\
\end{array}$} & \multicolumn{2}{|l|}{$E D F$} \\
\hline & \multicolumn{2}{|l|}{$\square \square$} & \multicolumn{2}{|l|}{$\square \square$} & \multicolumn{2}{|l|}{$\square \square$} & \multicolumn{2}{|l|}{$\square 1 \square$} & \multicolumn{2}{|l|}{$\square$} & \multicolumn{2}{|l|}{$\square 10$} \\
\hline \multirow{2}{*}{ Lerner (firm level) } & $2.9766^{*}$ & & $0.6389^{*}$ & & $2.9752^{* * *}$ & & $2.8090^{* *}$ & & $0.5733^{* *}$ & & $2.5936^{* *}$ & \\
\hline & $(1.7860)$ & & $(0.3349)$ & & $(0.6470)$ & & $(1.3535)$ & & $(0.2632)$ & & (1.1968) & \\
\hline \multirow[t]{2}{*}{ Securitization } & $-0.6453^{* *}$ & & $-0.4358^{* *}$ & & $-0.3544^{* *}$ & & $-0.5715^{* * *}$ & & $-0.6611^{* * *}$ & & $-0.6226^{*}$ & \\
\hline & $(0.2828)$ & & $(0.2154)$ & & $(0.1674)$ & & $(0.1626)$ & & $(0.0823)$ & & $(0.3573)$ & \\
\hline \multirow[t]{2}{*}{ Capitalization } & $-0.0478^{* *}$ & & $-0.0237^{* *}$ & & $-0.0586^{* *}$ & & $-0.0205^{*}$ & & $-0.0154^{*}$ & & $-0.0808^{* * *}$ & \\
\hline & $(0.0232)$ & & $(0.0092)$ & & $(0.0241)$ & & $(0.0122)$ & & $(0.0088)$ & & $(0.0204)$ & \\
\hline \multirow[t]{2}{*}{ Size } & $1.1379^{* * *}$ & & $0.3182^{* * *}$ & & 0.1738 & & $0.9907^{* * *}$ & & $0.2184^{* * *}$ & & 0.2185 & \\
\hline & $(0.1954)$ & & $(0.0499)$ & & $(0.1755)$ & & $(0.1357)$ & & $(0.0438)$ & & $(0.1648)$ & \\
\hline \multirow[t]{2}{*}{ Excessive loan growth } & $0.2352^{*}$ & & $0.0857^{* *}$ & & $0.2581^{*}$ & & $0.2756^{* * *}$ & & $0.1190^{* * *}$ & & $0.3984^{* * *}$ & \\
\hline & $(0.1388)$ & & $(0.0387)$ & & $(0.1440)$ & & $(0.0907)$ & & $(0.0252)$ & & $(0.1380)$ & \\
\hline \multirow[t]{2}{*}{ Deposit funding } & $-0.0503^{* *}$ & & $-0.0517^{* * *}$ & & $-0.0522^{* *}$ & & $-0.0525^{* * *}$ & & $-0.0578^{* *}$ & & -0.0187 & \\
\hline & $(0.0234)$ & & $(0.0152)$ & & $(0.0209)$ & & $(0.0154)$ & & $(0.0239)$ & & $(0.0191)$ & \\
\hline \multicolumn{13}{|l|}{ Competition interactions } \\
\hline \multirow[t]{2}{*}{$\begin{array}{l}\text { Capitalization * Lerner (firm } \\
\text { level) }\end{array}$} & & & & & & & $-0.0458^{* *}$ & & $-0.0296^{* * *}$ & & $-0.1219^{* * *}$ & \\
\hline & & & & & & & $(0.0203)$ & & $(0.0079)$ & & $(0.0336)$ & \\
\hline \multirow[t]{2}{*}{$\begin{array}{l}\text { Securitization * Lerner (firm } \\
\text { level) }\end{array}$} & & & & & & & $0.2922^{* *}$ & & $0.3377^{* * *}$ & & $0.5737^{*}$ & \\
\hline & & & & & & & $(0.1181)$ & & $(0.0133)$ & & $(0.3101)$ & \\
\hline \multirow[t]{2}{*}{ Constant } & $-7.4066^{* * *}$ & & $-2.3678^{* * *}$ & & 0.7044 & & $-6.7387^{* * *}$ & & $-1.8564^{* * *}$ & & -0.0723 & \\
\hline & $(1.3144)$ & & $(0.2893)$ & & $(0.9154)$ & & $(1.0551)$ & & $(0.3390)$ & & $(0.9450)$ & \\
\hline 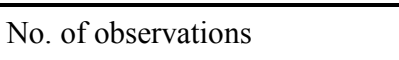 & $\square \square$ & $\square$ & $\square$ & $\square$ & $\square$ & $\square$ & $\square$ & $\square$ & $\square$ & $\square$ & $\square$ & $\square$ \\
\hline$\square^{\square} \square$ & 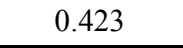 & 口 & 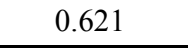 & $\square$ & 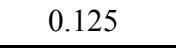 & 口 & 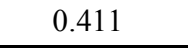 & $\square$ & 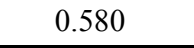 & ए & 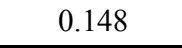 & $\square$ \\
\hline
\end{tabular}

Note: This table provides the estimated results of Model (1) (Columns (1)-(3)) and Model (2) (Columns (4)-(6)) for U.S banks. Columns (1)-(3) shows the effect of bank balance sheet variables and Lerner (firm level). Columns (4)-(6) introduce the interaction terms of securitization and capitalization with bank-specific market power. Systemic risk is measured by the MES in Columns (1) and (3), by bank-specific beta in Columns (2) and (4), and by EDF in Columns (3) and (6). The dependent variable is calculated during the crisis period (2007Q4 to 2009Q4). Regressors are calculated as averages of quarterly data for individual banks during the pre-crisis period (2003Q4 to 2007Q3) unless otherwise indicated. Robust standard errors are in parentheses. * ${ }^{* *}$ and ${ }^{* * *}$ indicate statistical significance at the 10 percent, 5 percent and 1 percent levels, respectively. The definition of variables can be found in Table $1 . \square$ 
Table 11: Estimated results with additional bank-specific control variables during the pre-crisis period

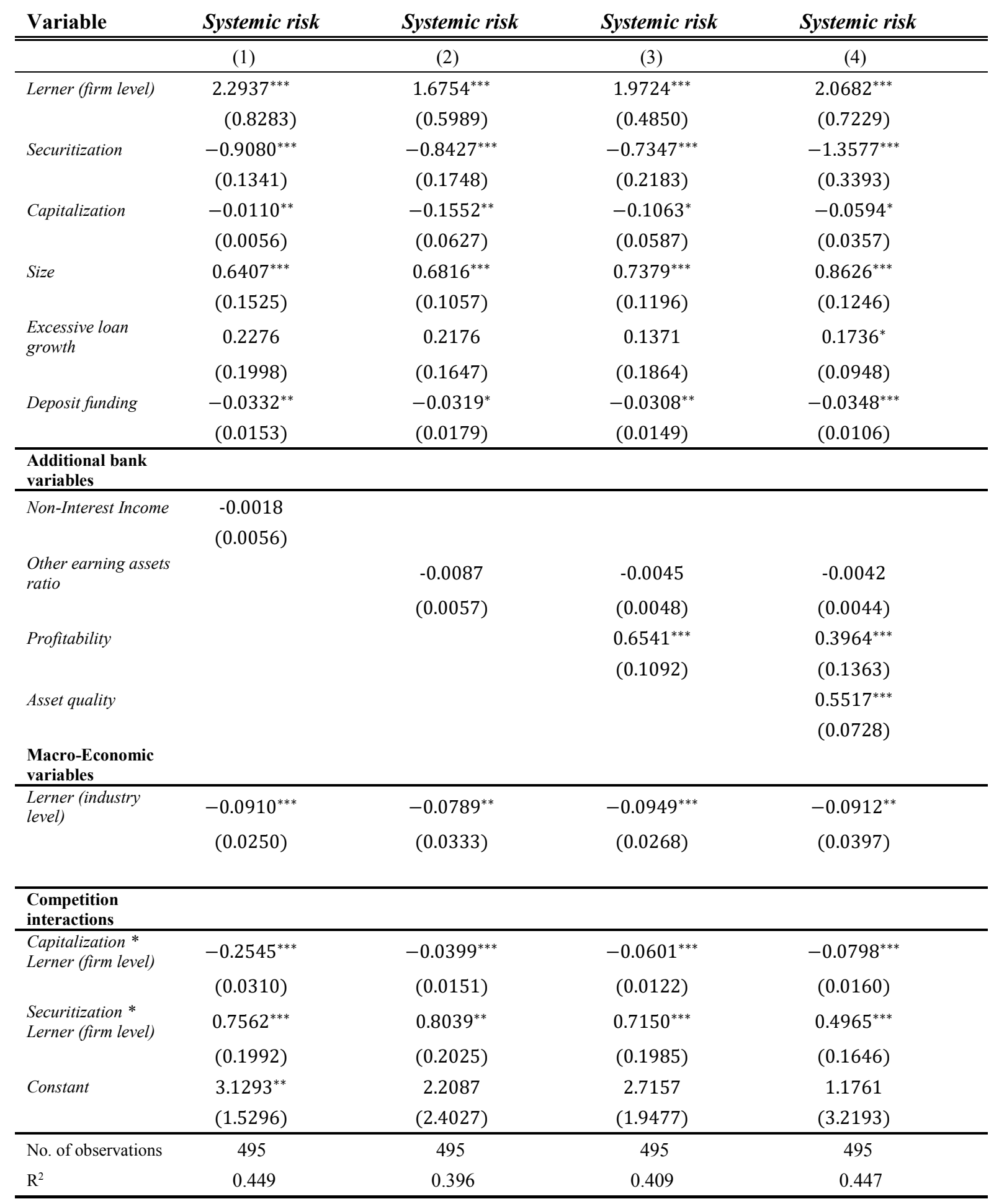

Note: This table provides the estimated results of Model (2), with additional bank-specific control variables in the pre-crisis period. Systemic risk is measured by the MES. The dependent variable is calculated during the crisis period (2007Q4 to 2009Q4). Regressors are calculated as averages of quarterly data for individual banks during the pre-crisis period (2003Q4 to 2007Q3) unless otherwise indicated. Robust standard errors are in parentheses. ${ }^{*},{ }^{* *}$ and ${ }^{* * *}$ indicate statistical significance at the 10percent, 5percent and 1percent levels, respectively. The definition of variables can be found in Table 1. 
Table 12: Estimated results for mortgage backed securitization

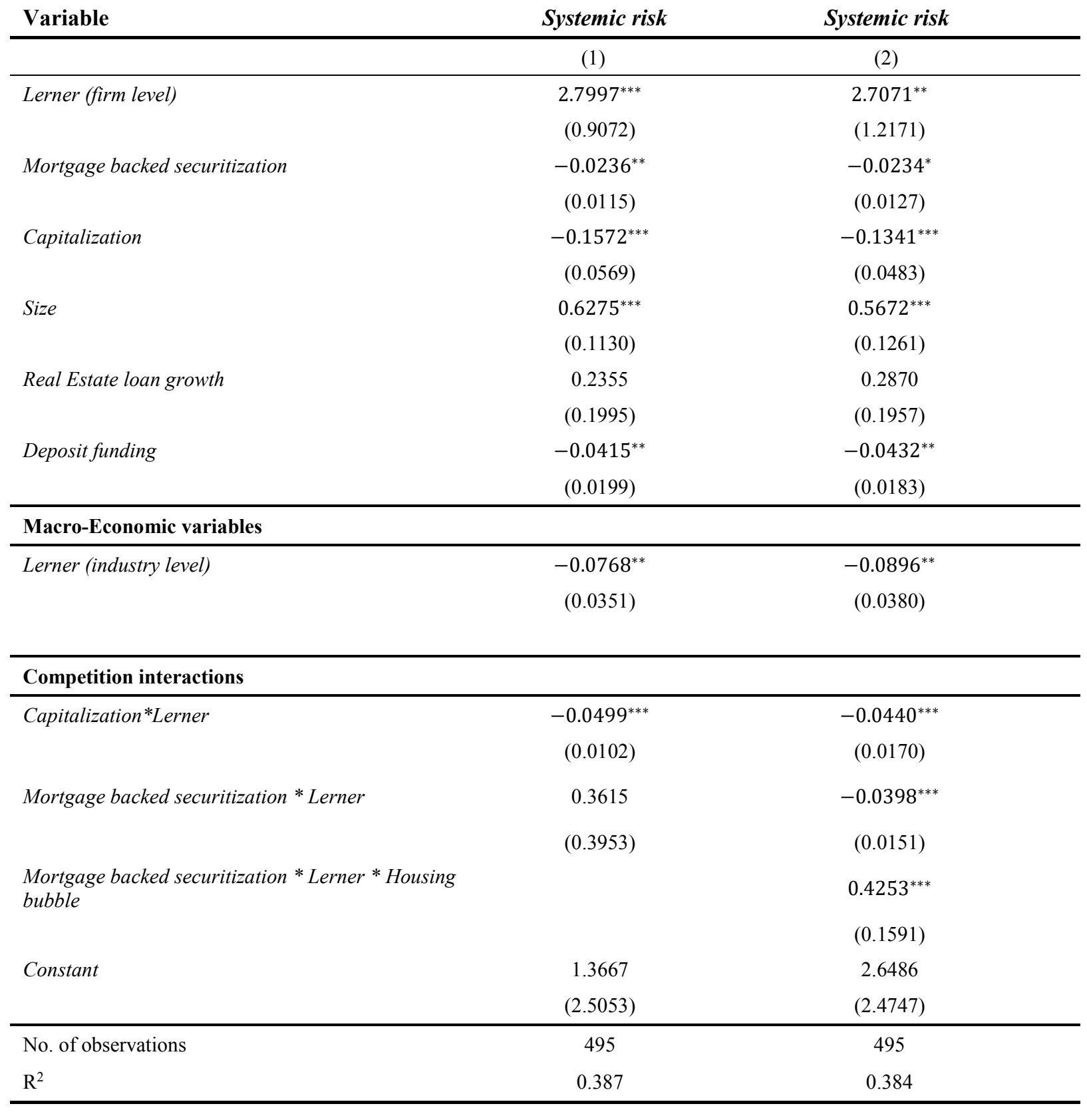

Note: The table contains the estimated results of Model (2) for mortgage backed securitization only. Systemic risk is measured by the MES. The dependent variable is calculated during the crisis period (2007Q4 to 2009Q4). Regressors are calculated as averages of quarterly data for individual banks during the pre-crisis period (2003Q4 to 2007Q3) unless otherwise indicated. Robust standard errors are in parentheses. ${ }^{*},{ }^{* *}$ and ${ }^{* * *}$ indicate statistical significance at the 10 percent, 5 percent and 1 percent levels, respectively. The definition of variables can be found in Table 1. 
Table 13: Estimated results for non-mortgage backed securitization

\begin{tabular}{|c|c|c|c|c|}
\hline \multirow{2}{*}{$\begin{array}{l}\text { Variable } \\
\square\end{array}$} & \multicolumn{2}{|l|}{ Systemic risk } & \multicolumn{2}{|l|}{ Systemic risk } \\
\hline & 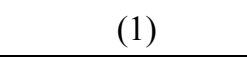 & & 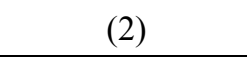 & \\
\hline Lerner (firm level) & $1.4151^{* * *} \square$ & $\square$ & $2.0794^{* * *} \square$ & $\square$ \\
\hline$\square$ & पाणा1ा & $\square$ & एाणा1ा & $\square$ \\
\hline Non-mortgage backed securitization & $-0.9062^{* * *} \square$ & $\square$ & $-0.8381^{* * *} \square$ & $\square$ \\
\hline$\square$ & पाणामा & $\square$ & एणाएण & $\square$ \\
\hline Capitalization & $-0.1162^{* *} \square$ & $\square$ & $-0.1467^{* *} \square$ & $\square$ \\
\hline$\square$ & पाயा1ா & $\square$ & एणामाण & $\square$ \\
\hline Size & $0.4540^{* * *} \square$ & $\square$ & $0.6151^{* * *} \square$ & $\square$ \\
\hline$\square$ & पाणा1ा & $\square$ & एवागा & $\square$ \\
\hline Excessive loan growth & $0.4128^{* *} \square$ & $\square$ & $\square \square \square \square$ & $\square$ \\
\hline$\square$ & पाणाएा & $\square$ & 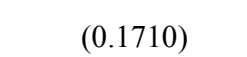 & $\square$ \\
\hline Deposit funding & $-0.0336^{*} \square$ & $\square$ & $-0.0385^{* *} \square$ & $\square$ \\
\hline$\square$ & 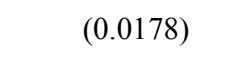 & 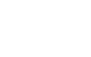 & $\square 1 \| 1110$ & $\square$ \\
\hline Macro-Economic variables & & $\square$ & & 四 \\
\hline Lerner (industry level) & $-0.1041^{* * *} \square$ & $\square$ & $-0.0940^{* * *} \square$ & $\square$ \\
\hline$\square$ & एणाएण & $\square$ & एाणामा & $\square$ \\
\hline Competition interactions & & $\square$ & & 四 \\
\hline Capitalization * Lerner (firm level) & & $\square$ & $-0.0561^{* * *} \square$ & $\square$ \\
\hline$\square$ & $\square$ & $\square$ & एवाएा & $\square$ \\
\hline Non-mortgage backed securitization * Lerner (firm level) & & $\square$ & $0.5259^{* *} \square$ & $\square$ \\
\hline$\square$ & $\square$ & $\square$ & पाणामाप्य & $\square$ \\
\hline Constant & $4.2287^{* *} \square$ & $\square$ & $\square \square \square \square$ & $\square$ \\
\hline$\square$ & पाणाएा & 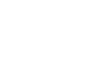 & 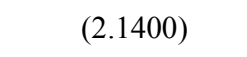 & 四 \\
\hline 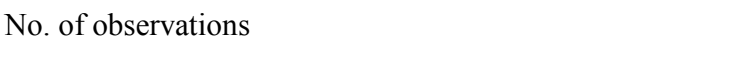 & 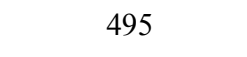 & & 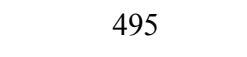 & \\
\hline$\square^{\square} \square$ & 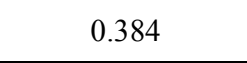 & & 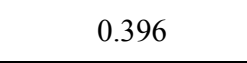 & \\
\hline 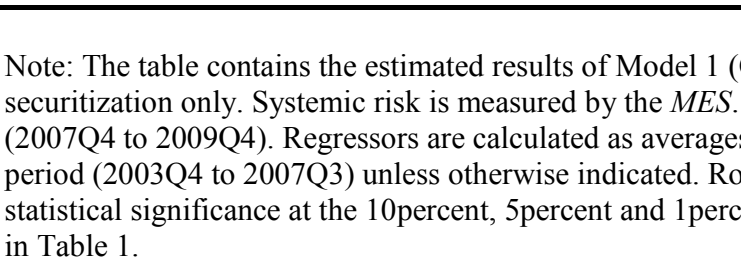 & 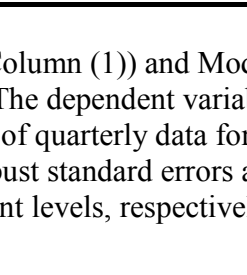 & 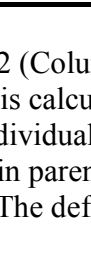 & 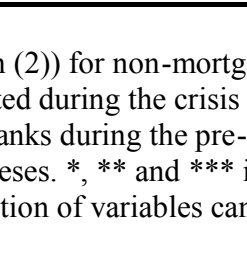 & 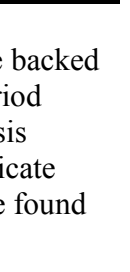 \\
\hline
\end{tabular}

